\title{
RETENÇÃO E TRANSMISSÃO DE ÁGUA EM UM LATOSSOLO ROXO SOB DIFERENTES SISTEMAS DE CULTIVO
}

\author{
Francisco Roberto C. do Espírito Santo \\ Engenheiro Agrônomo
}

Orientador: Prof. Dr. PaUlo LeONEl Libardi

Tese apresentada à Escola Superior de Agricultura "Luiz de Queiroz", Universidade de São Paulo, para obtenção do título de Doutor em Agronomia. Área de Concentração: Solos e Nutrição de Plantas.

\author{
P I R A C I C A B A \\ Estado de São Paulo - Brasil \\ Janeiro - 1998
}


Dados Internacionais de Catalogação na Publicação (CIP) DIVISÃO DE BIBLIOTECA E DOCUMENTAÇĀO - Campus "Luiz de Queiroz"/USP

Espirito Santo, Francisco Roberto C. do

Retenção e transmissão de água em um latossolo roxo sob diferentes sistemas de cultivo / Francisco Roberto C. do Espirito Santo. - - Piracicaba, 1998

104 p. : il.

Tese (doutorado) - - Escola Superior de Agricultura Luiz de Queiroz, 1998.

Bibliografia.

1. Condutividade hidráulica do solo 2. Curva de retenção 3. Degradação do solo 4. Latossolo 5. Propriedade fisico-quimica do solo 6. Sistema de cultivo I. Título 


\section{RETENÇÃO E TRANSMISSÃO DE ÁGUA EM UM LATOSSOLO ROXO SOB DIFERENTES SISTEMAS DE CULTIVO}

FRANCISCO ROBERTO C. DO ESPÍRITO SANTO

Aprovado em: 27.03.1998

Comissão julgadora:

Prof. Dr. Paulo Leonel Libardi

ESALQ/USP

Prof. Dr. Álvaro Pires da Silva

ESALQ/USP

Prof. Dr. Sergio Oliveira Moraes

ESALQ/USP

Dr. Antonio Melhem Saad

IPT

Profa. Dra. Maria Helena Moraes

UNESP

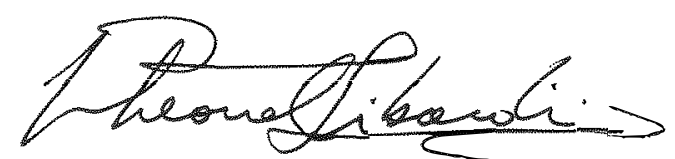

Prof. PAULO LEONEL LIBARDI

Orientador 
À minha esposa Evelise e aos meus filhos Daniel e Giovanni 


\section{AGRADECIMENTOS}

Ao Professor Paulo Leonel Libardi pela confiança, amizade, companheirismo e orientação durante o curso.

Aos professores Klaus Reichardt e Sergio Oliveira Moraes pela amizade e ensinamentos.

Ao colega Antonio Melhem Saad pela inestimável colaboração nas diversas fases deste trabalho.

Aos colegas de pós-graduação pelo convívio durante o curso e que colaboraram de diversas formas para a concretização deste trabalho: Cláudio Roberto Marciano, Francisco Ocian, Fernando Luis Dultra Cintra, Maria do Rosário L. Rodrigues, Elcio José do Nascimento e Carmen V. J. Neves.

Aos funcionários do Laboratório de Física do Solo do Departamento de Física e Meteorologia Luiz Fernando Novello e Francisco Bernardo Dias.

Ao técnico José Aparecido Silvério dos Santos e funcionários do Laboratório de Física do Instituto de Pesquisas Tecnológicas do Estado de São Paulo IPT.

Às bibliotecárias Eliana M. Garcia Sabino e Kátia M. de Andrade Ferraz, da DIBD/ESALQ/USP, pela revisão das referências bibliográficas.

À administração da EPAGRI, pela oportunidade da realização do curso.

Ao colega Armando Corrêa Pacheco, pelo apoio e incentivo na realização do curso.

Ao CNPq pela concessão da bolsa de estudo.

Aos anônimos que muito contribuiram para a realização deste trabalho. 


\section{SUMÁRIO}

página

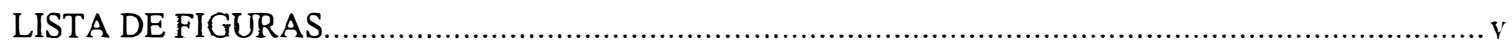

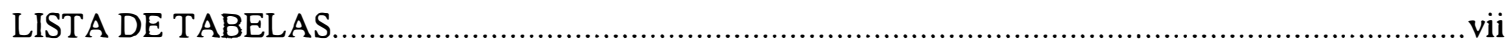

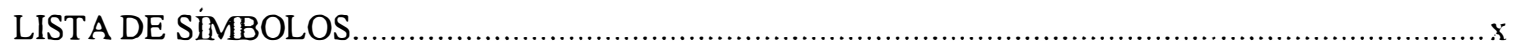

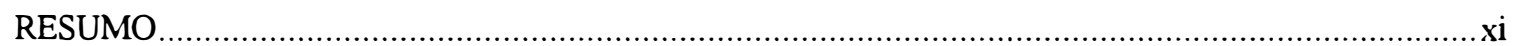

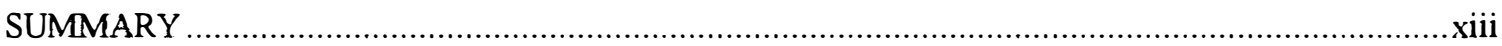

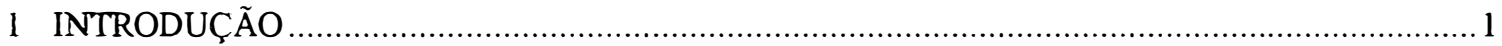

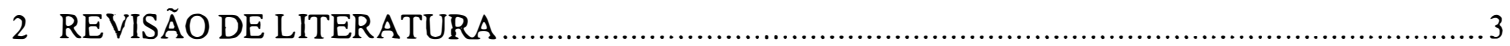

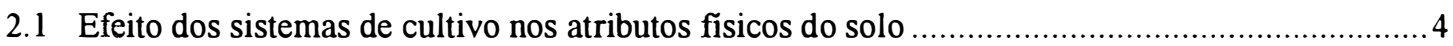

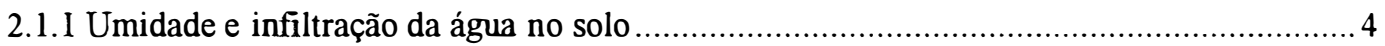

2.1.2 A densidade do solo e a resistência à penetração ...........................................................

2.1.3 Condutividade hidráulica $(\mathrm{K}(\theta))$ e curva de retenção da água no solo $(\mathrm{h}(\theta))$................... 9

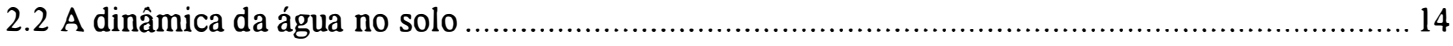

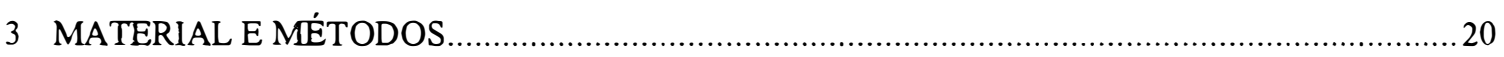

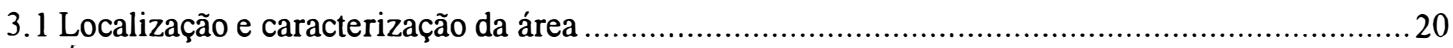

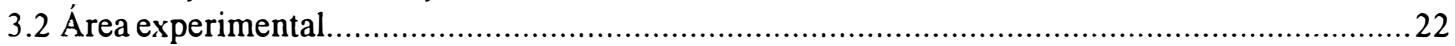

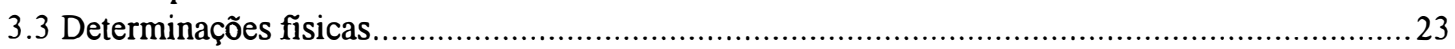

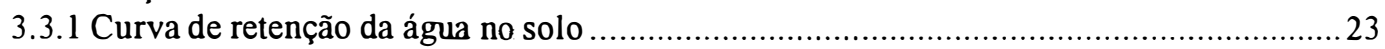

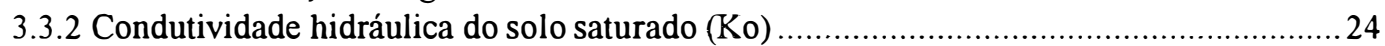

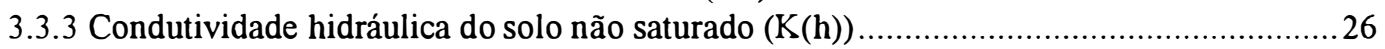

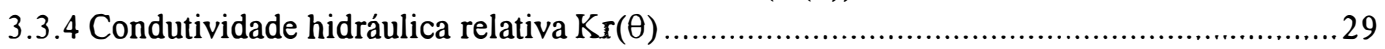

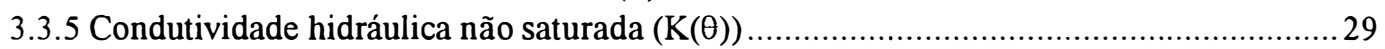

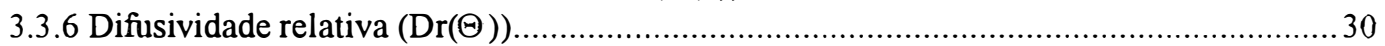

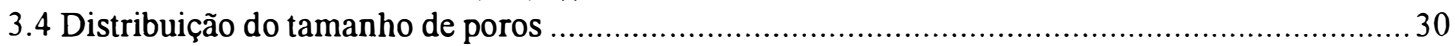

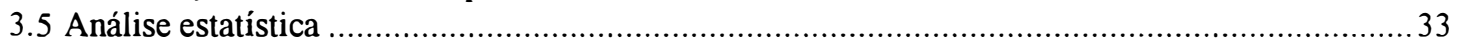

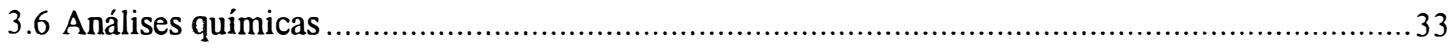

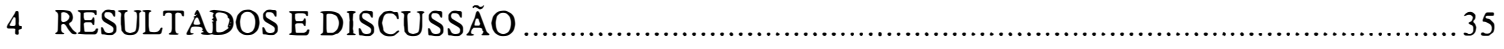

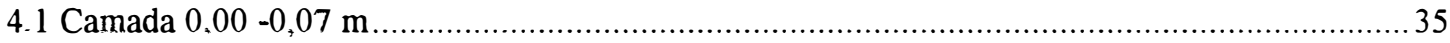

4.1.1 Sistemas de cultivo plantio direto irrigado e convencional irrigado............................... 35

4.1.2 Curvas de retenção da água no solo .............................................................................. 35

4.1.3 Análise da distribuição do tamanho de poros através da curva de retenção da água no solo. 
4.1.4 Densidade do solo para a sequiência dos sistemas de cultivo plantio direto irrigado e convencional irrigado, na profundidade de $0,00-0,07 \mathrm{~m}$............................................ 42

4.1.5 Condutividade hidráulica do solo saturado (Ko) na profundidade de $0,00-0,07 \mathrm{~m} \ldots \ldots \ldots . . .43$

4.1.6 Condutividade hidráulica relativa $(\operatorname{Kr}(\Theta))$, condutividade hidráulica do solo não

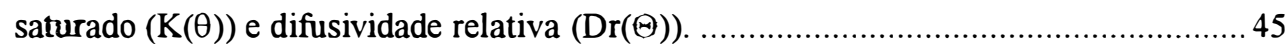

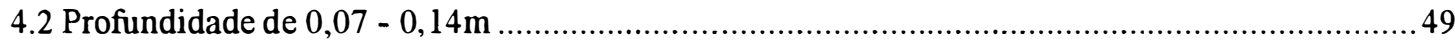

4.2.1 Sistemas de cultivo plantio convencional não irrigado, plantio direto irrigado e plantio

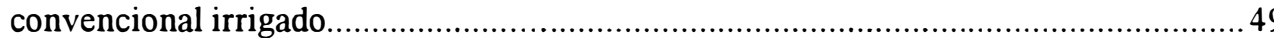

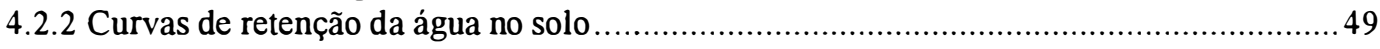

4.2.3 Análise da distribuição do tamanho de poros através da curva de retenção da água no solo.

4.2.4 Condutividade hidráulica relativa $(\operatorname{Kr}(\Theta))$, condutividade hidráulica do solo não

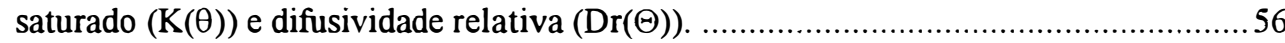

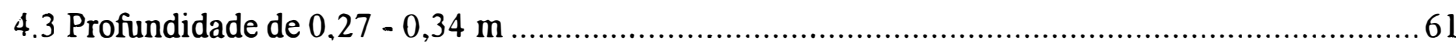

4.3.1 Sistemas de cultivo plantio convencional não irrigado, plantio direto irrigado e plantio

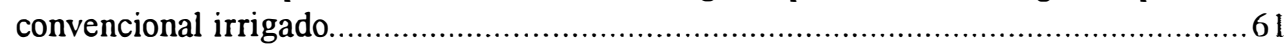

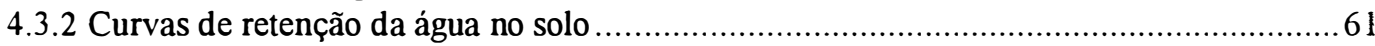

4.3.3 Análise da distribuição do tamanho de poros através da curva de retenção da água no solo.

4.3.4 Condutividade hidráulica relativa $(\operatorname{Kr}(\Theta))$, condutividade hidráulica do solo não

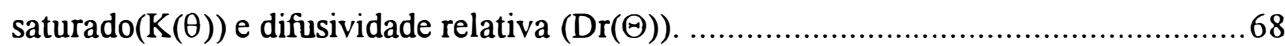

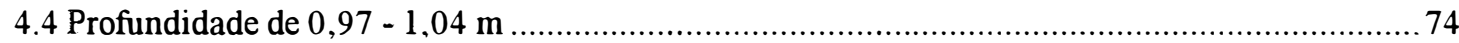

4.4.1 Sistemas de cultivo plantio convencional não irrigado, plantio direto irrigado e plantio

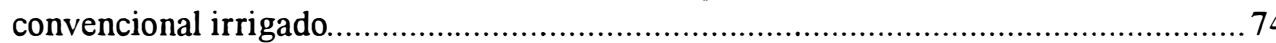

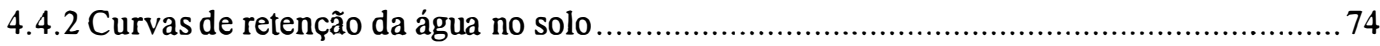

4.4.3 Análise da distribuição do tamanho de poros através da curva de retenção da água no solo

4.4.4 Condutividade hidráulica relativa $(\operatorname{Kr}(\Theta))$, condutividade hidráulica do solo não saturado $(\mathrm{K}(\theta))$ e difusividade relativa $(\operatorname{Dr}(\Theta))$..................................................... 81

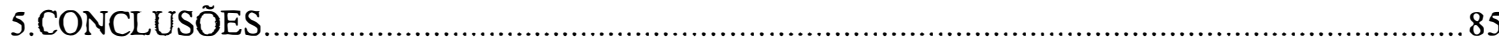

ANEXO A

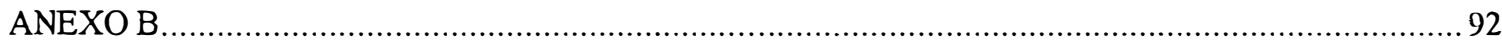

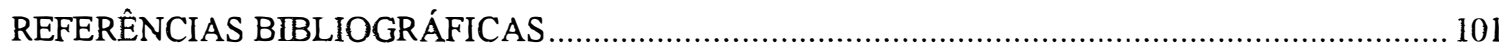




\section{LISTA DE FIGURAS}

Página

Figura 1 - Mapa da microbacia do Ribeirão Jardim, com a área de estudo delimitada em negrito e localização dos pivôs centrais (circunferências). (IPT, 1995)....

Figura 2 - Aspectos da superficie de relevo suave ondulado a plano, típica da área de estudo.

Figura 3 - Perfil de Latossolo Roxo Distrófico, predominante da área de estudo.

Figuras 4 e 5 - Processo de retirada das amostras indeformadas de perfis de solo descritos para cada sistema de cultivo e manejo.

Figura 6 - Arranjo experimental de laboratório para a determinação da condutividade hidráulica do solo saturado $\left(K_{o}\right)$.

Figura 7 - Diagrama do aparelho para medida da condutividade hidráulica de solo não saturado.

Figura 8 - Seqüencia da montagem dos componentes do modelo experimental de laboratório para determinação da condutividade hidráulica do solo não saturado $(K(h))$.

Figura 9 - Curvas de retenção da água do Latossolo Roxo, para os sistemas plantio direto irrigado e convencional irrigado, na profundidade de 0,00 - 0,07 m...

Figura 10 - Distribuição do tamanho de poros do Latossolo Roxo, nos sistemas plantio direto irrigado e convencional irrigado, na profundidade de $0.00-0.07 \mathrm{~m}$...

Figura 11 - Relação entre ln $\mathrm{Kr}(\Theta)$ e a umidade para seqüencia dos sistemas de cultivo plantio direto irrigado e convencional irrigado. na profundidade 0.00 $0,07 \mathrm{~m}$

Figura 12 - Curvas de retenção da água do Latossolo Roxo, para os sistemas plantio convencional não irrigado, direto irrigado e convencional irrigado. na profundidade de 0,07-0,14 $\mathrm{m}$.

Figura 13 - Distribuição do tamanho de poros do Latossolo Roxo, nos sistemas plantio convencional não irrigado, plantio direto irrigado e plantio convencional irrigado, na profundidade de 0,07-0,14 $\mathrm{m}$.

Figura 14 - Relação entre a ln $\operatorname{Kr}(\Theta)$ e a umidade para a seqüência dos sistemas de cultivo plantio convencional não irrigado, plantio direto irrigado $e$ convencional irrigado na profundidade 0,07 - 0,14 $\mathrm{m}$.

Figura 15 - Curvas de retenção da água de Latossolo Roxo, para os sistemas de cultivo plantio convencional não irrigado, plantio direto irrigado e convencional irrigado, na profundidade de 0,27 - 0,34 $\mathrm{m}$.

Figura 16 - Distribuição do tamanho de poros do Latossolo Roxo, nos sistemas plantio convencional não irrigado, plantio direto irrigado e plantio convencional irrigado, na profundidade de 0,27 - 0,34 $\mathrm{m}$. 
Figura 17 - Relação entre ln $\mathrm{Kr}(\Theta)$ e a umidade $\theta$ para a seqüência dos sistemas plantio convencional não irrigado. plantio direto irrigado e convencional irrigado na profundidade $0,27-0,34 \mathrm{~m}$

Figura 18 - Curvas de retenção da água de Latossolo Roxo, para os sistemas de cultivo plantio convencional não irrigado, plantio direto irrigado e convencional irrigado, na profundidade de 0,97-1,04 m.

Figura 19 - Distribuição do tamanho de poros do Latossolo Roxo, nos sistemas plantio convencional não irrigado, plantio direto irrigado e plantio convencional irrigado, na profundidade de $0.97-1,04 \mathrm{~m}$.

Figura 20 - Relação entre ln $\mathrm{Kr}(\Theta)$ e a umidade $\theta$ para a seqüência dos sistemas plantio convencional não irrigado, plantio direto irrigado $e$ convencional irrigado na profundidade 0,97 - 1,04 m. 


\section{LISTA DE TABELAS}

Página

Tabela 1 - Valores numéricos das curvas de retenção da água no solo e da densidade para a seqüência dos sistemas de cultivo plantio direto irrigado e convencional irrigado na profundidade de $0,00-0,07 \mathrm{~m}$, com as médias (três repetições), desvios padrões e coeficientes de variação

Tabela 2 - Valores máximos da função derivada $\mathrm{d} \theta / \mathrm{d} \tau$, com os correspondentes valores de tensão $\tau^{*}$, do raio equivalente $r^{*}$, da umidade $\theta^{*}$, e os valores da condutividade hidráulica saturada $K_{o}$, na profundidade de $0,00-0,07 \mathrm{~m}$.

Tabela 3 - Valores da porosidade total, da macroporosidade e da microporosidade calculados para a seqüência dos sistemas de cultivo plantio direto irrigado e plantio convencional irrigado, na profundidade de $0,00-0,07 \mathrm{~m}$.

Tabela 4 - Comparação através do teste de Tukey dos valores da densidade do solo para a seqüência dos sistemas de cultivo plantio direto irrigado e convencional irrigado, na profundidade de $0,00-0,07 \mathrm{~m}$.

Tabela 5 - Comparação através do teste de Tukey, dos valores da condutividade hidráulica saturada $\left(\mathrm{K}_{\mathrm{o}}\right)$, para os sistemas plantio direto irrigado $\mathrm{e}$ convencional irrigado, na profundidade de $0,00-0,07 \mathrm{~m}$.

Tabela 6 - Valores de tensão $\tau(\tau=-\Phi \mathrm{m}$, onde $-\Phi \mathrm{m}$ é o potencial mátrico), da umidade volumétrica $(\theta)$ e relativa $(\Theta)$, da condutividade hidráulica relativa $(\operatorname{Kr}(\Theta))$, e hidráulica não saturada $K(\theta)$ e da difusividade relativa $(\operatorname{Dr}(\Theta))$, para a seqüência dos sistemas de cultivo plantio direto irrigado e convencional irrigado, na profundidade $0,00-0,07 \mathrm{~m}$

Tabela 7 - Indices de concordância (d) de Willmott obtidos na comparação das funções $(\operatorname{Kr}(\Theta)),(\operatorname{K}(\theta))$ e $(\operatorname{Dr}(\Theta))$ dos sistemas plantio direto irrigado em relação ao convencional irrigado na profundidade de $0,00-0,07 \mathrm{~m}$.

Tabela 8 - Valores numéricos das curvas de retenção da água no solo e da densidade para a seqüência dos sistemas plantio convencional não irrigado, direto irrigado e convencional irrigado na profundidade de $0,07-0,14 \mathrm{~m}$ com as médias (3 repetições), desvios padrões e coeficientes de variação.

Tabela 9 - Indices de concordância (d) de Willmott obtidos na comparação da função $h(\theta)$ entre os sistemas plantio convencional não irrigado (PCNI), plantio direto irrigado (PDI) e plantio convencional irrigado (PCI), na profundidade de $0,07-0,14 \mathrm{~m}$

Tabela 10 - Valores máximos da derivada $\mathrm{d} \theta / \mathrm{d} \tau$, com os correspondentes valores da tensão $\tau^{*}$, do raio equivalente $r^{*}$, da umidade $\theta^{*}$ e os valores da condutividade hidráulica do solo saturado $\left(\mathrm{K}_{\mathrm{o}}\right)$, na profundidade de $0,07-0,14 \mathrm{~m}$. 
Tabela 11 - Valores da porosidade total, da macroporosidade e da microporosidade calculados, para os sistemas de cultivo plantio convencional não irrigado, direto irrigado e convencional irrigado, na profundidade de $0,07-0,14 \mathrm{~m}$.

Tabela 12 - Valores da tensão $\tau(\tau=-\phi \mathrm{m}$, onde $-\phi \mathrm{m}=$ potencial mátrico), da umidade volumétrica $(\theta)$ e relativa $(\Theta)$, da condutividade hidráulica relativa $(\operatorname{Kr}(\Theta))$, da condutividade hidráulica do solo não saturado $(K(\theta))$ e da difusividade relativa $(\operatorname{Dr}(\Theta))$, para a seqüência dos sistemas plantio convencional não irrigado, plantio direto irrigado e convencional irrigado, na profundidade $0,07-0,14 \mathrm{~m}$.

Tabela 13 - Índices de concordância (d) Willmott obtidos na comparação dos valores das funções $(\operatorname{Kr}(\Theta),(\operatorname{K}(\theta))$ e $(\operatorname{Dr}(\Theta))$ entre os sistemas plantio convencional não irrigado (PCNI), plantio direto irrigado (PDI) e plantio convencional irrigado (PCI), na profundidade $0,07-0,14 \mathrm{~m}$.

Tabela 14 - Valores numéricos das curvas de retenção da água no solo e da densidade para a seqüência dos sistemas plantio convencional não irrigado, direto irrigado e convencional irrigado na profundidade de $0,27-0,34 \mathrm{~m}$ com as médias (3 repetições), desvios padrões e coeficientes de variação.

Tabela 15 - Índices de Willmott para comparação da função $h(\theta)$ entre os sistemas plantio convencional não irrigado, plantio direto irrigado e plantio convencional irrigado, na profundidade de 0,27-0,34 m

Tabela 16 - Valores máximos da derivada $\mathrm{d} \theta / \mathrm{d} \tau$, com os correspondentes valores da tensão $\tau^{*}$, do raio equivalente $r^{*}$, da umidade $\theta^{*}$ e os valores da condutividade hidráulica do solo saturado $\left(\mathrm{K}_{\mathrm{o}}\right)$, na profundidade de $0,27-0,34 \mathrm{~m}$.

Tabela 17 - Valores da porosidade total, da macroporosidade e da microporosidade calculadas, para a seqüência dos sistemas de cultivo plantio convencional não irrigado, plantio direto irrigado e plantio convencional irrigado, na profundidade de $0,27-0,34 \mathrm{~m}$.

Tabela 18 - Valores da tensão $\tau$ ( $\tau=-\phi \mathrm{m}$, onde $-\phi \mathrm{m}=$ potencial mátrico), da umidade volumetrica $(\theta)$ e relativa $(\Theta)$, da condutividade hidráulica relativa $(\operatorname{Kr}(\Theta))$, da condutividade hidráulica do solo não saturado $(K(\theta))$ e da difusividade relativa $(\operatorname{Dr}(\Theta))$, para a seqüência dos sistemas plantio convencional não irrigado, plantio direto irrigado e convencional irrigado, na profundidade de $0,27-0,34 \mathrm{~m}$.

Tabela 19 - Índices de concordância (d) de Willmott obtidos na comparação dos valores das funções $(\operatorname{Kr}(\Theta),(K(\theta))$ e $(\operatorname{Dr}(\Theta))$ entre os sistemas plantio convencional na irrigado (PCNI), plantio direto irrigado (PDI) e plantio convencional irrigado (PCI), na profundidade $0,27-0,34 \mathrm{~m}$.

Tabela 20 - Valores numéricos das curvas de retenção da água no solo e da densidade para a seqüência dos sistemas plantio convencional não irrigado, direto irrigado e convencional irrigado na profundidade de $0,97-1,04 \mathrm{~m}$ com as médias (3 repetições), desvios padrões e coeficientes de variação. 
Tabela 21 - Índice de concordância (d) de Willmott obtidos na comparação da função $h(\theta)$ entre os sistemas plantio convencional não irrigado (PCNI), plantio direto irrigado (PDI) e plantio convencional irrigado (PCI), na profundidade de $0,97-1,04 \mathrm{~m}$.

Tabela 22 - Valores máximos da derivada $\mathrm{d} \theta / \mathrm{d} \tau$, com os correspondentes valores da tensão $\tau^{*}$, do raio equivalente $r^{*}$, da umidade $\theta^{*}$ e os valores da condutividade hidráulica do solo saturado $\left(\mathrm{K}_{\mathrm{o}}\right)$, na profundidade de $0,97-1,04 \mathrm{~m}$.

Tabela 23 - Valores da porosidade total, da macroporosidade e da microporosidade calculados para a seqüência dos sistemas de cultivo plantio convencional não irrigado, plantio direto irrigado e plantio convencional irrigado, na profundidade de $0,97-1,04 \mathrm{~m}$

Tabela 24 - Valores da tensão $\tau(\tau=-\phi \mathrm{m}$, onde $-\phi \mathrm{m}=$ potencial mátrico), da umidade volumétrica $(\theta)$ e relativa $(\Theta)$, da condutividade hidráulica $(\operatorname{Kr}(\Theta))$, da condutividade hidráulica do solo não saturado $(K(\theta))$ e da difusividade relativa $(\operatorname{Dr}(\Theta))$, para a seqüência dos sistemas plantio convencional não irrigado, plantio direto irrigado e convencional irrigado, na profundidade de $0,97-1,04 \mathrm{~m}$.

Tabela 25 - Índices de concordância (d) de Willmott (d) obtidos na comparação dos valores das funções $(\operatorname{Kr}(\Theta),(\mathrm{K}(\theta))$ e $(\operatorname{Dr}(\Theta))$ entre os sistemas plantio convencional na irrigado (PCNI), plantio direto irrigado (PDI) e plantio convencional irrigado (PCI), na profundidade $0,97-1,04 \mathrm{~m}$. 


\section{LISTA DE SÍMBOLOS}

$\vec{q}=$ densidade de fluxo

$\vec{\nabla}=$ operador Nabla

$\theta=$ umidade volumétrica

$\theta_{r}=$ umidade residual

$\theta_{s}=$ umidade de saturação

$\alpha, m, n=$ parâmetros empíricos de ajuste da curva de retenção da água no solo. $\tau=-\phi_{m}=$ tensão ou potencial mátrico da água no solo.

$K_{s}=K_{o}=$ condutividade hidráulica do solo saturado.

$K(h)=$ condutividade hidráulica do solo não saturado.

$L=$ comprimento da amostra.

$h=$ potencial de pressão ou carga hidráulica.

$\nabla H=$ gradiente de potencial total.

$\Theta=$ umidade relativa.

$\operatorname{Kr}(\Theta)=$ condutividade hidráulica relativa .

$K(\theta)=$ condutividade hidráulica do solo não saturado.

$\operatorname{Dr}(\Theta)=$ difusividade relativa .

PDI = Plantio Direto Irrigado

$\mathrm{PCI}=$ Plantio Convencional Irrigado

PCNI = Plantio Convencional Não Irrigado 


\title{
RETENÇÃO E TRANSMISSÃO DE ÁGUA EM UM LATOSSOLO ROXO SOB DIFERENTES SISTEMAS DE CULTIVO
}

\author{
Autor: FRANCISCO R. C. DO ESPÍRITO SANTO \\ Orientador: PAULO LEONEL LIBARDI
}

\section{RESUMO}

Considerando a hipótese da ocorrência de diferenças nos valores das propriedades de retenção e de transmissão da água de um Latossolo Roxo, sob os sistemas de cultivo plantio convencional não irrigado, plantio direto irrigado e plantio convencional irrigado, foram selecionadas três áreas distintas de uma microbacia, representando os diferentes sistemas. Em cada uma delas foram abertas três trincheiras, a partir das quais foram retiradas amostras com estrutura indeformada nas profundidades de 0,00-0,07 $\mathrm{m}$, de $0,07-0,14 \mathrm{~m}$, de $0,27-0,34$ e de 0,97 - 1,04 m, para a determinação da condutividade hidráulica saturada $\left(K_{o}\right)$ e não saturada $(K(h)$, elaboração das curvas de retenção e através destas estimar os valores da condutividade hidráulica relativa $K_{r}(\Theta)$, da condutividade hidráulica não saturada $K(\theta)$ e da difusividade relativa $\operatorname{Dr}(\Theta)$. Os resultados indicaram valores mais baixos da condutividade hidráulica saturada $\left(K_{\circ}\right)$, da condutividade hidráulica relativa $\operatorname{Kr}(\Theta)$, da condutividade hidráulica do solo não saturado $(\mathrm{K}(\theta))$ e da difusividade relativa $(\operatorname{Dr}(\Theta))$, na camada $0,00-0,07 \mathrm{~m}$, para o plantio direto irrigado em relação ao convencional irrigado, como resultado da menor porosidade total e macroporosidade, acompanhados por um aumento da microporosidade e também dos valores da densidade do solo, do plantio direto. A partir da profundidade de 0,07-0,14 m e através de 0,27-0,34 e 0,97-1,04 m, os valores de $K_{o}$ não diferiram entre si, nos diferentes sistemas de cultivo, ocorrendo, no entanto, 
diferenças nos valores de $\operatorname{Kr}(\Theta),(\mathrm{K}(\theta))$ e $(\operatorname{Dr}(\Theta))$ envolvendo os três sistemas, até a profundidade de 0,27 - 0,34 m. Assim, na camada de 0,07 - 0,14 m, os valores mais elevados de $\operatorname{Kr}(\theta)$, $(\mathrm{K}(\theta)$ e $\operatorname{Dr}(\Theta)$ ocorreram no plantio convencional irrigado, que apresentou maior porosidade total e macroporosidade e menores valores da microporosidade, em comparação com o plantio direto irrigado e plantio convencional não irrigado. Na profundidade de 0,27 - 0,34, as diferenças nos valores da condutividade hidráulica saturada $\left(K_{o}\right)$, para os três sistemas, não foram significativas. Para a condutividade hidráulica relativa $\operatorname{Kr}(\theta)$, condutividade hidráulica do solo não saturado $(\mathrm{K}(\theta))$ e difusividade relativa $(\operatorname{Dr}(\Theta))$ ocorrem diferenças significativas dos valores para todas as comparações entre os sistemas de cultivo, principalmente entre o plantio convencional irrigado e plantio convencional não irrigado. Para a profundidade de 0,97 $1,04 \mathrm{~m}$, não ocorreram diferenças nos valores da condutividade hidráulica saturada $\left(K_{o}\right)$ e também para a condutividade hidráulica relativa $\operatorname{Kr}(\Theta)$, condutividade hidráulica do solo não saturado $K(\theta)$ e difusividade relativa $\operatorname{Dr}(\Theta)$ indicando que esta camada tem, com relação às camadas suprajacentes, uma maior uniformidade em relação às propriedades hidráulicas e também à dinâmica do espaço poroso. Os valores da condutividade hidráulica em função da tensão da água no solo, isto é, a função $K(h)$ obtidos através de método de laboratório, para as tensões 0,20 m, 0,40 m, 0,60 m e 0,80 m, e utilizados para o cálculo de $K r=K(h) K_{o}$ se ajustaram bem aos valores de $K r$ determinados pelo modelo de Genuchten (1980). 


\title{
RETENTION AND TRANSMISSION OF WATER IN AN OXISOL UNDER DIFFERENT CROPPING SYSTEMS
}

\author{
Author: FRANCISCO R. C. DO ESPÍRITO SANTO \\ Adviser: PAULO LEONEL LIBARDI
}

\section{SUMMARY}

With the objective of verifying the behaviour of the soil-water retention and transmission properties of a Brazilian oxisol under three different cropping systems (conventional non-irrigated, non-tillage irrigated and conventional irrigated), three different areas, representing the three different systems, were selected in a microwatershed. In each of them three pits were open and undisturbed soil samples were collected from the depths $0.00-0.07 \mathrm{~m}, 0.07-0.14 \mathrm{~m}, 0.27-0.34 \mathrm{~m}$ and $0.97-1.04 \mathrm{~m}$. Saturated hydraulic conductivity $\left(K_{o}\right)$, unsaturated hydraulic conductivity $(K(h)$ function) and soil-water retention curve were determined in these samples. By means of the soil-water retention curves, estimation of the relative hydraulic conductivity $(K r)$ was made by the Genuchten's model. Results indicated lower values of $K_{o}$ and $K r$ at the $0.00-0.07 \mathrm{~m}$ layer for the non-tillage irrigated system in relation to the conventional irrigated one, as a

result of the lower total porosity and macroporosity and higher microporosity and soil bulk density of the non-tillage system. For the other layers $(0.07-0.14 \mathrm{~m}, 0.27-0.34 \mathrm{~m}$ and $0.97-1.04 \mathrm{~m}) K_{o}$ values were not different for the different systems. Values of $K r$, $\operatorname{Kr}(\theta)$ and $\operatorname{Dr}(\Theta)$ however, showed differences in the three systems, for the layer 0.07 $0.14 \mathrm{~m}$. The higher $K r$ values of this layer occurred in the conventional irrigated system that presented higher values total porosity and macroporosity and lower values of microporosity, in comparison to non-tillage irrigated and conventional non-irrigated systems. In the $0.27-0.34$ layer there were significant differences of $K r, \operatorname{Kr}(\theta)$ and $\operatorname{Dr}(\Theta)$, for all systems, the highest values ocurring between conventional irrigated and conventional non-irrigated systems. For the $0.97-1.04$ m layer, $K r, \operatorname{Kr}(\theta)$ and $\operatorname{Dr}(\Theta)$ values were also not different for the different systems, indicating that this layer presents, 
with respect to the others above, a better uniformity in terms of hydraulic and porous space properties. Values of soil hydraulic conductivity as a function of soil water tension, that is, the $K(h)$ function, experimentally obtained in the laboratory for tensions of 0.20 $\mathrm{m}, 0.40 \mathrm{~m}, 0.60 \mathrm{~m}$ and $0.80 \mathrm{~m}$ of water and used to calculate $K r=K(\theta) / K_{o}$, had a good fitting with the $K r$ values estimated by Genuchten's model. 


\section{INTRODUÇÃO}

As áreas de latossolos das regiões sudeste e sul do Brasil representam um grande potencial para a produção agrícola.

Culturas como a cana de açúcar, milho, feijão e soja (São Paulo), e milho, feijão, soja e trigo (Paraná, Santa Catarina e Rio Grande do Sul) são exploradas intensivamente, em grandes áreas típicas de latossolos. Nestes locais, são frequentemente observadas ocorrências drásticas de degradação fisico hídrica dos solos, como resultado de alterações em propriedades importantes responsáveis pelo movimento da água no solo.

A região de Guaira ao norte do Estado de São Paulo, local definido para o estudo, é um exemplo típico onde ocorrem predominantemente os Latossolos Roxos, geralmente distróficos, argilosos, profundos e bem drenados, com relevo suave ondulado a plano, o que favorece sobremaneira a mecanização, com a prática da irrigação através pivô central

Neste tipo de agricultura intensiva, onde são colhidas 5 safras por biênio, os principais reflexos deste tipo de utilização do solo são observados na degradação da sua estrutura, com o aparecimento de crostas superficiais e camadas compactadas, implicando no aumento das necessidades das operações de preparo do solo, como resultado de alterações em propriedades importantes relacionadas com o movimento da água no solo, a saber, a retenção da água e a condutividade hidráulica do solo. Estas propriedades quando analisadas para diferentes sistemas de cultivo e manejo, durante um determinado tempo, suficiente para que em cada tipo de cultivo sejam expressos as características próprias de cada um, podem ter valores bem diferentes, 
principalmente nos horizontes superficiais dos solos, onde a mobilização por máquinas e implementos é sempre mais intensa.

O objetivo principal deste trabalho é analisar o comportamento das funções de retenção da água no solo $(h(\theta))$, da condutividade hidráulica relativa $(\operatorname{Kr}(\Theta))$, da condutividade hidráulica do solo não saturado $(K(\theta))$ e da difusividade relativa $(\operatorname{Dr}(\Theta))$, nas camadas do perfil de solo de 0,00 - 0,07 m; 0,07 - 0,14 m; 0,27 - 0,34 m e 0,97 - 1,04 m, para os seguintes sistemas de cultivo: plantio convencional não irrigado (PCNI), plantio direto irrigado (PDI) e plantio convencional irrigado (PCI).

Para tanto, destaca-se como hipótese central a ser testada nesse estudo a seguintes:

Há maior alteração nos valores das propriedades físico-hídricas das camadas superiores do solo $(0,00-0,07 \mathrm{~m} ; 0,07-0,14 \mathrm{~m}$ e $0,27-0,34 \mathrm{~m})$ em relação à camada profunda $(0,97$ - 104), para qualquer sistema de cultivo estudado. 


\section{REVISÃO DE LITERATURA}

Os sistemas de cultivos dos solos utilizados na produção agrícola têm características próprias que permitem distinguí-los, principalmente quanto ao emprego de máquinas e a intensidade com que são usadas. Isto é relativamente fácil quando se compara por exemplo, os sistemas convencional e plantio direto. Não obstante, entre esses extremos podem ser adotadas práticas que caracterizam um sistema intermediário, ou seja com variantes entre os dois acima citados. Assim, no sistema convencional, após a aração, o número de gradagens pode ser controlado de modo a influenciar a mobilização do solo de forma mais ou menos intensa. O mesmo pode ocorrer com relação ao sistema de plantio direto, onde ao invés da simples escarificação sobre os resíduos da cultura anterior na linha de plantio, procede-se à escarificações, por exemplo, em faixas, movimentando os residuos em pequenas profundidades.

Diante disto, ficam evidentes as dificuldades em se estabelecer comparações entre os diferentes sistemas de cultivos e manejo do solo, pois no geral todos levam a uma maior ou menor compactação do solo, influenciando a distribuição do tamanho de poros e a curva de retenção da água no solo, e por conseguinte propriedades não menos importantes como as funções condutividade hidráulica e difusividade da água.

Em função destas alterações, os processos erosivos passam a atuar de forma mais intensa e a degradação do solo, imperceptível no início, manifesta-se então, de forma mais visível, com o surgimento do selamento superficial do solo, dos sulcos de erosão e a exposição de camadas compactadas, resultando num decréscimo da produtividade das culturas. 


\subsection{Efeito dos sistemas de cultivo nos atributos físicos do solo}

Os sistemas de cultivo influem de diferentes formas e intensidades no comportamento dos atributos e/ou propriedades fisicas dos solos, os quais são discutidos a seguir.

\subsubsection{Umidade e infiltração da água no solo}

O solo descoberto, quando exposto aos impactos das gotas de chuva, tem suas partículas desagregadas, o que vem a ser um fator predisponente para a formação de crostas e o selamento superficial, ocasionando um decréscimo na capacidade de infiltração da água no solo e provocando o escorrimento superficial e a erosão. Quando isto ocorre, outras propriedades do solo também sofrem modificações: a densidade do solo tende a aumentar, ocorre uma redistribuição do tamanho de poros, alterando por conseguinte a curva característica da água no solo, e geralmente observamse decréscimos nos valores da função condutividade hidráulica do solo.

Estas alterações das propriedades fisico-hídricas do solo, decorrentes do uso de um determinado implemento mecânico, dentro de um sistema definido de cultivo e manejo, normalmente são analizadas, considerando-se as práticas culturais em conjunto, como por exemplo, as adubações, as rotações de culturas e o manejo dos resíduos quando pertinente. Tais práticas contribuem de modo eficaz para atenuar os efeitos danosos resultantes do cultivo inadequado do solo.

Com relação à adubação, por exemplo, Rasmussen \& Rohde (1988), observaram diferenças significativas nos teores de carbono orgânico, para diferentes níveis de nitrogênio adicionado ao solo, sugerindo uma maior produção de matéria orgânica, relativa ao nivel mais elevado de nitrogênio.

$\mathrm{O}$ aspecto prático desses resultados, para algumas propriedades fisicas do solo, como por exemplo, na infiltração da água no solo, pode ser avaliado no trabalho de Zuzel et al. (1990), que detectaram diferentes taxas de infiltração da água em solo sob três diferentes práticas mecânicas de cultivo (aração normal, escarificação com 
cultivadores, e gradagem), sendo as mais elevadas, observadas nos sistemas que receberam as doses mais elevadas de nitrogenio, com correspondentes teores de matéria orgânica também mais elevados, e de valores densidade do solo mais baixos, mostrando o efeito benéfico da matéria orgânica, no sentido de diminuir os riscos da compactação do solo. Neste mesmo estudo, os autores concluem que o selamento superficial do solo, resultante do impacto das gotas de chuva na superficie desprotegida do solo, tem efeitos mais pronunciados na redução das taxas de infiltração da água, do que as camadas compactadas resultantes das diferentes práticas mecânicas.

Ainda com relação aos resíduos de culturas na superficie do solo, Blevins et al.(1971) observaram teores de umidade mais elevados nas camadas de 0 - 8 $\mathrm{cm}$ do solo sob o sistema de plantio direto em relação ao sistema convencional, porém estas diferenças praticamente se anulam para as camadas mais profundas do solo. Estes teores de umidade mais elevados são o resultado da menor taxa de evaporação de água a partir da superficie do solo no sistema plantio direto, quando comparado ao convencional. Porém, nesse mesmo estudo não foram observadas diferenças significativas nos valores da condutividade hidráulica saturada $\left(\mathrm{K}_{\mathrm{o}}\right)$ na mesma profundidade, o que indica neste caso, que a maior influencia nos valores desta função, parece ser exercida pela arquitetura do meio poroso através da continuidade e da distribuição do tamanho de poros. do solo.

Dados que corroboram esta observação são discutidos por Gantzer \& Blake (1978), que observaram teores de umidade mais elevados na camada de 0,00 $0,30 \mathrm{~m}$ do plantio direto em relação ao convencional, sendo que nas camadas mais inferiores do perfil de solo não ocorreram diferenças. A importância deste estudo refletese no fato de que embora com valores de umidade mais elevados, o plantio direto pode não ter este excedente de umidade disponível para as culturas, devido à maior capacidade de retenção de água deste sistema justificada pelos valores mais elevados da microporosidade. 
Além disso é preciso considerar que os efeitos decorrentes da ação dos diferentes sistemas de cultivo são dependentes do espaço e do tempo. Isto quer dizer que o solo sob um determinado sistema de cultivo, seja convencional, cultivo mínimo ou plantio direto, pode apresentar teores médios de água bem diferentes, quando os mesmos são por exemplo medidos na linha da cultura e na entrelinha, denotando a ocorrência de uma variação espacial deste parâmetro, o qual normalmente também, varia com a época em que foi medido, indicando portanto a influencia do tempo (variação temporal). Assim, quanto maior a mobilização do solo pelos implementos mecânicos, tanto mais provável a ocorrência de diferenças significativas no espaço e no tempo, para esta importante propriedade do solo que é a umidade.

Em três sistemas distintos de cultivo com milho, definidos por convencional, plantio direto ( 1 ano) e plantio direto (15 anos), Zhai et al. (1990), estimaram a variância temporal e espacial da umidade e de coeficientes ou níveis de secagem do solo para diferentes épocas, em distintas posições como a linha de plantio, entrelinha e na distância correspondente a $1 / 4$ da entrelinha, utilizando-se de funções de distribuição de probabilidade temporais e espaciais respectivamente. Em termos gerais, para os três sistemas citados observou-se uma correlação negativa entre a variância espacial e o valor médio de umidade do solo, sendo que durante toda a estação de crescimento do milho ocorreram sistematicamente diferenças na distribuição espacial da umidade dentro de um determinado sistema e também entre os mesmos. Com relação à variância temporal da umidade, os sistemas de plantio direto correspondentes a 1 ano e 15 anos, apresentaram ambos uma variância temporal na linha de plantio, da ordem de $25 \%$ mais elevada em relação à observada na entrelinha; e quando comparados os diferentes sistemas, a variância temporal na posição de entrelinha foi cerca de $80 \%$ maior no cultivo convencional em relação, por exemplo, ao sistema plantio direto (15 anos). Esses fatos atestam portanto, a influência dos diferentes sistemas de cultivo agindo na expressão dos valores da variância espacial e temporal da umidade do solo. 
Entre o cultivo convencional e o plantio direto ( 1 ano), não se detectaram diferenças significativas entre os valores da variância espacial e o teor médio da umidade do solo, indicando que os processos que induzem às mudanças na umidade devem ter neste caso certa similaridade. O mesmo não ocorre com relação ao plantio direto (15 anos), onde a variância espacial teve maiores aumento ou decréscimos, com os correspondentes decréscimos ou aumentos de umidade, indicando que neste último caso, para distintas posições no espaço, as diferenças no processo de umedecimento e secagem foram maiores.

Analisando as posições pertinentes à linha de cultura e entrelinha, para o sistema convencional, Van Wesenbeeck \& Kachanoski (1988), concluiram que a variância temporal média da umidade do solo $(\theta)$, na linha de plantio foi $34 \%$ superior em comparação com a mesma medida determinada na entrelinha.

\subsubsection{A densidade do solo e a resistência à penetração}

A densidade do solo e a resistência à penetração são características do solo que permitem avaliar o grau de impedimento mecânico, com relação às culturas e o tipo de cultivo e manejo a que se propõem. Alterações na densidade do solo, afetam a disponibilidade de água, a aeração e permeabilidade do solo, a capacidade de infiltração da água e a penetração pelas raízes das plantas.

Com relação aos sistemas de cultivo, valores da resistência à penetração, da ordem de $5 \%$ mais elevados, foram observados nos solos sob cultivo mínimo em relação ao convencional (Tollner et al. 1984). Para o cultivo mínimo os valores mais elevados ocorreram na profundidade de 15 a $20 \mathrm{~cm}$ e para o convencional na profundidade de 30 a $40 \mathrm{~cm}$, correspondendo simultâneamente com valores também mais elevados da densidade do solo, para as respectivas profundidades em cada caso.

Pode ocorrer no entanto, que as diferenças nos parâmetros físicos acima descritos, não ocorra, ou então se manifeste de modo menos pronunciado, o que irá depender do manejo adotado em relação a o solo, em cada sistema de cultivo.Este fato 
ressalta não somente a importância de se adotar um determinado sistema, mas também de conduzir corretamente as práticas requeridas em cada situação.

Um exemplo típico, relacionando os sistemas convencional e cultivo mínimo, em solo por um período de 10 anos é descrito por Blevins et al. (1983), que não detectaram diferenças significativas para a densidade do solo nestas situações

Em solos de diferentes classes texturais Archer et al. (1972), estudaram o efeito de diferentes valores da densidade em amostras deformadas de solos, submetidas à tensão de $50 \mathrm{mb}$, observando no geral uma relação linear crescente dos valores da umidade do solo em relação à densidade. Considerando o tipo de solo, a capacidade de água apresentou um comportamento semelhante ao observado para a umidade. Estes dois parâmetros quando analisados conjuntamente com a capacidade de aeração, permitem avaliar o comportamento dos solos por intervalos de densidade.

Estes resultados de "per si", podem ser úteis para orientar as práticas de manejo deste parâmetro físico a campo. No entanto, o problema não é tão simples, uma vez que envolve outras variáveis que influem nos valores da densidade do solo, como é o caso por exemplo dos teores de carbono orgânico. Além disso, foram utilizadas amostras deformadas dos solos, o que é bem diferente das condições naturais de campo.

Em termos práticos, ao conceito de compactação do solo, associa-se a idéia da resistência à penetração pelas raízes das plantas. Também neste caso, saber quais os fatores que influem na resistência, tem maior aplicabilidade, do que propriamente o valor em si.

Com esse objetivo, Smith et al. (1977), avaliaram o parâmetro resistência à penetração de uma série de diferentes tipos de solos, de classes texturais distribuidas em um intervalo bem amplo ( 8 a $66 \%$ de argila) e teores de carbono orgânico variando entre 0,26 e 5,77\%, observando que para todos os solos os valores do parâmetro resistência à penetração aumentaram com os valores crescentes da densidade do solo e decrescentes da umidade. 
De resultados gerais como estes, é natural surgir novas indagações a respeito das relações obtidas acima. Assim, pode-se questionar se os resultados são válidos somente para um intervalo de umidade restrito, ou mais amplo, levando-se em conta também a relação textural do solo e os teores de carbono orgânico.

Como exemplo disto, os mesmos autores destacam a maior influência da matéria orgânica sobre o parâmetro da resistência à penetração, para um determinado intervalo de umidade e densidade, quando os teores de argila decrescem. Ou seja, para os solos de textura mais fina (>30\% argila), os resultados sugerem que os teores de carbono orgânico neste caso não são altos o suficiente para influenciar significativamente as relações entre o parâmetro resistência à penetração, densidade do solo e a umidade.

Passando por esses fatores que influenciam as propriedades fisicas do solo, chega-se aos componentes estruturais do solo (tipo de estrutura, grau de desenvolvimento) os quais também exercem influencia nos parâmetros físicos citados (Gardner, 1971).

\subsubsection{Condutividade hidráulica $(K(\theta))$ e curva de retenção da água no solo $(h(\theta))$.}

As diferenças observadas nos valores da densidade do solo, na distribuição do tamanho de poros e porosidade de aeração, e por conseguinte na umidade e na condutividade hidráulica, quando se compara diferentes sistemas de cultivo e manejo, podem ser melhor avaliadas, quando se tem disponível o histórico da área a ser estudada e o perfil cultural do solo, onde são avaliadas as possíveis modificações de algumas de suas propriedades, introduzidas através do tempo. Comparando os sistemas de plantio direto e convencional (Gantzer \& Blake, 1978), observaram valores da densidade do solo mais elevados no horizonte superficial do plantio direto, correspondendo também a teores de umidade $(\theta)$ mais elevados, e valores mais baixos da porosidade de aeração. A condutividade hidráulica saturada, de amostras avaliadas em duas épocas distintas; maio (primavera) e setembro (outono), apresentou valores mais elevados para este último período, tanto no plantio direto como no convencional, resultado das diferenças observadas nos teores de água do solo (umidade antecedente) 
em cada período, sendo que no período de outono (setembro) os solos estavam mais secos, culminando com o aparecimento de rachaduras ou fissuras resultante do processo de expansão e contração, e contribuindo desta maneira para os valores de condutividade hidráulica saturada mais elevados nesta época.

Em condições de clima subtropical, e após 7 anos de cultivo, nos sistemas definidos como plantio direto, cultivo mínimo e plantio convencional, Roth et al. (1988), confirmaram os resultados de valores mais elevados da densidade do solo, com simultâneo aumento da porcentagem de microporos, no sistema de plantio direto, nas profundidades de $0,00-0,10 \mathrm{~m}$ e 0,10 - 0,20 m, sendo que no plantio convencional houve a formação de uma camada adensada na profundidade de 0,20 - 0,30 m. Os valores observados para a condutividade hidráulica não saturada $(K(\theta))$, não diferiram significativamente entre os três sistemas de cultivo, sendo porém mais baixos nas profundidades de 0,00-0,10 m e 0,10-0,20 m, comparativamente com a subsuperficie $(0,70-0,80 \mathrm{~m})$, com valores mais elevados devido a que nesta situação, a mobilização do solo é pouca ou ausente.

Muito embora, no sistema de plantio direto, os valores da densidade do solo geralmente sejam mais elevados em superficies, e também ocorra uma melhor continuidade dos poros responsáveis pela transmissão de água; a quantidade destes pode ser bem diferente entre os sistemas de cultivo resultando em valores de condutividade também distintos.

Resultados que confirmam essas hipóteses são discutidos por Heard et al. (1988), considerando basicamente o sistema de cultivo convencional, o reduzido e o plantio direto. Neste último constatou-se uma maior continuidade dos poros, porém em quantidades menores, relativamente ao sistema que mobiliza o solo de forma mais intensa. Os valores da condutividade hidráulica saturada $\left(\mathrm{K}_{\mathrm{o}}\right)$, foram maiores no sistema convencional, porém neste caso com maior variabilidade, sugerindo que tanto o cultivo mínimo como o plantio direto pelas próprias características mantêm em relação ao primeiro, uma maior uniformidade destas propriedades físicas do solo. 
Outro fator a ser considerado quando se discute as diferenças nos valores dos parâmetros físicos como a densidade, a distribuição do tamanho de poros, a retenção de água no solo e a condutividade hidráulica, é o tipo de solo e suas características morfo-estruturais, como por exemplo o grau de estruturação e a qualidade e estabilidade dos agregados. Isto pode se constituir, num dos motivos de que em determinados solos e após anos sob diferentes sistemas de cultivo, não se observam diferenças significativas em um ou mais dos parâmetros fisicos citados. Obviamente, não se quer dizer que não estejam ocorrendo alterações no solo, dentro de cada sistema de cultivo, ao contrário, as alterações sempre ocorrem em maior ou menor intensidade, apenas que o tempo necessário para que tais diferenças se manifestem é variável com o tipo de solo.

Chan \& Heenan (1993), compararam as possíveis modificações resultantes da ação de diferentes sistemas de cultivo (plantio direto, cultivo mínimo e plantio convencional) e manejo dos resíduos culturais (manutenção na superficie ou queima), sobre um Alfissol (Xeralfs), não constatando diferenças significativas nos valores da densidade do solo e a porosidade total, embora dentro de cada sistema de cultivo a densidade aumentou com a profundidade do solo. A condutividade hidráulica saturada, no entanto teve valores siginificativamente distintos, sendo quatro vêzes mais elevada no plantio direto em relação ao convencional, indicando que no primeiro, a melhor continuidade dos macroporos, permitiu um fluxo mais rápido da água.

Inúmeras tentativas têm sido feitas no sentido de definir e estabelecer um conceito abrangente no que diz respeito não só à distribuição do tamanho de poros, mas também considerando a geometria e a configuração do espaço poroso. Devido a isto, pode-se esperar que as relações entre a geometria do espaço poroso e as características de fluxo da água, assumam de certa forma um caráter complexo, e em função disto têm surgido diferentes métodos indiretos de classificação do espaço poroso.

Utilizando-se da curva de retenção da água no solo, Germann \& Beven (1981a), estabeleceram estimativas do volume do sistema de macroporos, em amostras de 
horizontes superficiais de dois solos. Em ambos os casos, os valores da função condutividade hidráulica $(\mathrm{K}(\theta))$, decresceram rapidamente com o correspondente decréscimo da umidade do solo $(\theta)$, quando a porosidade de aeração aumentou, aproximando-se de valores limites para os quais, o sistema de macroporos tinha sido drenado.

Estes conceitos evoluiram rapidamente, e novas tentativas foram feitas no sentido de aprimorar e melhor compreende-los.

Germann \& Beven (1981b), testaram o conceito de "domínio ou campo de influência" para a simulação de um modelo unidimensional de fluxo em um sistema combinado de macroporos/microporos, definido através das condições de contorno, necessárias para se poder avaliar as interações entre os mesmos.

Embora de caráter restrito, a sua utilidade está em permitir avaliar a importância relativa da ocorrência dos domínios especiais de macroporos e microporos e a sua influência em solos com características hidráulicas distintas.

Ainda com relação ao fluxo da água, o estado de agregação do solo é outro fator importante a ser considerado.

Youngs et al. (1990), discutem estes aspectos para diferentes situações de saturação da matriz dos agregados e seu entorno, tendo por base a clássica equação da continuidade, com adequações pertinentes às restrições impostas pelas condições de contorno. Assim, foram estabelecidos didaticamente cinco situações distintas e descritas a seguir:

1 -regiões de microporos e macroporos, ambas saturadas

2 -região de macroporos saturada e de microporos não saturada

3 -região de macroporos parcialmente saturada e região de microporos não saturada

4 -região de macroporos não saturadas e de microporos saturada

5 -região de macro e microporos não saturadas. 
Como as práticas mecânicas adotadas nos diferentes sistemas de cultivo, geram diferentes tipos de agregados, dependendo das condições de solo, (como por exemplo, a umidade), e do tipo de equipamento, os autores sugerem que as mesmas sejam orientados no sentido de se obter uma dimensão dos agregados adequada ao tipo de manejo que se pretende impor.

Considerando as devidas proporções entre o modelo teórico e a prática, estas considerações têm procedência principalmente por possibilitar uma visualização mais global da dinâmica do movimento da água no solo, e talvez chamar a atenção para os fatos que geram indecisões por ocasião da adoção de um determinado sistema de cultivo.

Bullock \& Thomasson (1979), estudando a distribuição e a configuração do espaço poroso, avaliaram comparativamente os métodos de análise por imagem e o da curva de retenção da água, para uma série de solos.

Muito mais do que testar metodologias, a importância maior está nos resultados que caracterizam o espaço poroso em relação ao fluxo da água e as principais limitações a este.

Neste sentido, os autores relatam como relevantes dois tipos de distribuição de poros; o primeiro onde o total da macroporosidade foi devida à presença de poucos poros grandes com diâmetro em torno de $8 \mathrm{~mm}$, e ocorrência de muitos poros de menor diâmetro, com pouca contribuição para o total de macroporos,sugerindo que tal distribuição é consequência de uma estrutura do solo bem desenvolvida. Para o outro tipo, observou-se a distribuição equilibrada de macroporos por classe de diâmetro, podendo ser o resultado de uma condição de menor desenvolvimento da estrutura do solo.

Também com o propósito de obter mais informações e conhecimento sobre o fluxo da água em macroporos, Germann \& Beven (1981c), reuniram os dados de 
Burger $^{1}$ (1922 a 1940) relativos ao fluxo da água, influenciado pelo sistema de macroporos, e de Ehlers ${ }^{2}$ (1975), que estudou o mesmo assunto, como resultado da influência direta da fauna, em horizontes de solos submetidos aos sistemas de cultivo convencional e plantio direto. Os resultados obtidos da comparação entre o modelo teórico proposto e os dados originais reunidos dos dois pesquisadores, sugeriram uma aproximação razoável para o estudo do processo de fluxo em macroporos.

\subsection{A dinâmica da água no solo}

O movimento da água no solo é regido por funções importantes como a condutividade hidráulica e o potencial total da água no solo, influenciados diretamente pela arquitetura do meio poroso, sendo que a equação diferencial geral que descreve o processo, pode ser derivada combinando a equação de Darcy com a equação da continuidade (Richards, 1931).

O fluxo vertical não saturado em solo homogêneo, na direção $z$ pode ser descrito através da equação de Darcy, na forma:

$$
\vec{q}=-K(\theta) \frac{\partial \varphi}{\partial z}
$$

sendo,

$\vec{q}=$ a densidade de fluxo $\left(\mathrm{m}^{3} \mathrm{~m}^{-3} \mathrm{~s}^{-1}\right)$

$K=$ condutividade hidráulica do solo $\left(\mathrm{m} \mathrm{s}^{-1}\right)$, que é uma função da umidade do solo $(\theta)$ $\left(\mathrm{m}^{3} \mathrm{~m}^{-3}\right)$

${ }^{1}$ BURGER, H. Physikalische Eigenschaften von Wald-und Feilanböden. Mitteilungen der Schweizerischen Centralanstalf für das Forstliche Versuchswesen, v.13, p. 1-221, 1922; v.14, p.201-250, 1927; v.15, p.51-104, 1929; v.17, p.299-322, 1932; v.20, p.1-100, 1937; v.21, p.223-249. 1940.

2 EHLERS, W. Observation on earthworn channels and infiltration on tilled and untilled loess soil. Soil Science, v.119, p.242-249, 1975. 
$\Psi=$ o potencial total da água no solo $(\mathrm{m})$, que é a soma de uma série de componentes, sendo que para a infiltração vertical, os principais a serem considerados são os potenciais mátrico $\Phi \mathrm{m}(\mathrm{m})$ e gravitacional z $(\mathrm{m})$, desprezando-se os demais, sendo que a equação (1) pode ser escrita segundo Klute, 1972; Libardi \& Reichardt (1974) da seguinte forma:

$$
\vec{q}=-\left[K(\theta) \frac{\partial \phi m}{\partial z}+K(\theta)\right]
$$

Considerando o potencial mátrico como uma função unívoca de $(\theta)$, a equação de Darcy pode ser rescrita segundo Childs \& Collis Geoge (1950) e Klute (1972) como:

$$
\vec{q}=-\left[D(\theta) \frac{\partial \theta}{\partial z}+K(\theta)\right]
$$

sendo,

$$
D(\theta)=K(\theta) \frac{\partial \phi m}{\partial \theta}
$$

Por outro lado, a equação da continuidade aplicada a um elemento de volume de solo, onde ocorre a infiltração vertical é escrita na forma:

$$
\frac{\partial \theta}{\partial t}=\frac{\partial q}{\partial z}
$$

sendo t o tempo (s);

Substituindo nesta última equação as equações (2) e (3) resulta respectivamente: 


$$
\frac{\partial \theta}{\partial t}=\frac{\partial}{\partial z}\left[K(\theta) \frac{\partial \phi m}{\partial z}+K(\theta)\right]
$$

e

$$
\frac{\partial \theta}{\partial t}=\frac{\partial}{\partial z}\left[D(\theta) \frac{\partial \theta}{\partial z}+K(\theta)\right]
$$

que representam as duas equações diferenciais mais gerais que regem o movimento da água em solo homogêneo.

Em se tratando de uma coluna de solo homogêneo com umidade inicial constante $\left(\theta_{0}\right)$, para a qual é aplicada e mantida uma umidade $\left(\theta_{s}\right)$ na extremidade da coluna onde $z=0$, inicia-se o processo de infiltração, com a umidade $(\theta)$ sendo uma função do ponto considerado $z$ e do tempo $t$.

Assim, as seguintes condições iniciais e de contorno devem ser consideradas com relação à ultima equação:

$$
\begin{array}{lll}
\theta=\theta_{0}, & z>0, & t=0 \\
\theta=\theta s, & z=0, & t>0 \\
\theta=\theta_{0}, & z=\infty, & t>0
\end{array}
$$

No entanto tais condições podem ser simplificadas quando se dispõem para a determinação do fluxo e da condutividade hidráulica, as condições de equilíbrio dinâmico. Neste caso, a diferencial do potencial total da água no solo é expressa através de aproximações por diferenças finitas. Assim para o fluxo vertical em condições de saturação, o calculo de $\mathrm{K}_{\mathrm{o}}$ se resume à expressão:

$$
q=-K \circ[\nabla H]
$$

sendo, 
$\mathrm{q}=$ densidade de fluxo da água $\left(\mathrm{L} \cdot \mathrm{T}^{-1}\right)$

$\nabla . \mathrm{H}=$ Gradiente do potencial total da água, $\mathrm{H}\left(\mathrm{L} . \mathrm{L}^{-1}\right)$

$\mathrm{H}=\mathrm{h}+\mathrm{z}$

$\mathrm{h}=$ potencial de pressão (correspondente à pressão atmosférica local), e $\mathrm{z}=$ potencial gravitacional (L)

podendo também ser escrita na forma

$$
K_{\circ}=\frac{V L}{A t \Delta \Phi t}
$$

sendo,

$\mathrm{K}_{\mathrm{o}}=$ condutividade hidráulica do solo saturado

$\mathrm{V}=$ volume de água que atravessa uma área de secção transversal A no tempo $\mathrm{t}$.

$\mathrm{L}=$ comprimento da amostra

$\mathrm{A}=$ área da secção transversal da amostra

$\mathrm{t}=$ tempo

$\Delta \Phi \mathrm{t}=$ diferença de potencial total observada entre os pontos $\mathrm{A}$ e $\mathrm{B}$

Para as condições de fluxo vertical não saturado em pequenas colunas de solo tem-se a relação seguinte:

$$
\overrightarrow{\mathrm{q}}=-\mathrm{K}(\mathrm{h}) \nabla \mathrm{H}
$$

$\mathrm{q}=$ densidade de fluxo da água $\left(\mathrm{L} . \mathrm{T}^{-1}\right)$

$\nabla \mathrm{H}=$ Gradiente do potencial total da água , $\mathrm{H}\left(\mathrm{L} . \mathrm{L}^{-1}\right)$

$\mathrm{H}=\mathrm{h}+\mathrm{z}$;

$\mathrm{h}=$ potencial mátrico $(\mathrm{L})$

$\mathrm{z}=$ potencial gravitacional $(\mathrm{L})$

podendo também ser escrita na forma 


$$
K(h)=\frac{V L}{A t \Delta \Phi t}
$$

sendo,

$\mathrm{K}(\mathrm{h})=$ condutividade hidráulica do solo não saturado tomada como uma função do potencial mátrico $h=K(h)$

$\mathrm{V}=$ volume de água que atravessa uma área de secção transversal A no tempo $\mathrm{t}$

$\mathrm{L}=$ comprimento da amostra

$\mathrm{A}=$ área de secção transversal da amostra

$\mathrm{t}=$ tempo

$\Delta \Phi \mathrm{t}=$ diferença de potencial total observada entre os pontos A e B

Richards (1931) foi o primeiro a apresentar um método de determinação da condutividade hidráulica. Seu método constitui em se utilizar uma pequena coluna de solo entre duas placas porosas de cerâmica, mantendo um gradiente de potencial constante entre as extremidades da coluna por meio de colunas de água. Uma vez atingida a condição de equilíbrio dinâmico a condutividade hidráulica era estimada por meio da equação de Darcy.

A utilização deste procedimento, onde a coluna de solo é curta tem a vantagem de se poder utilizar amostras de solo com estrutura não deformada para a determinação da constante de proporcionalidade entre o fluxo de água no solo e o gradiente de potencial (Laliberte \& Corey ,1967).Não obstante, os métodos baseados no equilíbrio dinâmico têm a desvantagem da exigência de tempos relativamente longos para se estabelecer o regime de fluxo estacionário, o que pode acarretar mudanças nos valores das propriedades hidráulicas dos solos devido às alterações ocasionadas pelo desenvolvimento de microorganismos, sendo então necessário o emprego de produtos como o timol com o objetivo de inibir a atividade microbiana.(Klute, 1972).

Outro parâmetro importante e que tem sido utilizado para a determinação da condutividade hidráulica em função da umidade do solo é a curva de retenção da água no solo, como bem atestam os trabalhos de Marshall (1958); Millington 
\& Quirk (1959); Wind (1966); Campbell (1974); Van Genuchten (1980), Kosugui (1981) e Talsma (1985).

Dentre estes, Van Genuchten (1980) fundamentado nos modelos de Burdine (1953) e Muallen (1976), e utilizando-se dos dados da curva de retenção da água no solo, discute uma forma analítica de determinação da condutividade hidráulica.

Este e outros modelos têm grande importância não só pelo fato de permitir a determinação analítica de funções como a condutividade hidráulica e a difusividade da água, mas também de facilitar as comparações dos valores destas funções assim determinadas, com os resultados obtidos através de outros métodos experimentais de laboratório ou de campo empregados para o calculo de $(\mathrm{K}(\theta))$ e $(\mathrm{D}(\theta))$. Além disso, através da curva de retenção obtem-se por derivação a função $d \theta / d \tau$ que representa a distribuição do tamanho de poros do solo, sendo a umidade volumétrica $(\theta)$ uma função da tensão $\tau$, ou seja $d \theta=f(\tau) d \tau$. Um exemplo prático desta aplicação é discutido por Libardi (1995).

Todos esses métodos foram através do tempo, testados por outros estudiosos como Luxmoore et al. (1981), Schuh et al. (1984) e Jones \& Wagenet (1984).

Ainda com relação à determinação da condutividade hidráulica do solo, e diante do modelo anteriormente proposto, Van Genuchten \& Nielsen (1985) analisaram os modelos mais utilizados para o ajuste dos dados experimentais das curvas de retenção, concluindo que o modelo de Mualem (1976), com a equação de Van Genuchten (1980) para a curva de retenção foi o que apresentou um maior índice de validade com relação à totalidade dos solos analisados.

Mais recentemente, Pauletto et al. (1988), desenvolveram um método simples para a determinacão da funcão $\mathrm{K}(\theta)$ a partir da curva de retencão. 


\section{MATERIAL E MÉTODOS}

\subsection{Localização e caracterização da área}

A área de estudo localiza-se numa microbacia representativa dos rios Pardo e Grande, localizada no município de Guaira ao norte do Estado de São Paulo, com coordenadas de $20^{\circ} 22^{\prime} 29^{\prime \prime}$ de latitude sul, $48^{\circ} 15^{\prime} 43^{\prime \prime}$ de longitude oeste e altitude de $495 \mathrm{~m}$. (Figura 1).

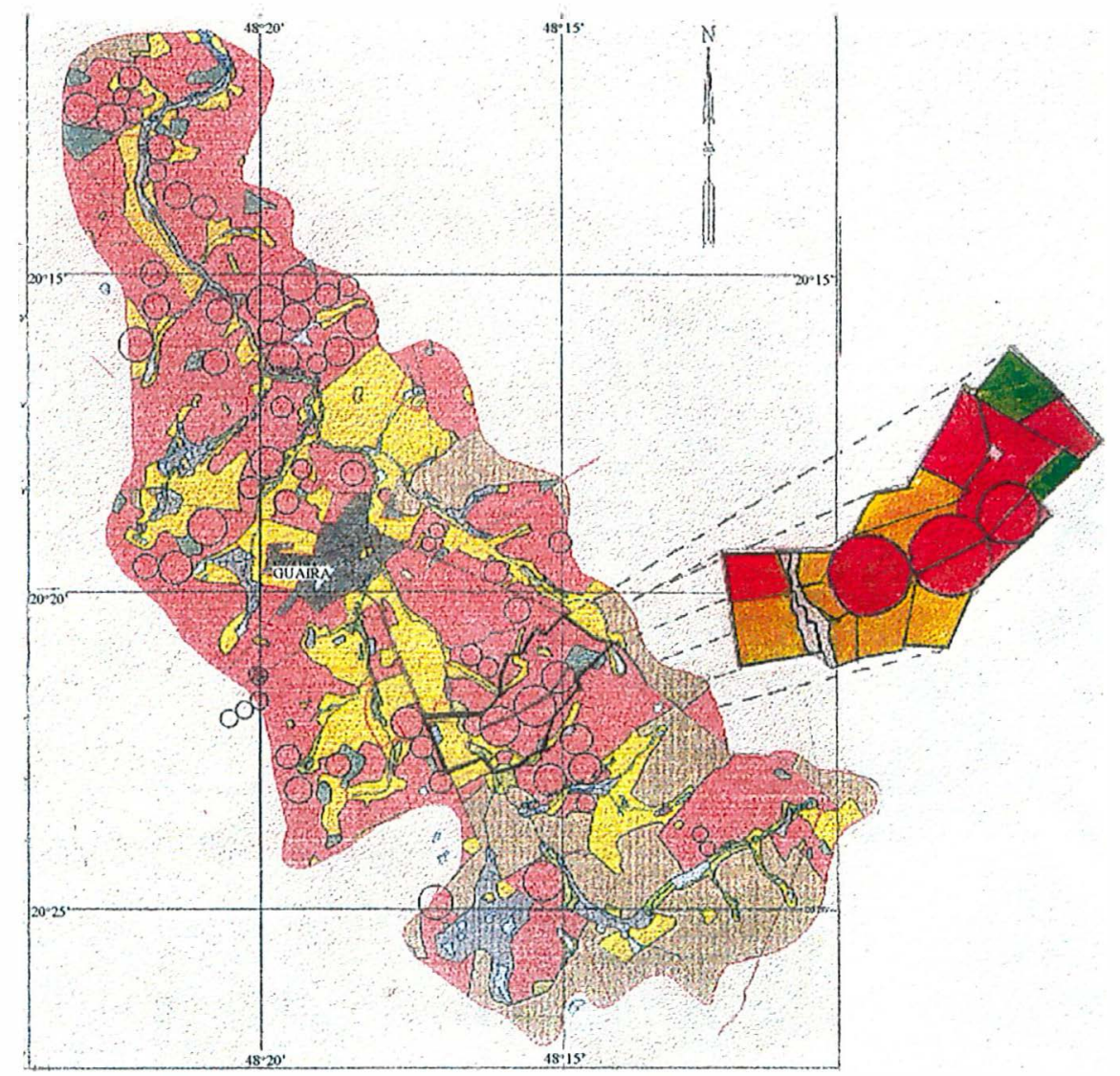

Figura I - Mapa da microbacia do Ribeirão Jardim, com a área de estudo delimitada em negrito e localização dos pivôs centrais (circunferências). (IPT', 1995). 
O clima da região é do tipo "Cwa" pela classitīcação de Köeppen, isto é, subtropical úmido com temperatura média do mês mais frio superior a $18^{\circ} \mathrm{C}$ e do mês mais quente superior a $22^{\circ} \mathrm{C}$. A precipitação média anual é de $1330 \mathrm{~mm}$, com ocorrência de uma estação seca de maio a setembro.

O relevo regional é ondulado, com declividades entre 8 e $20 \%$, caracterizado por colinas de baixa altitude e encostas convexas e uniformes com pendentes longas. O relevo do local das áreas experimentais é suave ondulado a plano, com declividade inferior a 3\% (Figura 2).

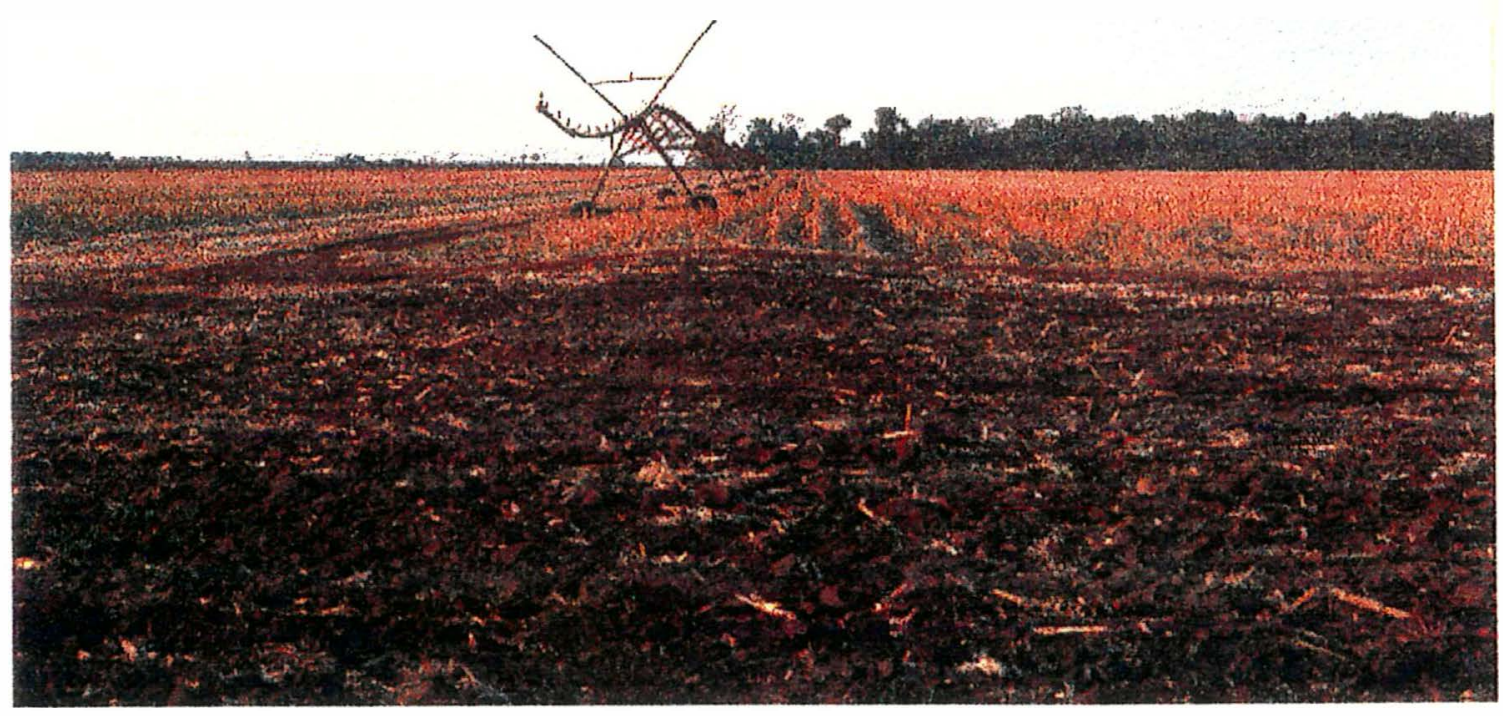

Figura 2 - Aspectos da superficie de relevo suave ondulado a plano, típica da área de estudo.

O solo que ocorre na área é o Latossolo Roxo Distrófico A moderado textura argilosa a muito argilosa. São solos profundos, bem drenados e de cores avermelhadas com matizes entre 2.5YR e 10R (Figura 3 ). 


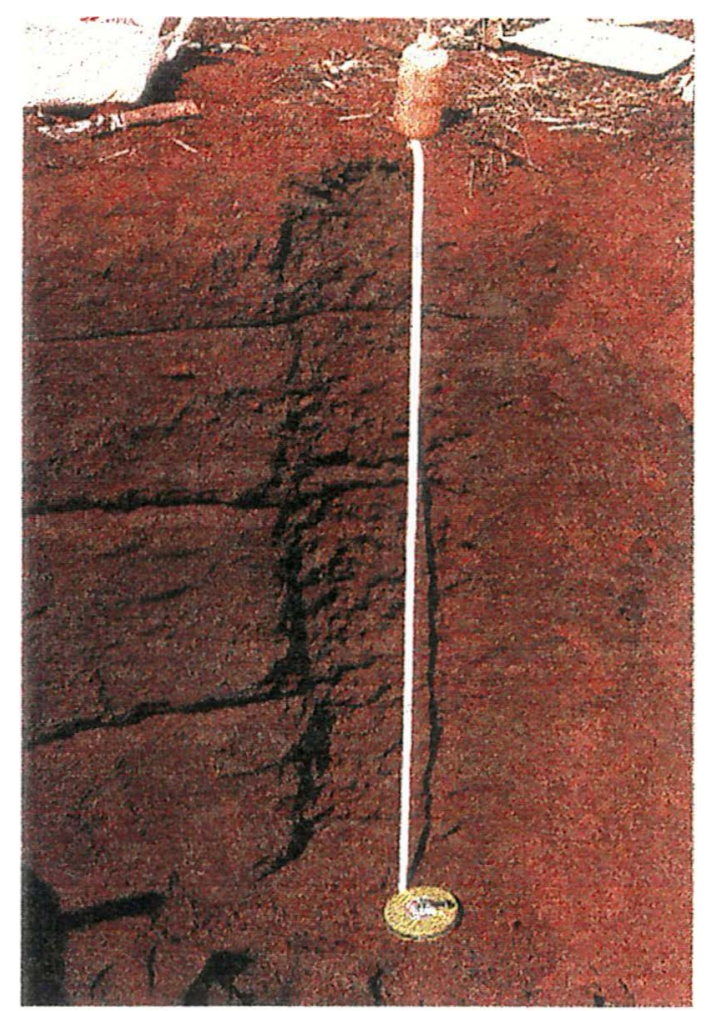

Figura 3 - Perfil de Latossolo Roxo Distrófico, predominante da área de estudo.

O material de origem são as rochas eruptivas básicas da formação Serra Geral, que abrange, além de São Paulo, os estados do Paraná, Santa Catarina e Rio Grande do Sul.

\section{2 Área experimental}

O local do experimento é constituído por três áreas distintas da microbacia, aqui definidas como Al (30,25 ha), A2 (26,01 ha) e A3 (12,3 ha), com culturas anuais em diferentes sistemas de cultivo, caracterizados por plantio convencional não irrigado (PCNI-15 anos) em sistema de rotação definido com feijão no inverno e milho e/ou soja no verão (área A2); plantio direto irrigado (PDI-8 anos) com feijão no inverno e milho e/ou soja no verão (área A3); e plantio convencional irrigado (PCI-15 anos) com feijão e ou tomate no inverno e soja e/ou milho no verão (área A1).

Em cada uma dessas áreas foram abertas três trincheiras de $2,0 \mathrm{~m} \times 1,5 \mathrm{~m} \times 1,0 \mathrm{~m}$, para a descrição dos perfís segundo a metodologia de 
Lemos \& Santos (1984) e, em seguida, coleta de amostras de cada um dos horizontes selecionados para as análises de granulometria e químicas.

Os resultados das análises químicas e as descrições morfológicos das solos, para os três sistemas de cultivo definidos acima são apresentados no Anexo A.

Nas trincheiras abertas foram feitas também coletas de amostras nas profundidades de 0,00 - 0,07 m;0,07-0,14 m;0,27-0,34 m e de 0,97 - 1,04, para a elaboração das curvas de retenção, determinação da densidade do solo e da condutividade hidráulica do solo saturado $\left(K_{\circ}\right)$ e não saturado $(K(h))$

Estas profundidades foram estabelecidas, após a descrição e separação dos horizontes do solo, levando em consideração o tipo de sistema do cultivo (PCNI, PDI e PCI), tendo como objetivo a comparação e análise da influência das diferentes práticas de manejo, nas propriedades físico-hídricos citadas acima. Portanto, elas não coincidem necessariamente com aquelas estabelecidas para a descrição dos horizontes do solo, onde as amostras retiradas foram destinadas principalmente às análises químicas e fisicas para fins de classificação do solo. Podem no entanto, fazer parte de um determinado horizonte, desde que seus limites estejam compreendidos no intervalo de profundidade do horizonte em questão.

\subsection{Determinações físicas}

\subsubsection{Curva de retenção da água no solo}

As curvas de retenção da água no solo $(h(\theta))$ foram elaboradas por secamento, em amostras de solo (num total de 144) com estrutura indeformada, obtidas das três trincheiras abertas em cada um dos sistemas de cultivo e nas profundidades específicas citadas no item 3.2, sendo que nas Figuras 4 e 5 é mostrado o processo de retirada das amostras. 


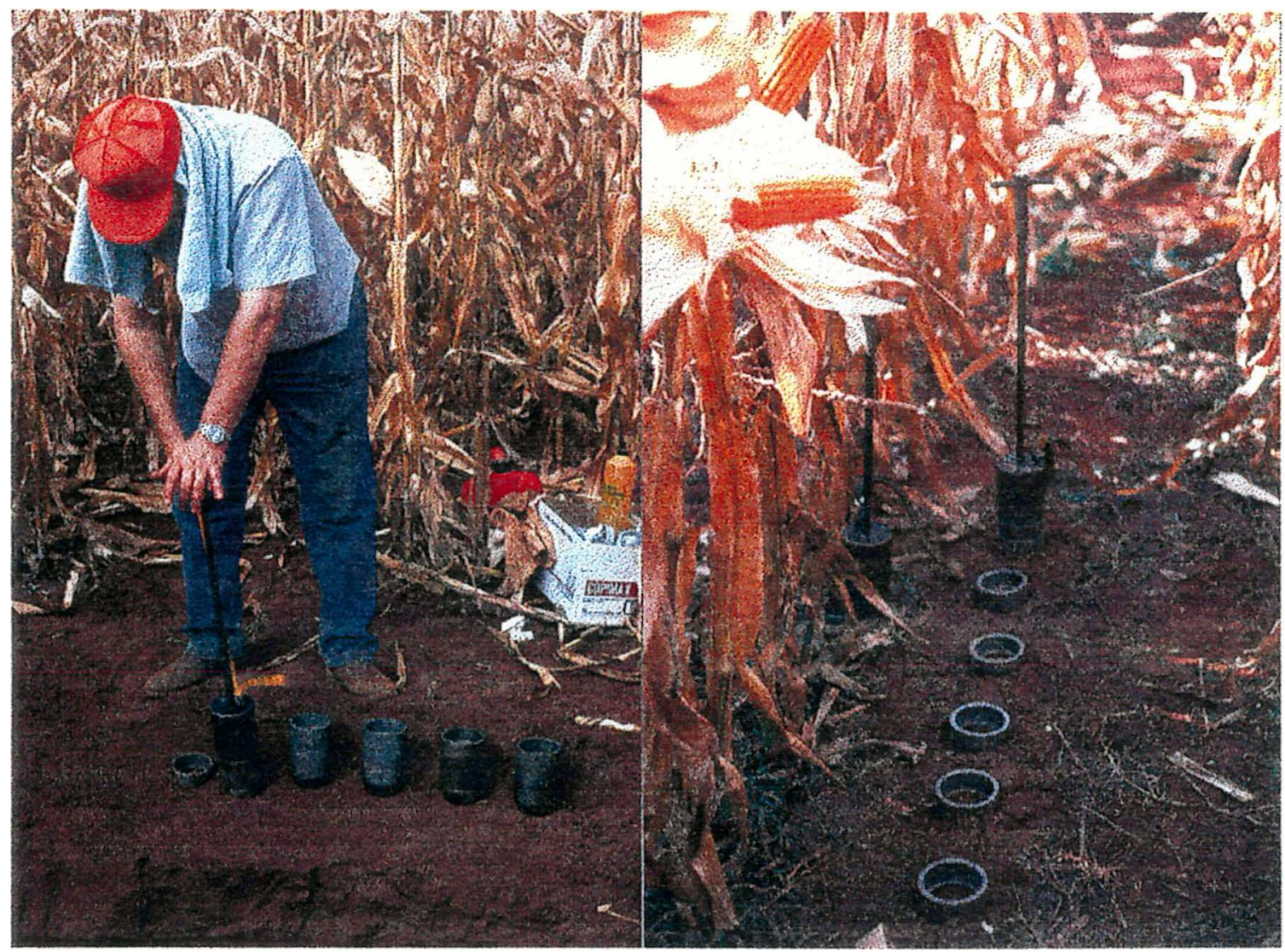

Figuras 4 e $5 \quad$ Processo de retirada das amostras indeformadas de perfis de solos descritos para cada sistema de cultivo e manejo.

A água das amostras foi submetida às tensões de $0,5,1,0,2,0,5,0,8,0$, $30,0,60,0$ e 1500,0 kPa, sendo que para as tensões de 0,5, 1,0, 2,0 e 5,0 kPa, utilizou-se de funis de placa porosa e para as demais tensões, as câmaras de pressão de Richards, conforme os cuidados recomendados por Moraes et al. (1993).

O ajuste das curvas de retenção foi feito através do programa SWRC, (Dourado Neto et al. 1990) utilizando o modelo de Genuchten (1980).

\subsubsection{Condutividade hidráulica do solo saturado $\left(K_{o}\right)$}

As determinações da condutividade hidráulica do solo saturado $\left(K_{o}\right)$ foram feitas pelo método do permeâmetro de carga constante (Libardi, 1995).

As amostras indeformadas obtidas com o extrator de Uhland nas profundidades de $0,00-0,07 \mathrm{~m}, 0,07-0,14 \mathrm{~m}, 0,27-0,34 \mathrm{~m}$ e $0,97-1,04 \mathrm{~m}$, num total 
de quatro por perfil e em três repetições dentro de cada sistema de cultivo, foram trabalhadas em laboratório, com o fim de sua adequação ao modelo experimental proposto (Figura 6), que preconiza alguns passos importantes para a sua elaboração.

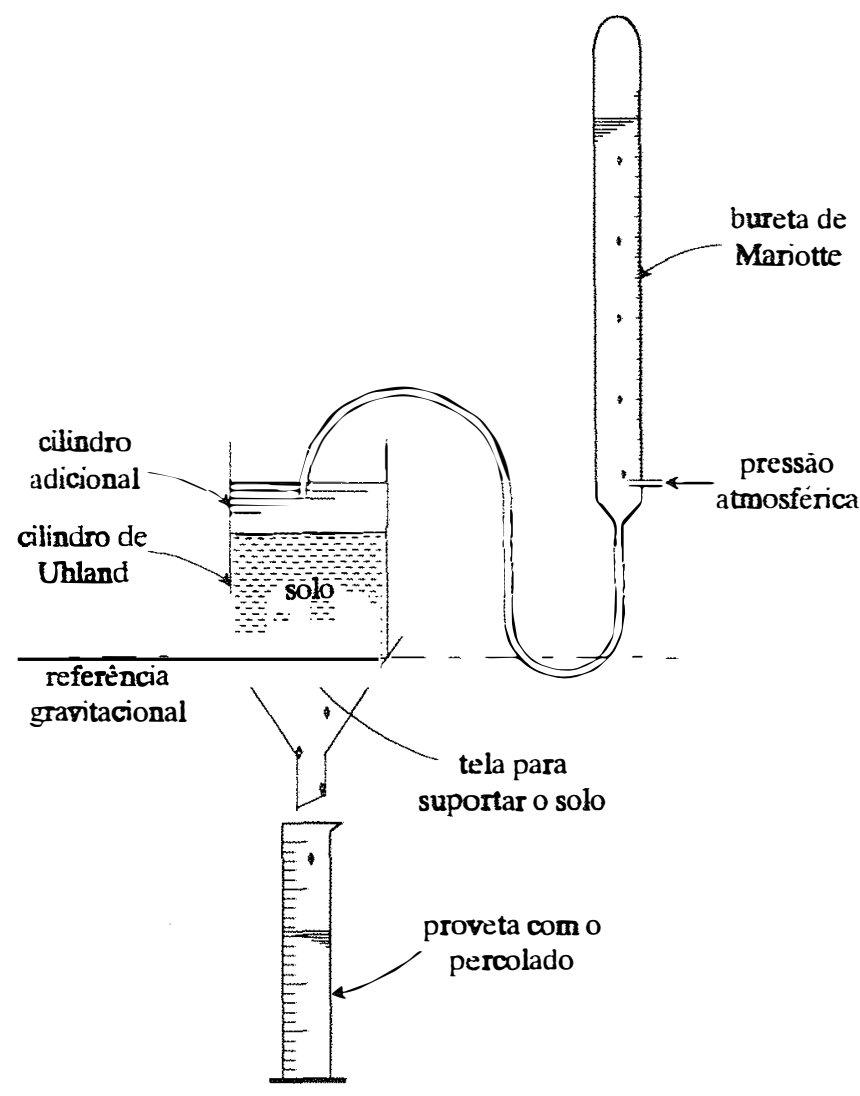

Figura 6 - Arranjo experimental de laboratório para a determinação da condutividade hidráulica do solo saturado $\left(K_{o}\right)$ (Libardi, 1995).

O processo de montagem tem início, pela retirada do excesso de solo da amostra indeformada, contida no cilindro de Uhland, através de uma escavação leve e cuidadosa, permitindo assim o completo nivelamento das duas superficies (superior e inferior). Após, a amostra é montada no dispositivo da Figura 6 e saturada por 24 horas no sentido ascendente, para posteriormente receber a carga hidráulica constante, onde a partir de então passava-se a contabilizar o tempo e o volume de água, calculando a densidade de fluxo, para posterior determinação de $K_{o}$ de acordo com a seguinte equação: 


$$
K_{o}=\frac{V \cdot L}{A \cdot t(h+L)}
$$

onde:

$V=$ volume de água coletado na proveta (ou medido pela bureta de Mariotte) durante o tempo $t$

$A=$ área da secção transversal da amostra;

$L=$ comprimento da amostra;

$h=$ potencial de pressão (= carga hidráulica) no topo da amostra.

\subsubsection{Condutividade hidráulica do solo não saturado $(K(h))$}

As determinações da condutividade hidráulica do solo não saturado foram feitas pelo método das colunas pequenas sob condição de regime estacionário cujo esquema pode ser visto na Figura 7 (Libardi, 1995).

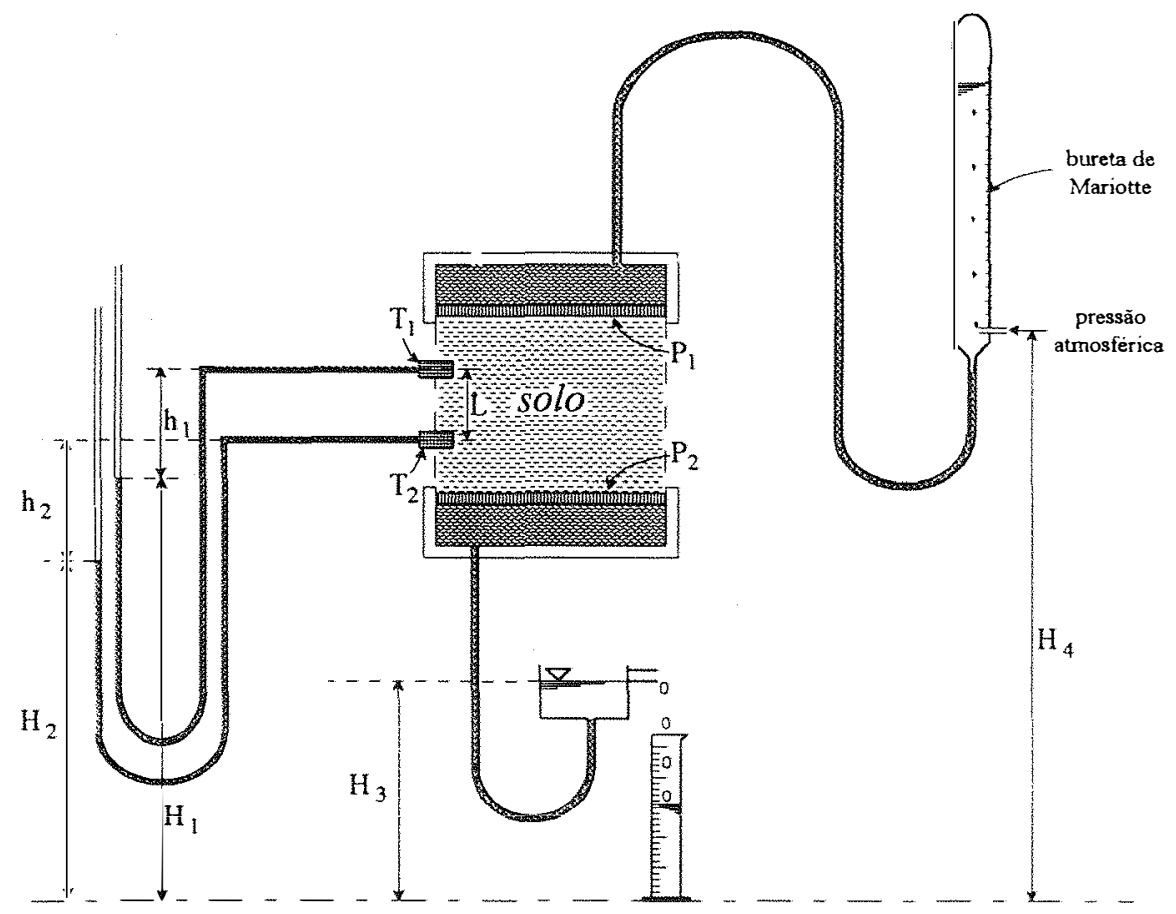

Figura 7 - Diagrama do aparelho para medida da condutividade hidráulica de solo não saturado. 
A amostra da Figura 7 foi submetida ao processo de dessaturação pela diminuição simultânea de $\mathrm{H}_{3}$ e $\mathrm{H}_{4}$, utilizando-se para isto, dos seguintes valores de tensão, em termos de coluna de água: 2,$0 ; 4,0 ; 6,0$ e $8,0 \mathrm{kPa}$. O cálculo da função $K(h)$ foi feito pela equação abaixo:

$$
K(\bar{h})=\frac{V / A t}{\left(H_{1}-H_{2}\right) / L}
$$

considerando cada nível de tensão aplicado, a saber, $K(h)_{2,0 \mathrm{kPa}}, K(h)_{4,0 \mathrm{kPa}}, K(h)_{6,0 \mathrm{kPa}} \mathrm{e}$ $K(h)_{8,0 \mathrm{kPa}}$,

onde,

$V=$ volume de água coletado na proveta (ou medida pela bureta de Mariotte) durante o tempo $t$;

$A=$ área da secção transversal da amostra;

$L=$ distância entre os tensiômetros $T_{1}$ e $T_{2}$;

$H_{1}$ e $H_{2}=$ potenciais totais calculados por meio dos tensiômetros $T_{1}$ e $T_{2}$, respectivamente;

$h_{l}=$ potencial mátrico correspondente à leitura do tensiometro $T_{l}$;

$h_{2}=$ potencial mátrico correspondente à leitura do tensiômetro $T_{2}$;

$R G=$ referência gravitacional.

A Figura 8 ilustra a montagem do sistema utilizado no presente experimento, onde podem ser observados os pequenos furos por todo o cilindro para, permitir a aeração do solo e dois furos maiores onde foram instalados os tensiômetros. Pode ser notar também, a placa porosa com um pequeno rebaixo para o bom contato com o solo e ajuste do cilindro via um aplicador de água de acrílico através do qual foram fixadas as buretas de Mariotte. 


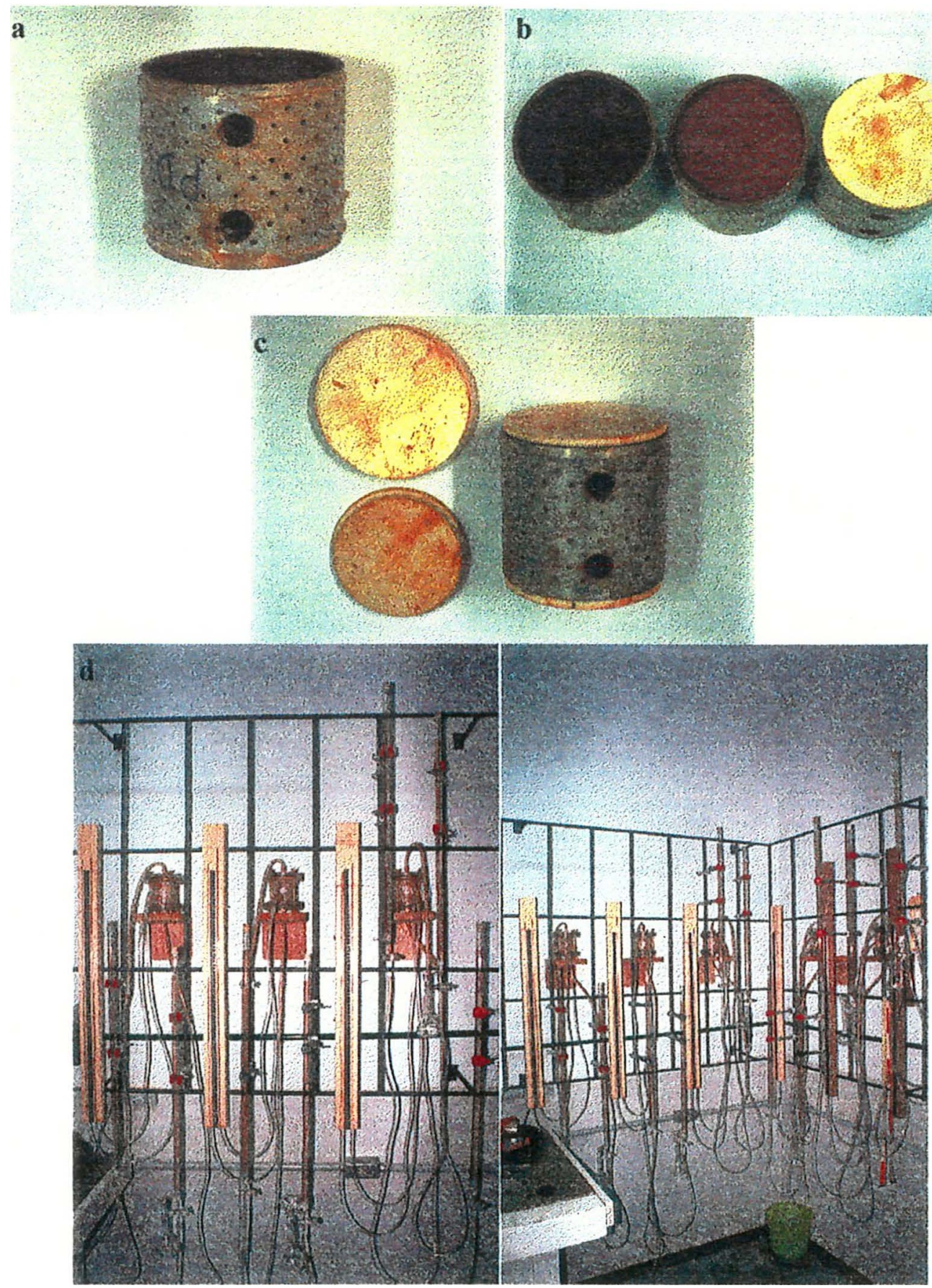

Figura 8 - Seqüência da montagem dos componentes do modelo experimental de laboratório para determinação da condutividade hidráulica do solo não saturado $(K(h))$ : a) cilindro de solo com os orificios pequenos para aeração do solo e os dois orifícios maiores para a fixação dos tensiômetros; b) detalhe do rebaixamento do solo para o encaixe da placa porosa; c) placa porosa com o rebaixo de encaixe e encaixada no cilindro; d) visão geral do conjunto montado. 


\subsubsection{Condutividade hidráulica relativa $\operatorname{Kr}(\theta)$}

A condutividade hidráulica relativa $\left(K_{r}\right)$ do solo, foi determinada, utilizando-se o modelo de Genuchten (1980), adaptado a partir do modelo de Mualem (1976), de acordo com a seqüência abaixo:

a) Ajuste da curva de retenção, através da equação:

$$
\Theta=\frac{\theta-\theta_{r}}{\theta_{s}-\theta_{r}}=\left[1+|\alpha \cdot h|^{n}\right]^{-m}
$$

onde,

$\Theta=$ saturação relativa;

$\theta_{r}=$ o teor volumétrico de água residual;

$\theta_{s}=$ o teor volumétrico de água na saturação;

$\alpha, m$ e $n$ são parâmetros empíricos a serem determinados.

a) Cálculo da condutividade hidráulica relativa propriamente dito, após o ajuste da curva de retenção, pela relação abaixo:

$$
K r(\Theta)=\Theta^{1 / 2}\left[1-\left(1-\Theta^{1 / m}\right)^{m}\right]^{2}
$$

\subsubsection{Condutividade hidráulica não saturada $(K(\theta))$}

Com os valores calculados de $K_{r}(\theta)$ e ainda com os valores da condutividade hidráulica saturada $\left(K_{s}\right)$ determinados experimentalmente, calculou-se também a condutividade hidráulica não saturada $(K(\theta)$, através da relação:

$$
K(\theta)=K_{r}(\Theta) \times K_{s}
$$




\subsubsection{Difusividade relativa $(\operatorname{Dr}(\Theta))$}

A determinação da difusividade relativa $\operatorname{Dr}(\Theta)$ foi feita através dos parâmetros resultantes do ajuste da curva de retenção, juntamente com os valores da condutividade hidráulica saturada $\left(K_{s}\right)$ obtidas experimentalmente, de acordo com a relação abaixo:

$$
D_{r}(\Theta)=\frac{(1-m) K_{s}}{\alpha m\left(\theta_{s}-\theta_{r}\right)} \Theta^{1 / 2-1 / m}\left\{\left[1-(\Theta)^{1 / m}\right]^{-m}+\left[1-(\Theta)^{1 / m}\right]^{m}-2\right\}
$$

\subsection{Distribuição do tamanho de poros}

O estudo da distribuição do tamanho de poros foi realizado através da equação de Kelvin, descrita e discutida por Libardi (1995) como:

$$
\tau=-\phi_{m}=-\frac{2 \sigma \cos \alpha}{r}=\rho_{a} g h \quad[\text { energia/volume }]
$$

ou

$$
\left.\tau=-\phi_{m}=\frac{2 \sigma \cos \alpha}{\rho_{a} g r}=h \quad \text { [altura de água }\right]
$$

onde,

$\sigma=$ tensão superficial da água

$\alpha=$ ângulo de contato entre a água e o poro do solo, o qual para fins de cálculo é assumido ser sempre igual a zero

$g=$ aceleração da gravidade

$\rho_{a}=$ densidade da água

$h=$ distância vertical do ponto de medida ao nível da água no manômetro do funil de placa porosa (equivalente à pressão $P$ no medidor de pressão da câmara de pressão). 
Através da equação 17 ,e justamente com as curvas de retenção $(h(\theta))$, que relacionam a quantidade de água no solo em equilíbrio com a tensão aplicada, procedeu-se ao cálculo da distribuição do tamanho de poros do solo. Para tanto foram determinadas funções derivadas das curvas de retenção, estabelecendo-se gráficos na forma $d \theta / d \tau$ versus $\tau$. Como $d \theta / d \tau$ é função de $\tau$ ou seja,

$$
d \theta / d \tau=f(\tau)
$$

ou

$$
d \theta=f(\tau) \cdot d \tau
$$

e integrando-se esta última equação membro a membro entre $\theta_{l}$ e $\theta_{2}$ e entre $\tau_{l}$ e $\tau_{2}$, simultaneamente, resulta.

$$
\int_{\theta_{1}}^{\theta_{2}} d \theta=\int_{\tau_{1}}^{\tau_{2}} f(\tau) d \tau \Rightarrow \theta_{2}-\theta_{1}=\int_{\tau_{1}}^{\tau_{2}} f(\tau) d \tau
$$

podendo também ser escrita como:

$$
\theta_{1}-\theta_{2}=\int_{\tau_{2}}^{\tau_{1}} f(\tau) d \tau
$$

quando se inverte os limites de integração.

A partir desta definição e considerando dois níveis de tensão, designados respectivamente por 1 e 2 , pode-se escrever a equação (17) na forma:

$$
\tau_{(1,2)}=-\phi_{m(1,2)}=\frac{2 \sigma \cos \alpha}{r_{(1,2)}}
$$


sendo a mesma utilizada para o cálculo da distribuição do tamanho de poros, considerando o intervalo de tensões entre os níveis 1 e 2.

Para analisar as curvas de retenção e de distribuição do tamanho de poros do solo foi estabelecido também um referencial quanto ao tipo de poro (intraagregados, interagregados e canais), com seus respectivos intervalos dos valores de raio equivalente (RE). Estas informações estão reunidas no Quadro 1 abaixo (Kertzman, 1996 - modificado).

Quadro 1 - Tipos de poros, tamanho de raio equivalente e as técnicas utilizadas no estudo da porosidade do solo.

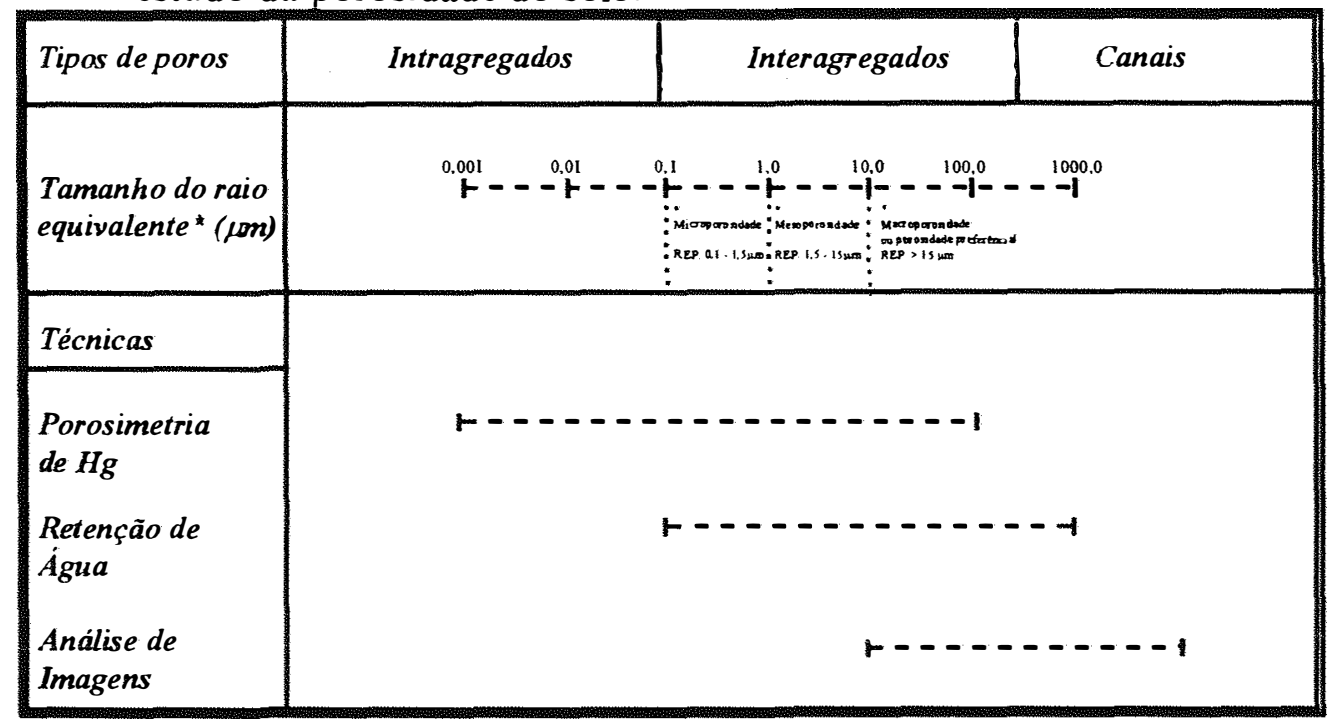

* Dados de Mbagwn (1997), que define o espaço poroso em:

1 - Macroposidade ou Porosidade Preferencial $\left(P_{e}\right)$ é aquela constituída dos poros com raio equivalente $-\mathrm{RE}>15 \mu \mathrm{m}$, ou seja, o espaço poroso drenando a uma tensão $\tau=10 \mathrm{kPa}$.

2 - Mesoporosidade $\left(P_{n}\right)$ é a constituída dos poros com raio equivalente - RE no intervalo de $1,5-15 \mu \mathrm{m}$, ou seja, o espaço poroso drenando no intervalo de tensões de $100 \mathrm{kPa}$ e $10 \mathrm{kPa}$.

3 - Microporosidade $\left(P_{m}\right)$ é a constituída dos poros com raio equivalente - RE no intervalo de tensões de $0,1-1,5 \mu \mathrm{m}$, ou seja, o espaço poroso drenando no intervalo de tensões entre $1500 \mathrm{kPa}$ e $100 \mathrm{kPa}$. 


\subsection{Análise estatística}

Inicialmente foram obtidos os parâmetros de ajuste da função $h(\theta)$ pelo método de Genuchten (1980) juntamente com valores estimados das funções $\operatorname{Kr}(\Theta), \operatorname{K}(\theta)$ e $\operatorname{Dr}(\Theta)$

Em seguida procurou-se verificar através do índice (d) de Willmott (1981), o grau de adequação do modelo utilizado na estimativa dos valores destas funções, com os valores observados das análises de laboratório e simulações. Este índice reflete a discrepância entre os valores observados e os estimados pelo modelo. É definido como:

$$
d=1-\frac{\sum_{i=1}^{N}\left(P_{i}-O_{i}\right)^{2}}{\sum_{i=1}^{N}\left(\left|P_{i}^{\prime}\right|+\left|O_{i}^{\prime}\right|\right)^{2}}
$$

onde:

$P_{i}=$ valores previstos;

$O_{i}=$ valores observados;

$P_{i}^{\prime}=P_{i}-O_{m}$ e $O_{i}^{\prime}=O_{i}-O_{m}$, sendo $O_{m}$ o valor médio das observações.

Seus valores variam entre 0 e 1 , sendo que 0 valor 1 indica uma concordância perfeita entre os valores observados e os estimados e o valor zero indica uma série de discrepâncias ou dissimilaridades.

\subsection{Análises químicas}

As análises químicas foram realizadas no CNPS-EMBRAPA.

$\mathrm{O} \mathrm{pH}$ foi medido em água e em $\mathrm{KCl} \mathrm{N}$, utilizando-se uma relação solo:solução de 1:2,5 (EMBRAPA, 1979). 
O carbono orgânico foi determinado por combustão úmida segundo Walkley \& Black (1960).

A extração dos cations trocáveis $\mathrm{Ca}^{++}, \mathrm{Mg}^{++}, \mathrm{K}^{+}$e $\mathrm{Na}^{+}$foi feita com acetato de amônio $\mathrm{N}$, de acordo com EMBRAPA (1979), a determinação do $\mathrm{Ca}^{++}$e $\mathrm{Mg}^{++}$ sendo realizada por espectrofotometria de absorção atômica e o $\mathrm{K}^{+}$e $\mathrm{Na}^{+}$, determinados por fotometria de chama.

Para a determinação dos índices $K_{i}$ e $K_{r}$, nas amostras dos horizontes selecionados dos solos, procedeu-se à extração com $\mathrm{H}_{2} \mathrm{SO}_{4}$ a quente segundo EMBRAPA (1979).

$\mathrm{O}$ alumínio trocável $\mathrm{Al}^{+++}$foi extraído com $\mathrm{KCl} \mathrm{N}$. Para a acidez titulável $\left(\mathrm{H}^{+}+\mathrm{Al}^{+++}\right)$utilizou-se como extrator o acetato de cálcio $\mathrm{N}$ a pH $=7,0$. Tanto o alumínio trocável como a acidez titulável foram determinados por titulação (EMBRAPA 1979).

As análises granulométricas foram feitas pelo método do densímetro Day (1965) e EMBRAPA(1979). 


\section{RESULTADOS E DISCUSSÃO}

Os resultados dos parâmetros físico-hídricos analisados obedeceram uma seqüência de discussão ordenada a partir de cada camada de solo estudada, levandose em consideração os três sistemas de cultivo identificado como plantio convencional não irrigado (PCNI), plantio direto irrigado (PDI) e plantio convencional irrigado (PCI).

\subsection{Camada 0,00 -0,07 m}

Esta camada no sistema de cultivo convencional não irrigado e irrigado é mais intensamente homogeneizada, juntamente com as outras camadas até a profundidade em torno de $0,4 \mathrm{~m}$, devido a ação do arado + grade, fato que não ocorre de forma tão intensa no sistema plantio direto irrigado. Portanto podem ocorrer diferenças nos valores de alguns dos parâmetros físicos, quando se compara os sistemas de cultivo plantio direto irrigado e convencional irrigado.

\subsubsection{Sistemas de cultivo plantio direto irrigado e convencional irrigado}

Para a camada de 0,00 - 0,07 m foram estudadas e comparadas entre si, os parâmetros físicos obtidos para os sistemas plantio direto irrigado e convencional irrigado. Nesta camada, não foi possível incluir o sistema plantio convencional não irrigado pelas dificuldades na obtenção das amostras, devido o solo estar muito seco na ocasião.

\subsubsection{Curvas de retenção da água no solo}

Os valores de umidade correspondentes às tensões de 0,$5 ; 1,0 ; 2,0 ; 5,0$ e $8,0 \mathrm{kPa}$ (Tabela 1) são mostrados inicialmente para a seqüência dos sistemas plantio 
direto irrigado e plantio convencional irrigado, na profundidade de 0,00-0,07 $\mathrm{m}$, (média de três repetições). Os valores da densidade do solo também são mostrados. No Anexo B são apresentados os valores numéricos das curvas de retenção juntamente com os parâmetros de ajuste através do método de Genuchten (1980) com as três repetições.

Tabela 1 - Valores numéricos das curvas de retenção da água no solo e da densidade para a seqüência dos sistemas de cultivo plantio direto irrigado e convencional irrigado na profundidade de $0,00-0,07 \mathrm{~m}$, com as médias (três repetições), desvios padrões e coeficientes de variação.

\begin{tabular}{|c|c|c|c|c|c|c|}
\hline \multicolumn{7}{|c|}{ Plantio Direto Irrigado } \\
\hline \multirow{2}{*}{$\begin{array}{c}\text { Potencial } \\
\text { mátrico }\left(\phi_{m}\right) \\
k P a\end{array}$} & \multicolumn{6}{|c|}{$0,00-0,07 \mathrm{~m}$} \\
\hline & $\begin{array}{c}\theta \\
m^{3} \boldsymbol{m}^{-3}\end{array}$ & $\begin{array}{l}\text { Desvio } \\
\text { Padrão }\end{array}$ & $\begin{array}{l}\text { Coeficiente } \\
\text { de variação }\end{array}$ & $\begin{array}{c}\text { densidade } \\
\mathrm{kg} \mathrm{m}^{-3}\end{array}$ & $\begin{array}{l}\text { Desvio } \\
\text { Padrâo }\end{array}$ & $\begin{array}{l}\text { Coeficiente } \\
\text { de variaçẫo }\end{array}$ \\
\hline 0.50 & 0,5715 & 0,0190 & 3,32 & 1113 & 16,522 & 1,48 \\
\hline 1,00 & 0,5520 & 0,0204 & 3,71 & 1140 & 7,572 & 0,66 \\
\hline 2.00 & 0,5065 & 0,0120 & 2,36 & 1147 & 40,037 & 3,49 \\
\hline 5,00 & 0.4360 & 0,0110 & 2,51 & 1115 & 34,078 & 3,06 \\
\hline 8,00 & 0.4102 & 0,0181 & 4,41 & 1159 & 43,278 & 3,73 \\
\hline \multicolumn{7}{|c|}{ Plantio Convencional Irrigado } \\
\hline Potencial & \multicolumn{6}{|c|}{$0,00-0,07 m$} \\
\hline $\begin{array}{c}\text { mátrico }\left(\phi_{m}\right) \\
k P a\end{array}$ & $\begin{array}{c}\theta \\
m^{3} m^{-3}\end{array}$ & $\begin{array}{c}\text { Desvio } \\
\text { Padrão }\end{array}$ & $\begin{array}{l}\text { Coeficiente } \\
\text { de variaçấo }\end{array}$ & $\begin{array}{c}\text { densidade } \\
\mathrm{kg} \mathrm{m}^{-3}\end{array}$ & $\begin{array}{l}\text { Desvio } \\
\text { Padrão }\end{array}$ & $\begin{array}{l}\text { Coeficiente } \\
\text { de variação }\end{array}$ \\
\hline 0.50 & 0,6176 & 0,0105 & 1,70 & 993 & 11,930 & 1,20 \\
\hline 1,00 & 0,5875 & 0,0174 & 2,97 & 994 & 17,349 & 1,74 \\
\hline 2,00 & 0,5404 & 0,0200 & 3,68 & 1004 & 30,000 & 2,99 \\
\hline 5.00 & 0,3933 & 0,0065 & 1,66 & 994 & 34,000 & 3,42 \\
\hline 8.00 & 0.3647 & 0.0039 & 1.09 & 1021 & 5.000 & 0.48 \\
\hline
\end{tabular}

A Figura 9 a seguir representa as curvas de retenção da água no solo, na ordem dos sistemas de cultivo plantio direto irrigado e convencional irrigado. 


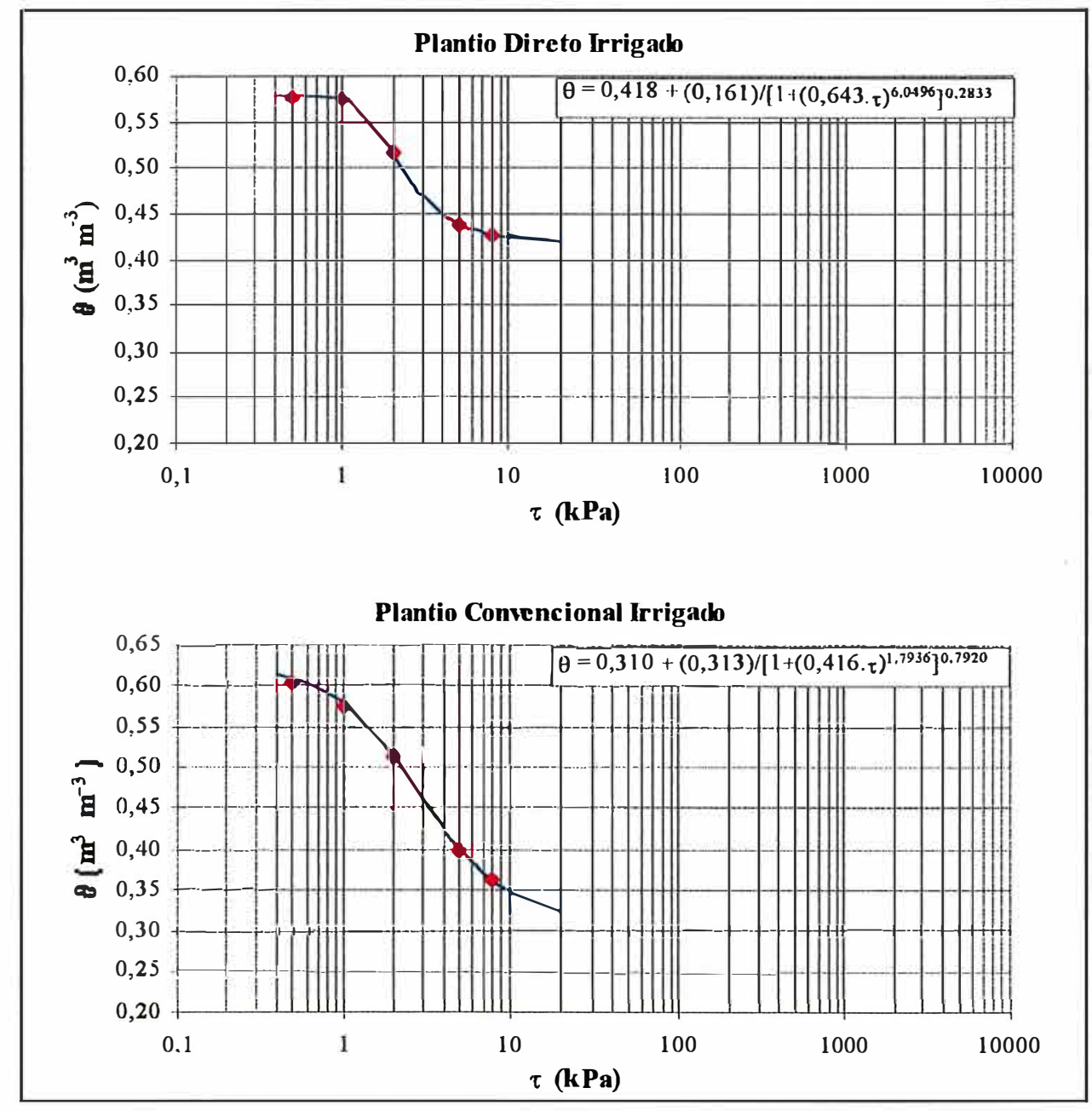

Figura 9 - Curvas de retenção da água do Latossolo Roxo, para os sistemas de cultivo plantio direto irrigado e convencional irrigado, na profundidade de $0,00-0,07 \mathrm{~m}$.

Embora as curvas não se apresentem completas tendo somente os pontos de baixa tensão $(0,5 ; 1,0 ; 2,0 ; 5,0$; e $8,0 \mathrm{kPa})$, ou seja, os pontos determinados utilizando-se do funil de Haines, a importância das mesmas está em auxiliar na interpretação das propriedades responsáveis pelo movimento da água no solo.

Para verificar o grau de similaridade ou discrepância dos valores da função $h(\theta)$ entre os dois sistemas de cultivo foi determinado o índice de concordância 
(d) de Wilmott (1981), cujo valor de 0,6970 sugere a ocorrência de diferenças nos valores da função $h(\theta)$. Deste modo, quando se compara a curva de retenção da água do sistema plantio direto irrigado com a curva correspondente do plantio convencional irrigado, após aplicar um incremento de tensão de $0,5 \mathrm{kPa}$ para $0,8 \mathrm{kPa}$ pode-se observar que o sistema plantio convencional irrigado perde mais água que o plantio direto irrigado, sendo os valores da umidade volumétrica $\left(\theta, \mathrm{m}^{3} \mathrm{~m}^{-3}\right)$ correspondentes à tensão de $0,8 \mathrm{kPa}$, respectivamente de 0,4102 e $0,3697 \mathrm{~m}^{3} \mathrm{~m}^{-3}$. Este fato é uma indicação de que a quantidade e a distribuição do tamanho de poros é diferente entre os dois sistemas, sugerindo um maior volume de macroporos no sistema convencional irrigado, responsáveis pelo processo mais rápido de drenagem no intervalo de tensões considerado, quando comparado ao sistema plantio direto irrigado.

O estudo de Hill (1990), que analisou o efeito dos sistemas de cultivo convencional (aração+gradagem) com milho, e plantio direto com milho, sobre as propriedades fisicas do solo, como a curva de retenção e a distribuição do tamanho de poros corrobora as afirmações acima: o sistema convencional apresentou um maior volume de poros com raio equivalente $r, 15 \mu \mathrm{m}$ (correspondendo aos macroporos), sendo que no plantio direto, a maior quantidade de poros ficou no intervalo de 0,1 $15 \mu \mathrm{m}$, o que indica uma redução do raio equivalente, com aumento de intensidade das "forças de retenção" diminuindo o fluxo de drenagem, o qual foi menor quando comparado com o correspondente para o plantio convencional.

A função derivada $(\mathrm{d} \theta / \mathrm{d} \tau)$ da curva de retenção é mostrada a seguir e exemplifica melhor as relações do espaço poroso entre os sistemas de cultivo.

\subsubsection{Análise da distribuição do tamanho de poros através da curva de retenção da água no solo.}

Através da Figura 10 observa-se a curva de distribuição do tamanho de poros na ordem dos sistemas plantio direto irrigado e convencional irrigado. 


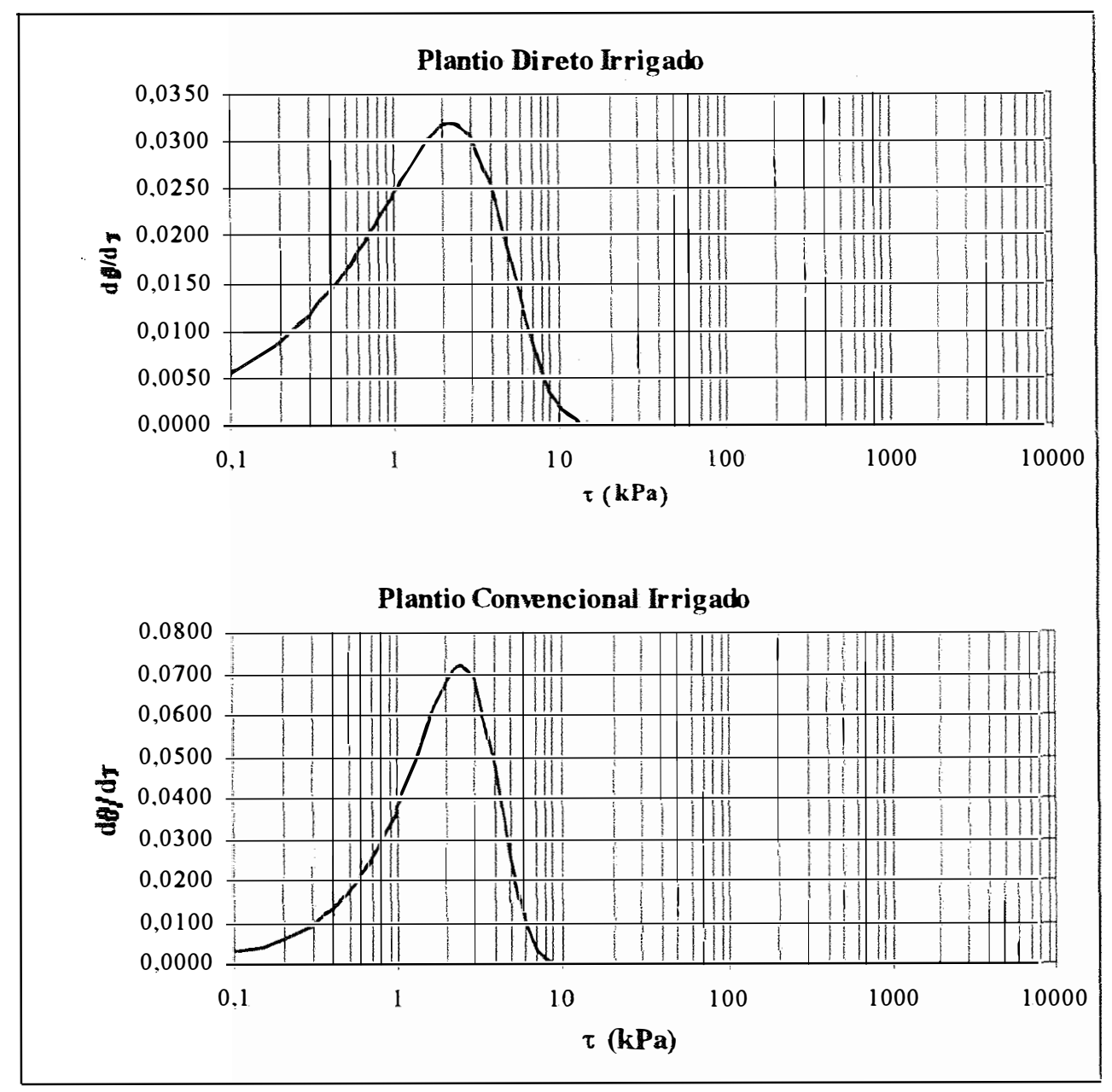

Figura 10 -Distribuição do tamanho de poros do Latossolo Roxo, nos sistemas plantio direto irrigado e convencional irrigado, na profundidade de 0,00-0,07 m.

Considerando a equação de Kelvin (pág. 30) escrita como:

$$
\tau_{(1,2)}=-\phi_{m(1,2)}=\frac{2 \sigma \cos \alpha}{r_{(1,2)}}
$$

tem-se que à tensão $\tau_{1}$ corresponde o raio equivalente $r_{1}$ e à tensão $\tau_{2}$ o raio equivalente $\mathrm{r}_{2}$. Assumindo $\tau_{1}=0,5 \mathrm{kPa}$ (Figuras 9 e 10), todos os poros de raio equivalente $r_{1}>29,376 \mu \mathrm{m}$ serão esvaziados, e após aplicar a tensão $\tau_{2}=8,0 \mathrm{kPa}$, todos os poros de 
raio $r_{2}>1,836 \mu \mathrm{m}$ serão esvaziados. Este incremento de tensão faz com que sejam esvaziados todos os poros de raio menor que $r_{1}$ e maior que $r_{2}\left(r_{2}<r_{1}\right)$, sendo neste caso, o volume de água liberado do solo estimado pela diferença de umidade observada nas tensões $\tau_{1}$ e $\tau_{2}$ e que corresponde ao volume dos poros de raio menor que $r_{1}=29,376 \mu \mathrm{m}$ e maior que $r_{2}=1,836 \mu \mathrm{m}$. No plantio direto irrigado (PDI) a diferença dos valores de umidade correspondentes a $\tau_{1}=0,5 \mathrm{kPa}$ e $\tau_{2}=8,0 \mathrm{kPa}$ é $\Delta \theta_{(\mathrm{PDI})}=0,5715-0,4102=$ $0,161 \mathrm{~m}^{3} \mathrm{~m}^{-3}$ e no plantio convencional irrigado $(\mathrm{PCI})$ corresponde a $\Delta \theta_{(\mathrm{PCl})}=0,6176$ $0,3647=0,253 \mathrm{~m}^{3} \mathrm{~m}^{-3}$. Portanto, o plantio convencional irrigado tem o maior número de poros com raios equivalentes entre os valores $r_{1}=29,376 \mu \mathrm{m} \mathrm{e} r_{2}=1,836 \mu \mathrm{m}$ (Figura 10).

Esta quantificação do espaço poroso assume importância indiscutível para avaliar por exemplo a deterioração da estrutura do solo Low (1972). Porém as medições a serem feitas devem seguir critérios pré-estabelecidos com relação às diferentes épocas de amostragem do solo, levando-se em conta o tipo de preparo adotado, que é em última análise dependente do sistema de cultivo, seja ele convencional, plantio direto ou ainda cultivo mínimo.

As observações de Hamblin (1984) ilustram bem estas questões, onde o simples fato da ocorrencia de um maior número de macroporos e também da maior porosidade total no sistema convencional em relação ao plantio direto, pode significar em muitos casos apenas uma condição transitória favorável que se segue logo após ao preparo do solo pelo sistema convencional, a qual tende a se deteriorar rapidamente num intervalo de tempo relativamente curto, e a partir daí podendo ocasionar alterações indesejáveis em varias propriedades do solo, como o aumento da densidade do solo e da resistência ’a penetração com conseqüente decréscimo dos valores de funções importantes como a condutividade hidráulica do solo.

Ainda com relação à distribuição do tamanho de poros do solo, através da Figura 10 e Tabela 2 são relacionados na seqüência dos sistemas plantio direto irrigado e convencional irrigado, os valores máximos da derivada $d \theta / d \tau$, com os 
correspondentes valores de tensão $\tau^{*}$, do raio equivalente $r^{*}$, da umidade $\theta^{*}$, e os valores da condutividade hidráulica saturada $\mathrm{K}_{0}$, na profundidade de $0,00-0,07 \mathrm{~m}$.

Tabela 2 - Valores máximos da função derivada $\mathrm{d} \theta / \mathrm{d} \tau$, com os correspondentes valores de tensão $\tau^{*}$, do raio equivalente $r^{*}$, da umidade $\theta^{*}$, e os valores da condutividade hidráulica saturada $\mathrm{K}_{\mathrm{o}}$, na profundidade de $0,00-0,07 \mathrm{~m}$.

\begin{tabular}{lccccc}
\hline \hline \multicolumn{1}{c}{ Sistema de cultivo } & $\begin{array}{c}\boldsymbol{\tau} \\
\boldsymbol{k P a}\end{array}$ & $\begin{array}{c}\boldsymbol{r}^{*} \\
\boldsymbol{\mu} \boldsymbol{m}\end{array}$ & $\begin{array}{c}\boldsymbol{\theta}^{*} \\
\boldsymbol{m}^{\mathbf{3}} \boldsymbol{m}^{-3}\end{array}$ & $\begin{array}{c}\boldsymbol{d} \theta \boldsymbol{d} \boldsymbol{\tau} \\
\boldsymbol{m}^{3} \boldsymbol{m}^{-3} \boldsymbol{m}^{-1}\end{array}$ & $\begin{array}{c}\boldsymbol{K}_{\boldsymbol{o}} \\
\boldsymbol{m} \boldsymbol{s}^{-1}\end{array}$ \\
\hline Plantio direto irrigado & 2,25 & 6,528 & 0,4989 & $3,2 \times 10^{-2}$ & $3,31 \times 10^{-5}$ \\
Plantio convencional irrigado & 2,50 & 5,875 & 0.5195 & $7,2 \times 10^{-2}$ & $5,11 \times 10^{-5}$ \\
\hline \hline
\end{tabular}

Obs: : Os valores de tensão $\tau^{*}$, do raio equivalente $r^{*}$ e da umidade volumétrica $\theta^{*}$ são acompanhados do asterisco para indicar neste caso, que são valores específicos relativos à função derivada $\mathrm{d} \theta / \mathrm{d} \tau$.

De acordo com a definição previamente estabelecida no Quadro I (pág. 32) observa-se que os valores dos raios equivalentes $\mathrm{r}^{*}$ referentes aos dois sistemas de cultivo acima descritos estão no intervalo considerado dos mesoporos.

O valor máximo da derivada $\mathrm{d} \theta / \mathrm{d} \tau$ indica para o plantio direto e para a situação analisada, uma maior freqüência da ocorrência de poros com raio equivalente $r^{*}=6,528 \mu \mathrm{m}$, e para o plantio convencional irrigado a maior ocorrência de poros com raio equivalente $r^{*}=5,875 \mu \mathrm{m}$.

Para os dois sistemas de cultivo acima descritos (Tabela 2), a prática da irrigação tende a exercer maior influência no sistema convencional principalmente na camada superficial do solo, onde ocorre uma certa homogenização, geralmente acompanhada do aumento no número de macroporos. Estes, devido à ação dos implementos mecânicos são instáveis, têm uma distribuição espacial aleatória e são descontínuos, fatores esses que induzem a um rearranjo interno dos sistema poroso original juntamente com uma redistribuição na camada superficial, Gjettermann et al. (1997). Todas estas alterações na dinâmica do espaço poroso afetam diretamente os fenômenos de armazenagem e do movimento da água e dos gases no solo, bem como a resistência à penetração pelas raízes das plantas, que são fatores que interferem diretamente no desenvolvimento e rendimento das culturas. 
A seguir, na Tabela 3, são apresentados os valores da porosidade total, da macroporosidade e da microporosidade calculados, para a seqüência dos sistemas de cultivo plantio direto irrigado e convencional irrigado, na profundidade de $0,00-0,07 \mathrm{~m}$.

Tabela 3 - Valores da porosidade total, da macroporosidade e da microporosidade calculados para a seqüência dos sistemas de cultivo plantio direto irrigado e plantio convencional irrigado, na profundidade de $0,00-0,07 \mathrm{~m}$.

\begin{tabular}{ccc}
\hline \hline Plantio direto irrigado & $0,00-0,07 \mathrm{~m}$ & Plantio convencional irrigado \\
& Porosidade Total Calculada (\% Volume) & 62,3 \\
55,1 & Macroporosidade (\% Volume) & 27,4 \\
16,6 & Microporosidade (\% Volume) & 34,9 \\
\hline 38,5 & & \\
\hline \hline
\end{tabular}

Comparando os dois sistemas de cultivo, o maior número de poros do plantio convencional irrigado com raios equivalentes entre os valores $r_{1}=29,376 \mu \mathrm{m}$ e $\mathrm{r}_{2}=1,836 \mu \mathrm{m}$, em relação ao plantio direto irrigado, como já citado anteriormente, justifica os valores mais elevados da porosidade total e macroporosidade, bem como os valores mais baixos da microporosidade do primeiro sistema em relação ao segundo. Por outro lado, estas diferenças observadas sugerem a influência direta de outras propriedades físicas do solo, como por exemplo, do parâmetro densidade do solo, cujos valores são mostrados a seguir.

\subsubsection{Densidade do solo para a seqüência dos sistemas de cultivo plantio direto irrigado e convencional irrigado, na profundidade de $0,00-0,07 \mathrm{~m}$.}

A tabela 4 , seguinte apresenta o resultado do teste de Tukey para os valores da densidade do solo entre os sistemas de cultivo plantio direto irrigado e convencional irrigado. 
Tabela 4 - Comparação através do teste de Tukey dos valores da densidade do solo para a seqüência dos sistemas de cultivo plantio direto irrigado e convencional irrigado, na profundidade de $0,00-0,07 \mathrm{~m}$.

\begin{tabular}{cccc}
\hline \hline & $\begin{array}{c}\text { Densidade do solo }\left(\mathbf{K g ~ m}^{-3}\right) \\
\mathbf{0 , 0 0 ~ 0 , 0 7 ~} \mathbf{~}\end{array}$ \\
\hline Repetições & Plantio direto irrigado & Plantio convencional irrigado & Coeficiente de variação \\
\hline 1 & 1146 & 1020 & 1,552 \\
2 & 1117 & 0988 & \\
3 & 1147 & 1000 & \\
\hline *Médias & $1137 \mathrm{a}$ & $1003 \mathrm{~b}$
\end{tabular}

*Médias seguidas de letras distintas diferem significativamente pelo teste de Tukey $(\mathrm{P}>0.01)$

Heard et al. (1988) obtiveram resultados semelhantes ao verificarem que os solos no sistema de plantio direto apresentaram uma maior continuidade dos macroporos, em relação aos solos submetidos ao sistema convencional. Além disso, os valores de densidade mais elevados do plantio direto influíram diretamente nos valores mais baixos da condutividade hidráulica saturada $\left(\mathrm{K}_{\mathrm{o}}\right)$, sendo esta uma propriedade importante e que será discutida no ítem seguinte.

\subsubsection{Condutividade hidráulica do solo saturado $\left(K_{0}\right)$ na profundidade de 0,00 - $0,07 \mathrm{~m}$.}

Os resultados da Tabela 5 mostram os valores da condutividade hidráulica saturada para os sistemas de cultivo plantio direto irrigado e convencional irrigado na profundidade de $0,00-0,07 \mathrm{~m}$.

Tabela 5 - Comparação através do teste de Tukey, dos valores da condutividade hidráulica saturada $\left(\mathrm{K}_{\mathrm{o}}\right)$, para os sistemas plantio direto irrigado $\mathrm{e}$ convencional irrigado, na profundidade de $0,00-0,07 \mathrm{~m}$

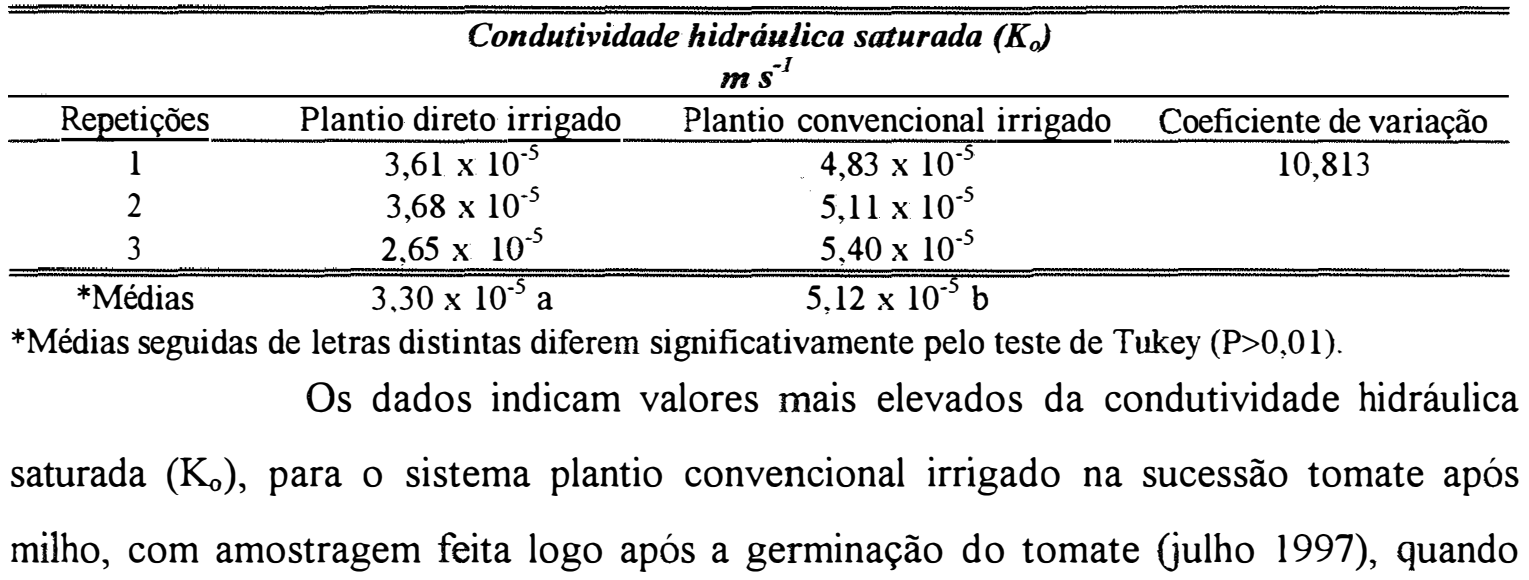


comparado com o plantio direto irrigado na sucessão milho após soja, com amostragem correspondendo ao estágio final do ciclo do milho (julho 1997).

No plantio direto, a densidade do solo foi mais elevada em relação ao convencional (Tabela 4), o que influiu diretamente na distribuição do tamanho de poros e por conseguinte nos valores da condutividade hidráulica saturada. Assim, o plantio direto irrigado apresentou valores da porosidade total de 55\%, de macroporosidade em torno de $16 \%$ e de microporosidade de $38 \%$, comparativamente aos valores obtidos para o plantio convencional irrigado, respectivamente de $62 \%, 27 \%$ e de $35 \%$ (Tabela 3 ).

Heard et al. (1998) analisaram a influencia dos sistemas de cultivo convencional (aração+gradagem), do preparo reduzido através de cultivadores e do plantio direto, no comportamento da condutividade hidráulica saturada $\left(\mathrm{K}_{\mathrm{o}}\right)$, para dois tipos de solos, o primeiro com textura franco argilo siltosa e o segundo de textura franco siltosa. Em ambos os solos, os valores da condutividade hidráulica saturada foram maiores no sistema convencional, sendo intermediários no sistema de cultivo reduzido, e tendo os valores mais baixos registrados no sistema plantio direto, o qual também apresentou os valores da densidade do solo mais elevados, sugerindo a influencia deste parâmetro, nos valores da condutividade hidráulica saturada. Outro ponto importante deste estudo e que deve ser salientado é que os valores de densidade do solo mais elevados do plantio direto podem ter um componente oriundo da influência ou ação de uma outra prática de cultivo (cultivo convencional) agindo durante um determinado tempo, anterior à implantação definitiva do sistema plantio direto. Este fato também poderia estar ocorrendo para o solo no sistema plantio direto irrigado do estudo aqui proposto, porém não é um objetivo a ser seguido, já que não se dispõe de determinações específicas realizadas através do tempo, que confirmem tal hipótese. Entretanto têm sido comum os relatos de valores mais altos da densidade do solo no sistema plantio direto irrigado em relação ao convencional irrigado Chan \& Heenan (1993), e também mais elevados do plantio direto em comparação com solo de mata (Kertzman 1996).

As diferenças observadas nos valores da condutividade hidráulica saturada também ocorrem para os valores da condutividade hidráulica relativa $(\mathrm{Kr}(\Theta))$, 
da condutividade hidráulica do solo não saturado $(K(\theta))$ e da difusividade relativa $(\operatorname{Dr}(\Theta))$, e são discutidas a seguir.

\subsubsection{Condutividade hidráulica relativa $(\operatorname{Kr}(\Theta))$, condutividade hidráulica do solo não saturado $(K(\theta))$ e difusividade relativa $(\operatorname{Dr}(\Theta))$.}

$\mathrm{Na}$ Tabela 6 estão relacionados os valores destas funções para os níveis de tensão de 0,$5 ; 1,0 ; 2,0 ; 5,0 ; 8,0 ; 30,0 ; 60,0 ; 300,0$ e $1500,0 \mathrm{kPa}$.

Tabela 6 - Valores de tensão $\tau(\tau=-\Phi \mathrm{m}$, onde $-\Phi \mathrm{m}$ é o potencial mátrico), da umidade volumétrica $(\theta)$ e relativa $(\Theta)$, da condutividade hidráulica relativa $(\operatorname{Kr}(\Theta))$, e hidráulica não saturada $\mathrm{K}(\theta)$ e da difusividade relativa $(\operatorname{Dr}(\Theta))$, para a seqüência dos sistemas de cultivo plantio direto irrigado e convencional irrigado, na profundidade $0,00-0,07 \mathrm{~m}$.

\begin{tabular}{|c|c|c|c|c|c|c|}
\hline \multicolumn{7}{|c|}{ Plantio Direto Irrigado } \\
\hline $\begin{array}{c}\tau \\
k P a\end{array}$ & $\begin{array}{c}\theta \\
m^{3} m^{-3}\end{array}$ & $\Theta$ & $\frac{\theta-\theta_{r}}{\theta_{s}-\theta_{r}}$ & $K_{r}(\Theta)$ & $\begin{array}{l}K(\theta) \\
m s^{-1}\end{array}$ & $\operatorname{Dr}(\Theta)$ \\
\hline 0.5 & 0,561 & & 0,89 & $6.5 \times 10^{-2}$ & $2,14 \times 10^{-6}$ & $1,08 \times 10^{-3}$ \\
\hline 1.0 & 0,541 & & 0,76 & $1,5 \times 10^{-2}$ & $4,84 \times 10^{-7}$ & $3,51 \times 10^{-4}$ \\
\hline 2,0 & 0,519 & & 0,63 & $3,0 \times 10^{-3}$ & $9,09 \times 10^{-8}$ & $1,22 \times 10^{-4}$ \\
\hline 5,0 & 0,507 & & 0,55 & $1,0 \times 10^{-3}$ & $3,30 \times 10^{-8}$ & $6,78 \times 10^{-5}$ \\
\hline 8.0 & 0,501 & & 0.52 & $5.7 \times 10^{-4}$ & $1,91 \times 10^{-8}$ & $4,97 \times 10^{-5}$ \\
\hline 30.0 & 0,475 & & 0,35 & $3,2 \times 10^{-5}$ & $1,06 \times 10^{-9}$ & $1,01 \times 10^{-5}$ \\
\hline 60.0 & 0,469 & & 0,32 & $1,4 \times 10^{-5}$ & $4,52 \times 10^{-10}$ & $6,43 \times 10^{-6}$ \\
\hline 300.0 & 0,457 & & 0,24 & $1,8 \times 10^{-6}$ & $5,91 \times 10^{-11}$ & $2,16 \times 10^{-6}$ \\
\hline 1500.0 & 0,445 & & 0.17 & $1,1 \times 10^{-7}$ & $3,65 \times 10^{-12}$ & $4,88 \times 10^{-7}$ \\
\hline \multicolumn{7}{|c|}{ Plantio Convencional Irrigado } \\
\hline $\begin{array}{c}\tau \\
k P a\end{array}$ & $\begin{array}{c}\theta \\
m^{3} m^{-3}\end{array}$ & $\Theta$ & $\left.\frac{\theta-\theta_{r}}{\theta_{s}-\theta_{r}}\right)$ & $K_{r}(\Theta)$ & $\begin{array}{l}K(\theta) \\
m s^{-1}\end{array}$ & $\overline{D r}(\Theta)$ \\
\hline 0,5 & 0,587 & & 0,88 & $5.81 \times 10^{-1}$ & $2,96 \times 10^{-5}$ & $3,26 \times 10^{-3}$ \\
\hline 1,0 & 0.547 & & 0,76 & $3,33 \times 10^{-1}$ & $1,70 \times 10^{-5}$ & $1,28 \times 10^{-3}$ \\
\hline 2,0 & 0,503 & & 0,62 & $1,68 \times 10^{-1}$ & $8,57 \times 10^{-6}$ & $5,92 \times 10^{-4}$ \\
\hline 5,0 & 0,479 & & 0,54 & $1,09 \times 10^{-1}$ & $5,58 \times 10^{-6}$ & $3,98 \times 10^{-4}$ \\
\hline 8,0 & 0,467 & & 0,50 & $8,63 \times 10^{-2}$ & $4,41 \times 10^{-6}$ & $3,27 \times 10^{-4}$ \\
\hline 30,0 & 0,415 & & 0,34 & $2,44 \times 10^{-2}$ & $1,25 \times 10^{-6}$ & $1,26 \times 10^{-4}$ \\
\hline 60,0 & 0,403 & & 0,30 & $1,68 \times 10^{-2}$ & $8,56 \times 10^{-7}$ & $9,69 \times 10^{-5}$ \\
\hline 300,0 & 0,379 & & 0,22 & $6,7 \times 10^{-3}$ & $3,42 \times 10^{-7}$ & $5,28 \times 10^{-5}$ \\
\hline 1500.0 & 0,355 & & 0,14 & $1,8 \times 10^{-3}$ & $9,24 \times 10^{-8}$ & $2,32 \times 10^{-5}$ \\
\hline
\end{tabular}

Os índices (d) de Willmott que permitem comparar as funções $(\operatorname{Kr}(\Theta))$, $(\mathrm{K}(\theta))$ e $(\operatorname{Dr}(\Theta))$ entre os sistemas plantio direto irrigado e convencional irrigado na profundidade de 0,00 - 0,07 m estão relacionados abaixo na Tabela 7 . 
Tabela 7 - Índices de concordância (d) de Willmott obtidos na comparação das funções $(\operatorname{Kr}(\Theta)),(\mathrm{K}(\theta))$ e $(\operatorname{Dr}(\Theta))$ dos sistemas plantio direto irrigado em relação ao convencional irrigado na profundidade de $0,00-0,07 \mathrm{~m}$.

\begin{tabular}{c|c}
\hline Funçöes & Indices de Willmott (d) \\
\hline $\operatorname{Kr}(\Theta)$ & 0,123456 \\
$\operatorname{K}(\theta)$ & 0,131745 \\
$\operatorname{Dr}(\Theta)$ & 0,163456 \\
\hline
\end{tabular}

Estes resultados evidenciam uma baixa sensibilidade do índice (d) em relação aos valores das funções $(\operatorname{Kr}(\Theta)),(\operatorname{K}(\theta))$ e $(\operatorname{Dr}(\Theta))$ entre os sistemas plantio direto irrigado e convencional irrigado na profundidade de $0,00-0,07 \mathrm{~m}$, o que indica que os valores mais elevados do plantio convencional irrigado são dissimilares em relação aos valores observados no plantio direto irrigado, ou seja, diferem entre si.

Embora aparentemente clara e definida pelos dados apresentados acima, as diferenças observadas, principalmente em se tratando de fluxo não saturado podem não ter uma explicação tão simples, onde os valores mais elevados da densidade do solo no plantio direto irrigado reduzindo a porosidade total e macroporosidade, e aumentando a microporosidade sejam os únicos responsáveis pelos valores mais baixos das funções condutividade hidráulica $(\operatorname{Kr}(\Theta), \mathrm{K}(\theta))$ e difusividade $(\operatorname{Dr}(\Theta))$, daquele sistema em relação ao convencional irrigado.

Hamblin (1984), num estudo comparativo de diferentes sistemas de cultivo (cultivo convencional, cultivo mínimo e plantio direto) observou para o plantio convencional, na época do preparo do solo, maior porosidade total e macroporosidade, porém estas condições tiveram um caráter transitório, no sentido de que num período relativamente curto ( 2 meses) foi possível detectar alterações nos valores da função difusividade da água $\mathrm{D}(\theta)$. Neste sentido fica então evidente a suscetibilidade da camada superficial dos solos cultivados onde a dinâmica do espaço poroso pode mudar rapidamente de acordo com as condições impostas pelos diferentes sistemas de cultivo, o que influi diretamente nas propriedades de transmissão da água no solo. 
$\mathrm{Na}$ seqüência, a figura 11 mostra a relação entre $\ln (\operatorname{Kr}(\Theta))$ e $(\theta)$, respectivamente para o plantio direto irrigado e plantio convencional irrigado, na profundidade de $0,00-0,07 \mathrm{~m}$. As linhas contínuas do gráfico representam os dados estimados através do ajuste, utilizando-se o modelo de Genuchten (1980), e os pontos referem-se aos dados obtidos através do modelo experimental de laboratório (Figuras 7 e 8 págs. 26 e 28$)$ utilizado para o calculo da função $(\mathrm{K}(\mathrm{h}))$ onde, através da qual procedeu-se à determinação de $(\operatorname{Kr}(\Theta))$ através da relação:

$$
K r(\Theta)=\frac{K(h)}{K_{0}}
$$

onde,

$\operatorname{Kr}(\Theta)=$ condutividade hidráulica relativa

$\mathrm{K}(\mathrm{h})$ = condutividade hidráulica como uma função do potencial mátrico

$\mathrm{K}_{\mathrm{o}}=$ condutividade hidráulica do solo saturado

No plantio direto irrigado, os valores de $K_{r}(\Theta)$ calculados pela equação anterior foram:

$$
\begin{aligned}
& K r_{(0.2 m)}=\frac{K(h)_{(0.2 m)}}{K_{0}} \text { ou } K r_{(0.2 m)}=\frac{1,6 \times 10^{-7}}{3,31 \times 10^{-5}}=4,83 \times 10^{-3} \text { e } \ln 4,83 \times 10^{-3}=-5,332 \\
& K r_{(0,4 m)}=\frac{K(h)_{(0.4 m)}}{K_{0}} \text { ou } K r_{(0,4 m)}=\frac{6,83 \times 10^{-8}}{3,31 \times 10^{-5}}=2,06 \times 10^{-3} \text { e } \ln 2,06 \times 10^{-3}=-6,183 \\
& K r_{(0,5 m)}=\frac{K(h)_{(0,6 m)}}{\tilde{K}_{0}} \text { ou } K r_{(0,6 m)}=\frac{4,1 \times 10^{-8}}{3,31 \times 10^{-5}}=1,24 \times 10^{-3} \text { e } \ln 1,24 \times 10^{-3}=-6,701
\end{aligned}
$$


$K r_{(0,8 m)}=\frac{K(h)_{(0.8 m)}}{K_{o}}$ ou $K r_{(0.8 m)}=\frac{2,71 \times 10^{-8}}{3,31 \times 10^{-5}}=8,18 \times 10^{-4}$ e $\ln 8,18 \times 10^{-4}=-7,108$

e no plantio convencional irrigado, os valores calculados de $\operatorname{Kr}(\Theta)$, através da mesma equação foram:

$K r_{(0,2 m)}=\frac{K(h)_{(0,2 m)}}{K_{o}}$ ou $K r_{(0,2 m)}=\frac{9,95 \times 10^{-6}}{5,11 \times 10^{-5}}=0,1948$ e $\ln 0,1948=-1,635400$

$K r_{(0.4 m)}=\frac{K(h)_{(0.4 m)}}{K_{o}}$ ou $K r_{(0.4 m)}=\frac{6,67 \times 10^{-6}}{5,11 \times 10^{-5}}=0,1307$ e $\ln 0,1307=-2,0345300$

$K r_{(0,6 m)}=\frac{K(h)_{(0,6 m)}}{K_{o}}$ ou $K r_{(0,6 m)}=\frac{6,107 \times 10^{-6}}{5,11 \times 10^{-5}}=0,1195$ e $\ln 0,1195=-2,1243500$

$K r_{(0.8 m)}=\frac{K(h)_{(0.8 m)}}{K_{o}}$ ou $K r_{(0.8 m)}=\frac{4,789 \times 10^{-6}}{5,11 \times 10^{-5}}=0,0937$ e $\ln 0,0937=-2,367500$

Estes valores de $(\operatorname{Kr}(\Theta))$ calculados através da função $(K(h))$ determinada pelo método experimental de laboratório, se ajustaram bem aos valores de $(\operatorname{Kr}(\Theta))$ calculados pelo modelo de Genuchten (1980), ilustrado na Figura 11 pelas linhas contínuas, sendo os pontos vermelhos representativos de $(\operatorname{Kr}(\Theta))$ calculado através de $(\mathrm{K}(\mathrm{h}))$. 

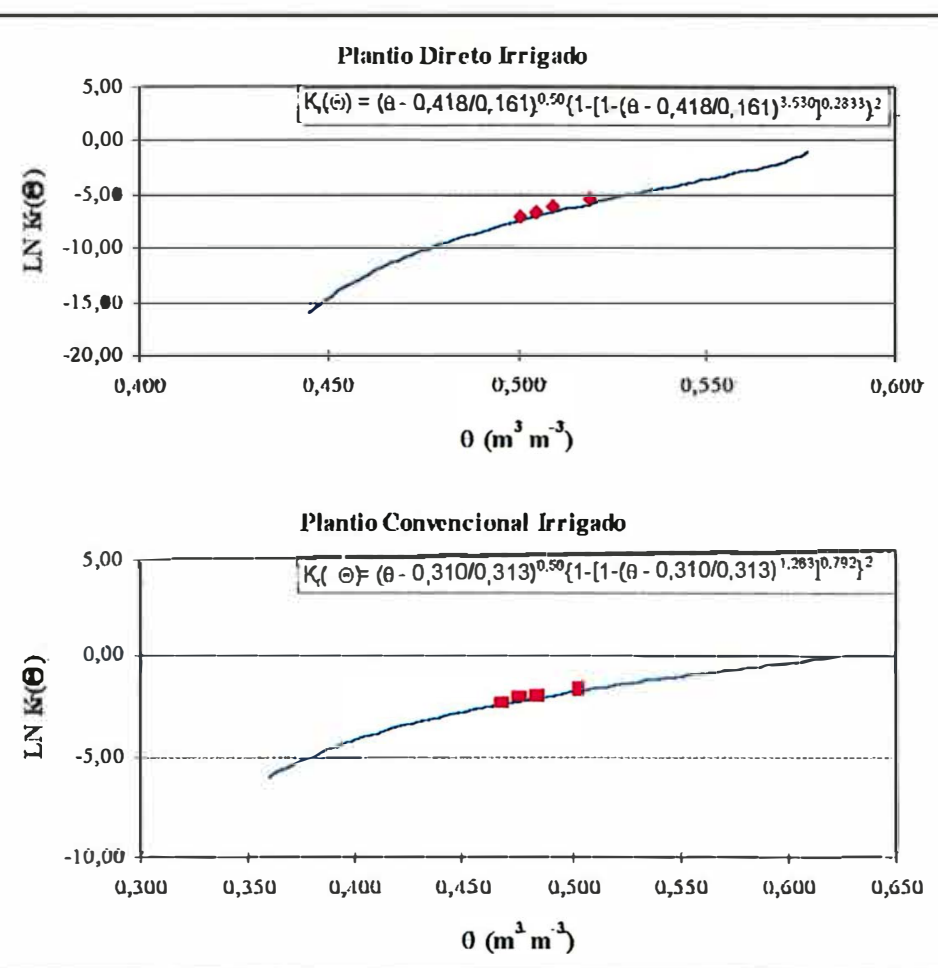

Figura 11 - Relação entre ln $\mathrm{Kr}(\Theta)$ e a umidade $(\theta)$ para a seqüência dos sistemas de cultivo plantio direto irrigado e convencional irrigado, na profundidade 0,00-0,07 m.

\subsection{Profundidade de $0,07-0,14 m$}

Na camada de 0,07 - 0,14 m foi possível estabelecer comparações dos parâmetros físicos do solo entre os três diferentes sistemas cultivo a seguir descritos.

\subsubsection{Sistemas de cultivo plantio convencional não irrigado, plantio direto irrigado e plantio convencional irrigado}

As possíveis diferenças entre os sistemas de cultivo são discutidos iniciando-se pela curva de retenção da água no solo $(\mathrm{h}(\theta))$.

\subsubsection{Curvas de retenção da água no solo}

$\mathrm{Na}$ Tabela 8 estão relacionados os dados (média de 3 repetições) de umidade correspondentes aos valores de tensão de 0,$5 ; 1,0 ; 2,0 ; 5,0 ; 8,0 ; 30,0 ; 60,0$; 300,0 e $1500,0 \mathrm{kPa}$, juntamente com os valores da densidade do solo distribuidos na mesma ordem, para os sistemas de cultivo plantio convencional não irrigado, plantio direto irrigado e plantio convencional irrigado, na profundidade de 0,07 - 0,14 m. 
As curvas de retenção juntamente com os parâmetros de ajuste através do método de Genuchten (1980), com as três repetições são apresentadas no Anexo B.

Tabela 8 - Valores numéricos das curvas de retenção da água no solo e da densidade para a seqüência dos sistemas plantio convencional não irrigado, direto irrigado e convencional irrigado na profundidade de $0,07-0,14 \mathrm{~m}$ com as médias ( 3 repetições), desvios padrões e coeficientes de variação.

\begin{tabular}{|c|c|c|c|c|c|c|}
\hline \multicolumn{7}{|c|}{ Plantio Convencional Não Irrigado } \\
\hline \multirow{2}{*}{$\begin{array}{c}\text { Potencial } \\
\text { mátrico }\left(\phi_{m}\right) \\
k P a\end{array}$} & \multicolumn{6}{|c|}{$0,07-0,14$} \\
\hline & $\begin{array}{c}\theta \\
m^{3} m^{-3} \\
\end{array}$ & $\begin{array}{l}\text { Desvio } \\
\text { Padrão } \\
\end{array}$ & $\begin{array}{l}\text { Coeficiente } \\
\text { de variação }\end{array}$ & $\begin{array}{c}\text { densidade } \\
\mathrm{kg} \mathrm{m}^{-3}\end{array}$ & $\begin{array}{l}\text { Desvio } \\
\text { Padrão } \\
\end{array}$ & $\begin{array}{l}\text { Coeficiente } \\
\text { de variação }\end{array}$ \\
\hline 0,50 & 0,6004 & 0,0141 & 2,34 & 1014 & 40,066 & 3,66 \\
\hline 1.00 & 0.5813 & 0,0134 & 2,32 & 1131 & 17.692 & 1.56 \\
\hline 2,00 & 0.5578 & 0.0168 & 3,00 & 1062 & 7,071 & 0,66 \\
\hline 5.00 & 0,4644 & 0.0200 & 4,30 & 11,04 & 68,039 & 6,16 \\
\hline 8,00 & 0,4221 & 0,0130 & 3,10 & 1104 & 68,039 & 6,16 \\
\hline 30.00 & 0,3612 & 0,0119 & 3,29 & 1094 & 40,060 & 3,66 \\
\hline 60.00 & 0,3097 & 0,0048 & 1,54 & 1131 & 17.690 & 1.56 \\
\hline 300.00 & 0,2658 & 0.0069 & 2,60 & 1085 & 40,150 & 3,70 \\
\hline 1500,00 & 0,2400 & 0,0132 & 5,51 & 1104 & 68,040 & 6,16 \\
\hline \multicolumn{7}{|c|}{ Plantio Direto Irrigado } \\
\hline Potencial & \multicolumn{6}{|c|}{$0,07-0,14$} \\
\hline $\begin{array}{c}\text { mátrico }\left(\phi_{m}\right) \\
\quad k P a\end{array}$ & $\begin{array}{c}\theta \\
m^{3} m^{-3}\end{array}$ & $\begin{array}{l}\text { Desvio } \\
\text { Padrão }\end{array}$ & $\begin{array}{l}\text { Coeficiente } \\
\text { de variação }\end{array}$ & $\begin{array}{c}\text { densidade } \\
\mathrm{kg} \mathrm{m}^{-3}\end{array}$ & $\begin{array}{l}\text { Desvio } \\
\text { Padrão } \\
\end{array}$ & $\begin{array}{l}\text { Coeficiente } \\
\text { de variação }\end{array}$ \\
\hline 0.50 & 0,5721 & 0,0209 & 3,66 & 1104 & 26.00 & 2,36 \\
\hline 1,00 & 0,5313 & 0.0146 & 2,76 & 1127 & 22,12 & 1,96 \\
\hline 2.00 & 0,4924 & 0,0146 & 2,98 & 1010 & 116.60 & 11,54 \\
\hline 5,00 & 0,4335 & 0,0096 & 2,22 & 1098 & 45.54 & 4,15 \\
\hline 8,00 & 0,4009 & 0,0071 & 1,77 & 1098 & 45.54 & 4.15 \\
\hline 30,00 & 0,3527 & 0,0142 & 4,04 & 1104 & 26,00 & 2,36 \\
\hline 60,00 & 0,3268 & 0,0011 & 0,33 & 1127 & 22,12 & 1,96 \\
\hline 300,00 & 0,3006 & 0,0031 & 1,02 & 1010 & 116,60 & 11,54 \\
\hline 1500,00 & 0,2803 & 0,0081 & 2,88 & 1098 & 45,54 & 4,14 \\
\hline \multicolumn{7}{|c|}{ Plantio Convencional Irrigado } \\
\hline Potencial & \multicolumn{6}{|c|}{$0,07-0,14$} \\
\hline $\begin{array}{c}\text { mátrico }\left(\phi_{m}\right) \\
\quad k P a \\
\end{array}$ & $\begin{array}{c}\theta \\
m^{3} m^{-3} \\
\end{array}$ & $\begin{array}{l}\text { Desvio } \\
\text { Padrão }\end{array}$ & $\begin{array}{l}\text { Coeficiente } \\
\text { de variação }\end{array}$ & $\begin{array}{c}\text { densidade } \\
\mathrm{kg} \mathrm{m}^{-3}\end{array}$ & $\begin{array}{l}\text { Desvio } \\
\text { Padrão }\end{array}$ & $\begin{array}{l}\text { Coeficiente } \\
\text { de variação }\end{array}$ \\
\hline 0,50 & 0,6014 & 0,0438 & 7,30 & 1007 & 61,08 & 6,06 \\
\hline 1,00 & 0,5715 & 0,0220 & 3,85 & 1043 & 73,38 & 7,04 \\
\hline 2,00 & 0,5299 & 0,0118 & 2,22 & 1007 & 63,10 & 6,26 \\
\hline 5.00 & 0,4505 & 0.0378 & 8,38 & 1093 & 89,94 & 8,23 \\
\hline 8,00 & 0,4081 & 0,0272 & 6,66 & 1093 & 89,94 & 8,23 \\
\hline 30,00 & 0,3360 & 0,0173 & 5,25 & 1007 & 61,08 & 6,06 \\
\hline 60,00 & 0,2958 & 0,0142 & 4,82 & 1043 & 73,38 & 7,04 \\
\hline 300,00 & 0,2601 & 0,0180 & 6,91 & 1007 & 63,10 & 6,26 \\
\hline 1500,00 & 0,2442 & 0,0141 & 5,76 & 1093 & 89,44 & 8,23 \\
\hline
\end{tabular}


Na Figura 12 abaixo são mostradas as curvas de retenção da água no solo, na ordem plantio convencional não irrigado, plantio direto irrigado e plantio convencional irrigado, na profundidade de 0,07-0,14 m.
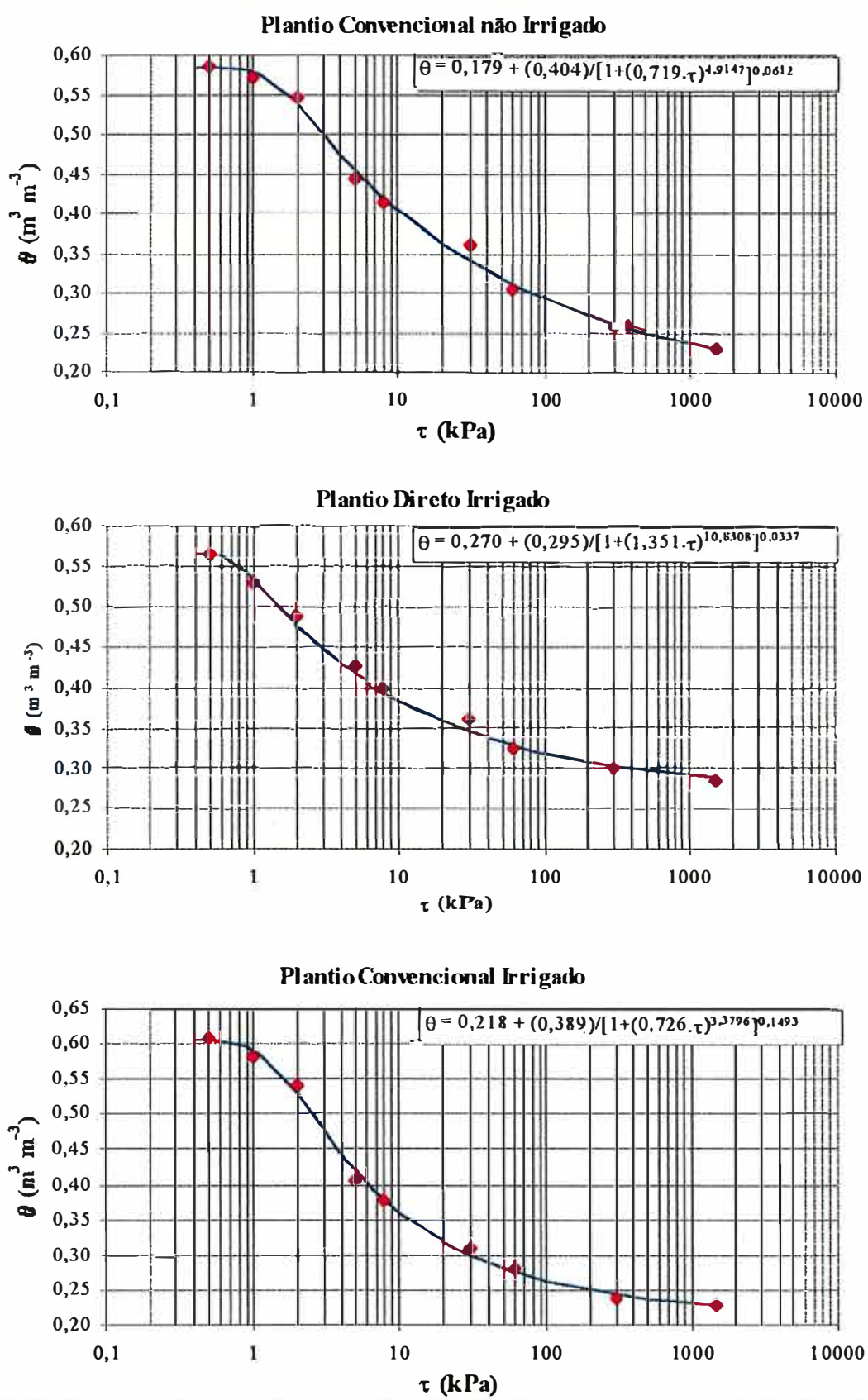

Figura 12 -Curvas de retenção da água do Latossolo Roxo, para os sistemas de plantio convencional não irrigado, direto irrigado e convencional irrigado, na profundidade de 0,07-0,14 m. 
Para comparação dos valores da função $(h(\theta))$ dos diferentes sistemas de cultivo foram calculados os índices (d) de Willmott, que são apresentados na Tabela 9. Tabele 9 - Índices de concordância (d) de Willmott obtidos na comparação da função $h(\theta)$ entre os sistemas plantio convencional não irrigado (PCNI), plantio direto irrigado (PDI) e plantio convencional irrigado (PCI), na profundidade de $0,07-0,14 \mathrm{~m}$.

\begin{tabular}{lc|c}
\hline \hline \multicolumn{1}{c}{ Índices de Willmott (d) para comparação dos valores da função $\overline{(h(\theta))}$} \\
\multicolumn{3}{c}{$0,07-0,14 m$} \\
\hline \\
PCNI & Comparações & indice (d) \\
PCNI & PDI & 0,9296 \\
PDI & PCI & 0,9895 \\
\hline \hline
\end{tabular}

Observa-se que os valores resultantes da comparação da relação $(h(\theta))$ envolvendo os diferentes sistemas de cultivo são próximos da unidade, o que indica semelhança entre as mesmas. Isto entretanto não implica necessariamente que outras funções importantes como a distribuição do tamanho de poros do solo, a condutividade hidráulica e a difusividade venham também apresentar valores semelhantes quando da comparação dos diferentes sistemas. Este fato começa a ser melhor compreendido quando se analisa a distribuição do tamanho de poros do solo para os diferentes sistemas.

\subsubsection{Análise da distribuição do tamanho de poros através da curva de retenção da água no solo}

Através da Figura 13 são mostrados os valores da função $d \theta / d \tau \times \tau$ relativos aos diferentes sistemas de cultivo. 


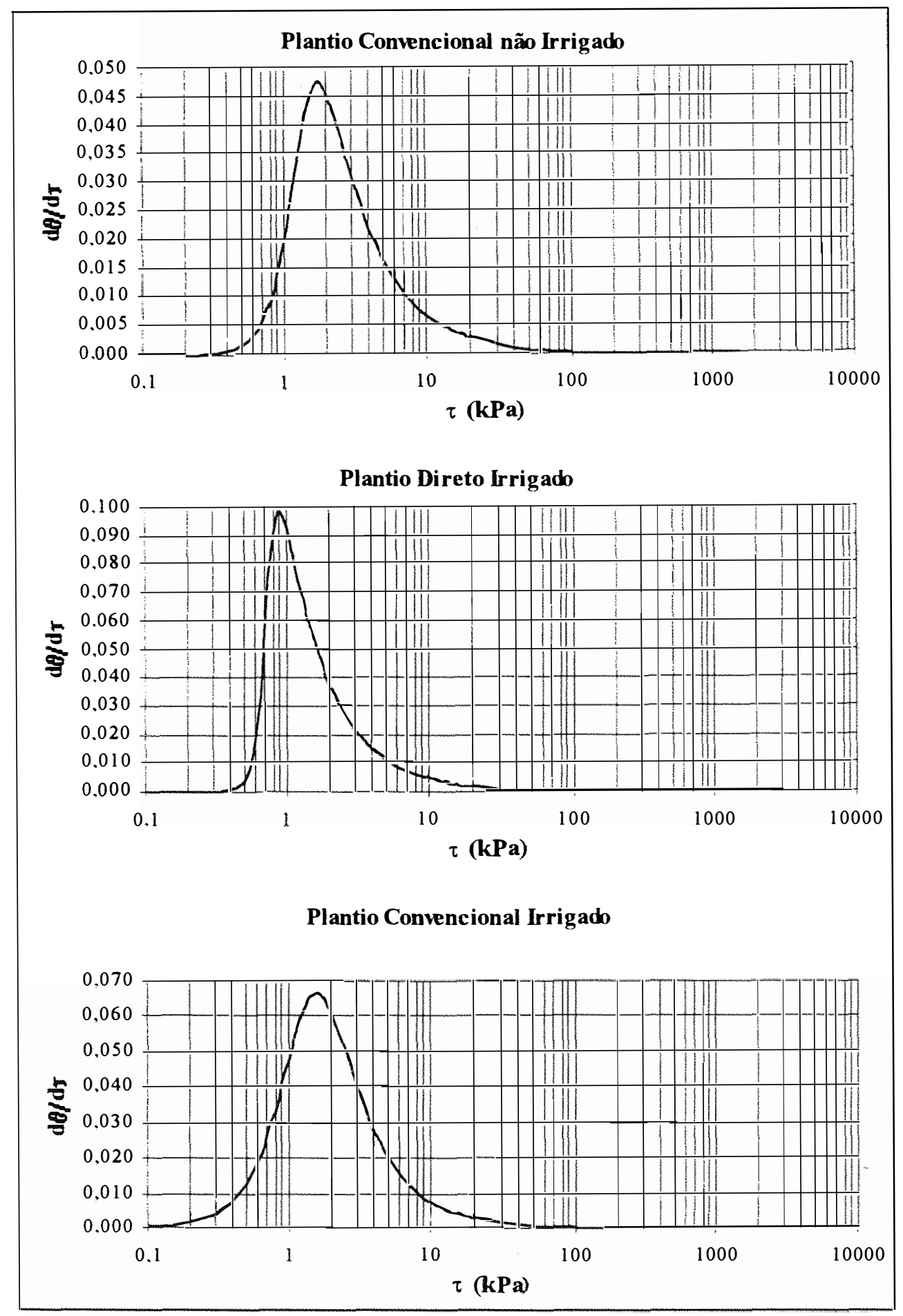

Figura I3 -Distribuição do tamanho de poros do Latossolo Roxo, nos sistemas plantio convencional não irrigado, plantio direto irrigado e plantio convencional irrigado, na profundidade de 0,07 - 0,14 $\mathrm{m}$. 
Através da equação de Kelvin (pág. 30) e considerando $\tau_{1}=0,5 \mathrm{kPa}$, todos os poros de raio equivalente $r_{1}>29,376 \mu \mathrm{m}$ serão esvaziados, e quando se aplica a tensão $\tau_{2}=10 \mathrm{kPa}$, todos os poros de raio $r_{2}>1,469 \mu \mathrm{m}$ serão esvaziados. O aumento da tensão de $\tau_{1}$ para $\tau_{2}$ faz com que sejam esvaziados todos os poros de raio menor que $r_{1}$ e maior que $r_{2}\left(r_{2}<r_{1}\right)$. Nesta situação, o volume de água liberado do solo é estimado pela diferença da umidade volumétrica nestas duas tensões, sendo então para o plantio convencional não irrigado $(\mathrm{PCNI}), \Delta \theta_{(\mathrm{PCNI})}=0,5828-04044=0,178 \mathrm{~m}^{3} \mathrm{~m}^{-3}$, para o plantio direto irrigado (PDI), $\Delta \theta_{(\mathrm{PDI})}=0,5649-0,3841=0,181 \mathrm{~m}^{3} \mathrm{~m}^{-3}$, e para o plantio convencional irrigado $(\mathrm{PCI}), \Delta \theta_{(\mathrm{PCI})}=0,6051-0,3610=0,244 \mathrm{~m}^{3} \mathrm{~m}^{-3}$. Deste modo, considerando a mesma diferença de tensões $\left(\tau_{2}-\tau_{1}\right)$, o plantio convencional irrigado tem um maior número de poros com raio equivalente entre os valores $r_{1}=29,376 \mu \mathrm{m}$ e $r_{2}=1,469 \mu \mathrm{m}$, vindo a seguir o plantio direto irrigado, com pequena diferença em relação ao convencional não irrigado (Figura 13). Nesta figura pode-se notar para os três sistemas de cultivo, os valores máximos da derivada $\mathrm{d} \theta / \mathrm{d} \tau$, que correspondem a determinados valores de $\tau^{*}$, os quais por sua vez se relacionam aos respectivos valores dos raios equivalentes $r^{*}$, através da equação 17 (pág. 30).

Na Tabela 10 abaixo, estes valores são mostrados para a seqüência plantio convencional não irrigado, plantio direto irrigado e plantio convencional irrigado, juntamente com a umidade $\theta^{*}$ e os valores da condutividade hidráulica do solo saturado $\left(\mathrm{K}_{\mathrm{0}}\right)$.

Tabela 10 - Valores máximos da derivada $\mathrm{d} \theta / \mathrm{d} \tau$, com os correspondentes valores da tensão $\tau^{*}$, do raio equivalente $\mathrm{r}^{*}$, da umidade $\theta^{*}$ e os valores da condutividade hidráulica do solo saturado $\left(\mathrm{K}_{\mathrm{o}}\right)$, na profundidade de 0,07-0,14 m.

\begin{tabular}{lccccc}
\hline \hline \multicolumn{1}{c}{ Sistema de cultivo } & $\tau^{*}$ & $\mathrm{r}^{*}$ & $\theta^{*}$ & $\mathrm{~d} \theta / \mathrm{d} \tau$ & $\mathrm{K}_{\mathrm{O}}$ \\
\hline Plantio Convencional Não Irrigado & 1,7 & 8,640 & 0,5525 & $4,74 \times 10^{-2}$ & $2,56 \times 10^{-5}$ \\
Plantio Direto Irrigado & 0,9 & 16,320 & 0,5436 & $9,91 \times 10^{-2}$ & $2,64 \times 10^{-5}$ \\
Plantio Convencional Irrigado & 1,6 & 9,180 & 0,5542 & $6,61 \times 10^{-2}$ & $3,72 \times 10^{-5}$ \\
\hline \hline
\end{tabular}

Obs.: Os valores de tensão $\tau^{*}$, do raio equivalente $r^{*}$ e da umidade volumétrica $\theta^{*}$ são acompanhados do asterisco para indicar neste caso, que são valores específicos relativos à função derivada $d \theta / d \tau$. 
Reportando-se às definições estabelecidas no Quadro 1 (pág. 32) temse que os valores dos raios equivalentes dos poros $r$ * referentes à seqüência dos sistemas de cultivo acima estabelecida estão no intervalo considerado dos macroporos (plantio direto irrigado) e mesoporos (plantio convencional não irrigado e convencional irrigado).

O valor máximo da função derivada $d \theta / d \tau$ indica para o plantio convencional não irrigado e plantio convencional irrigado uma maior freqüência da ocorrencia de poros com raios equivalentes $\mathrm{r}^{*}$ respectivamente de $8,640 \mu \mathrm{m}$ e $9,180 \mu \mathrm{m}$. Para o plantio direto ocorreu uma maior frequencia de poros com raio equivalente $r^{*}=16,320 \mu \mathrm{m}$. As diferenças observadas da ocorrencia do maior número de poros, no intervalo de tensões $\tau_{1}=0,5 \mathrm{kPa}$ e $\tau_{2}=10 \mathrm{kPa}$ favoráveis ao plantio convencional irrigado são equilibradas pela maior ocorrência de poros com raio equivalente $r=16,320 \mu \mathrm{m}$ (macroporos) do plantio direto irrigado. Esta afirmação pode ser confirmada pela ausência de diferenças significativas nos valores da condutividade hidráulica do solo saturado $\left(\mathrm{K}_{\mathrm{o}}\right)$, dos três sistemas em questão.

$\mathrm{Na}$ Tabela 11 estão os valores da porosidade total calculada, da macroporosidade e da microporosidade.

Tabela 11 - Valores da porosidade total, da macroporosidade e da microporosidade calculados, para os sistemas de cultivo plantio convencional não irrigado, direto irrigado e convencional irrigado, na profundidade de 0,07-0,14 m.

\begin{tabular}{|c|c|c|}
\hline $\begin{array}{c}\text { Plantio Convencional Não } \\
\text { Irrigado }\end{array}$ & Plantio Direto Irrigado & $\begin{array}{c}\text { Plantio Convencional } \\
\text { Irrigado } \\
\text { rrgato }\end{array}$ \\
\hline \multicolumn{3}{|c|}{$0,07-0,14 \mathrm{~m}$} \\
\hline \multicolumn{3}{|c|}{ Porosidade total calculada (\% volume) } \\
\hline 58,3 & 56,5 & 60,7 \\
\hline \multicolumn{3}{|c|}{ Macroporosidade (\% volume) } \\
\hline 17,9 & 18,1 & 24,6 \\
\hline \multicolumn{3}{|c|}{ Microporosidade (\% volume) } \\
\hline 40,3 & 38,4 & 36,1 \\
\hline
\end{tabular}

Através dos dados acima pode-se notar os valores da porosidade total e macroporosidade ligeiramente mais elevados para o plantio convencional irrigado, porém 
não se verificam diferenças significativas em relação aos demais sistemas a ponto de influenciar o comportamento da função condutividade hidráulica do solo saturado $\left(\mathrm{K}_{\mathrm{o}}\right)$. Por outro lado, as condições normais de não saturação dos solos pressupõem de certa forma uma seqüência ordenada de eventos, onde inicialmente são esvaziados os poros maiores e em progressão e gradualmente os poros menores, com os valores da condutividade hidráulica do solo não saturado $(\mathrm{K}(\theta))$ diminuindo rapidamente com o decréscimo da umidade $(\theta)$. O termo "condições de não saturação" neste caso, sugere um caráter dinâmico, no sentido de que passam a atuar forças como as de retenção e adsorção da água no solo, cuja intensidade irá depender da dinâmica do meio poroso influenciada diretamente pelo tipo de sistema de cultivo adotado, que interfere modificando a estrutura do solo, principalmente nas condições de superficie, como é o caso da profundidade aqui considerada.

Para a infiltração da água no solo no sentido vertical, a densidade de fluxo da água é uma função da condutividade hidráulica $(K(\theta))$ e do gradiente de potencial total, composto neste caso, principalmente pelos potenciais mátrico e gravitacional. Na seqüência são apresentados os valores das funções hidráulicas do solo não saturado.

\subsubsection{Condutividade hidráulica relativa $(\operatorname{Kr}(\Theta))$, condutividade hidráulica do solo não saturado $(K(\theta))$ e difusividade relativa $(\operatorname{Dr}(\Theta))$.}

Na tabela 12 são apresentados os valores da tensão $\tau(\tau=-\phi \mathrm{m}$, onde $-\phi \mathrm{m}=$ potencial mátrico), da umidade volumétrica $(\theta)$ e relativa $(\Theta)$, da condutividade hidráulica do solo não saturado $(K(\theta))$ e da difusividade relativa $(\operatorname{Dr}(\Theta))$, para a seqüência dos sistemas de cultivo plantio convencional não irrigado, plantio direto irrigado e plantio convencional irrigado, na profundidade de 0,07 - $014 \mathrm{~m}$. 
Tabela 12 - Valores da tensão $\tau(\tau=-\phi \mathrm{m}$, onde $-\phi \mathrm{m}=$ potencial mátrico), da umidade volumétrica $(\theta)$ e relativa $(\Theta)$, da condutividade hidráulica relativa $(\operatorname{Kr}(\Theta))$, da condutividade hidráulica do solo não saturado $(\mathrm{K}(\theta))$ e da difusividade relativa $(\operatorname{Dr}(\Theta))$, para a seqüência dos sistemas plantio convencional não irrigado, plantio direto irrigado e convencional irrigado, na profundidade $0,07-0,14 \mathrm{~m}$.

Plantio Convencional Não Irrigado

\begin{tabular}{|c|c|c|c|c|c|c|}
\hline $\begin{array}{c}\tau \\
k P a\end{array}$ & $\begin{array}{c}\theta \\
m^{3} m^{-3}\end{array}$ & $\Theta$ & $\left(\frac{\theta-\theta_{r}}{\theta_{s}-\theta_{r}}\right)$ & $K_{r}(\Theta)$ & $K(\theta)$ & $\operatorname{Dr}(\Theta)$ \\
\hline 0.5 & 0,555 & & 0,89 & $1,9 \times 10^{-3}$ & $4,91 \times 10^{-8}$ & $4.54 \times 10^{-5}$ \\
\hline 1.0 & 0,505 & & 0.77 & $8,9 \times 10^{-5}$ & $2.28 \times 10^{-9}$ & $7.93 \times 10^{-6}$ \\
\hline 2.0 & 0,450 & & 0.63 & $2,2 \times 10^{-6}$ & $5,58 \times 10^{-11}$ & $1,13 \times 10^{-6}$ \\
\hline 5.0 & 0.420 & & 0.56 & $2.1 \times 10^{-7}$ & $5.37 \times 10^{-12}$ & $3.38 \times 10^{-7}$ \\
\hline 8.0 & 0,405 & & 0.52 & $5.8 \times 10^{-8}$ & $1.48 \times 10^{-12}$ & $1.74 \times 10^{-7}$ \\
\hline 30.0 & 0,340 & & 0.36 & $5,9 \times 10^{-11}$ & $1,50 \times 10^{-15}$ & $5,06 \times 10^{-9}$ \\
\hline 60.0 & 0,325 & & 0,32 & $7,7 \times 10^{-12}$ & $1,94 \times 10^{-16}$ & $1,79 \times 10^{-9}$ \\
\hline 300.0 & 0,295 & & 0.25 & $5,9 \times 10^{-14}$ & $1,51 \times 10^{-18}$ & $1.47 \times 10^{-10}$ \\
\hline 1500.0 & 0,265 & & 0,17 & $8,1 \times 10^{-17}$ & $2,08 \times 10^{-21}$ & 0 \\
\hline \multicolumn{7}{|c|}{ Plantio Direto Irrigado } \\
\hline $\begin{array}{c}\tau \\
k P a\end{array}$ & $\begin{array}{c}\theta \\
m^{3} m^{-3}\end{array}$ & $\Theta$ & $\left(\frac{\theta-\theta_{r}}{\theta_{s}-\theta_{r}}\right)$ & $K_{r}(\Theta)$ & $K(\theta)$ & $\overline{\operatorname{Dr}(\Theta)}$ \\
\hline 0.5 & 0,546 & & 0,92 & $2,8 \times 10^{-4}$ & $7,49 \times 10^{-9}$ & $9,78 \times 10^{-6}$ \\
\hline 1.0 & 0,516 & & 0.83 & $7,3 \times 10^{-5}$ & $1.93 \times 10^{-10}$ & $1,35 \times 10^{-6}$ \\
\hline 2.0 & 0,483 & & 0,73 & $1,0 \times 10^{-7}$ & $2.68 \times 10^{-12}$ & $1,51 \times 10^{-7}$ \\
\hline 5.0 & 0,465 & & 0,68 & $7.8 \times 10^{-9}$ & $2.06 \times 10^{-13}$ & $4,10 \times 10^{-8}$ \\
\hline 8,0 & 0,456 & & 0,65 & $2,0 \times 10^{-9}$ & $5.30 \times 10^{-14}$ & $2,06 \times 10^{-8}$ \\
\hline 30.0 & 0,417 & & 0,53 & $2,7 \times 10^{-12}$ & $7.10 \times 10^{-17}$ & $7,17 \times 10^{-10}$ \\
\hline 60.0 & 0,408 & & 0.51 & $4,8 \times 10^{-13}$ & $1,26 \times 10^{-17}$ & $2,98 \times 10^{-10}$ \\
\hline 300,0 & 0,390 & & 0,45 & $1,1 \times 10^{-14}$ & $2,94 \times 10^{-19}$ & $4,40 \times 10^{-11}$ \\
\hline 1500.0 & 0,372 & & 0,40 & $1,6 \times 10^{-16}$ & $4.27 \times 10^{-21}$ & $8,97 \times 10^{-12}$ \\
\hline \multicolumn{7}{|c|}{ Plantio Convencional Irrigado } \\
\hline $\begin{array}{c}\tau \\
k P a\end{array}$ & $\begin{array}{c}\theta \\
m^{3} m^{-3}\end{array}$ & $\Theta$ & $\left(\frac{\theta-\theta_{r}}{\theta_{s}-\theta_{r}}\right)$ & $K_{r}(\Theta)$ & $K(\theta)$ & $\operatorname{Dr}(\Theta)$ \\
\hline 0,5 & 0,559 & & 0,88 & $9,12 \times 10^{-2}$ & $3,39 \times 10^{-6}$ & $7,73 \times 10^{-4}$ \\
\hline 1,0 & 0,509 & & 0,75 & $2,21 \times 10^{-2}$ & $8,24 \times 10^{-7}$ & $2,54 \times 10^{-4}$ \\
\hline 2,0 & 0,454 & & 0,60 & $4,40 \times 10^{-3}$ & $1,62 \times 10^{-7}$ & $8,85 \times 10^{-5}$ \\
\hline 5.0 & 0,424 & & 0,52 & $1,60 \times 10^{-3}$ & $5,94 \times 10^{-8}$ & $4,87 \times 10^{-5}$ \\
\hline 8,0 & 0,409 & & 0,48 & $9,0 \times 10^{-4}$ & $3,42 \times 10^{-8}$ & $3,54 \times 10^{-5}$ \\
\hline 30.0 & 0,344 & & 0,30 & $4,4 \times 10^{-5}$ & $1,64 \times 10^{-9}$ & $6,55 \times 10^{-6}$ \\
\hline 60,0 & 0,329 & & 0,26 & $1,7 \times 10^{-5}$ & $6,41 \times 10^{-10}$ & $3,92 \times 10^{-6}$ \\
\hline 300,0 & 0,299 & & 0,18 & $1,6 \times 10^{-6}$ & $5,79 \times 10^{-11}$ & $1,07 \times 10^{-6}$ \\
\hline 1500.0 & 0,269 & & 0,10 & $3,4 \times 10^{-8}$ & $1,27 \times 10^{-12}$ & $1,36 \times 10^{-7}$ \\
\hline
\end{tabular}


As funções $(\operatorname{Kr}(\Theta)),(\operatorname{K}(\theta))$ e $\operatorname{Dr}(\Theta))$ apresentaram valores bem distintos, quando foram comparadas entre si para os diferentes sistemas de cultivo. A Tabela 13 mostra os valores dos índices de concordância (d) de Willmott obtidos em cada caso.

Tabela 13 - Indices de concordância (d) Willmott obtidos na comparação dos valores das funções $(\operatorname{Kr}(\Theta),(K(\theta))$ e $(\operatorname{Dr}(\Theta))$ entre os sistemas plantio convencional não irrigado (PCNI), plantio direto irrigado (PDI) e plantio convencional irrigado (PCI), na profundidade $0,07-0,14 \mathrm{~m}$.

\begin{tabular}{clll}
\hline \hline & \multicolumn{2}{c}{$\begin{array}{c}\text { Indices (d) } \text { de Willmott } \\
\mathbf{0 , 0 7 - 0 , 1 4} \boldsymbol{~}\end{array}$} \\
\hline Funções & PCNI x PDI & PCNI x PCI & PDI x PCI \\
\hline $\operatorname{Kr}(\Theta)$ & 0,517736 & 0,703346 & 0,185024 \\
$\mathrm{~K}(\theta)$ & 0,528534 & 0,559248 & 0,135024 \\
$\operatorname{Dr}(\Theta)$ & 0,474166 & 0,773680 & 0,197416 \\
\hline \hline
\end{tabular}

Entre os sistemas de cultivo plantio direto irrigado e plantio convencional irrigado, os índices (d) de Willmott determinados nas comparações dos valores das funções $(\operatorname{Kr}(\Theta)),(\mathrm{K}(\theta))$ e $(\operatorname{Dr}(\Theta))$ foram respectivamente de 0,185024 , 0,135024 e 0,197416, estando bem próximos de zero e indicando que a transmissão de água entre os dois sistemas diverge bastante. Para a combinação dos sistemas PCNI e PDI, os índices (d) determinados para as funções $(\operatorname{Kr}(\Theta)),(\operatorname{K}(\theta))$ e $(\operatorname{Dr}(\Theta))$ foram respectivamente de $0,517736,0,528534$, e 0,474166, portanto mais elevados em relação ao caso anterior, mas ainda indicando diferenças no processo de transmissão de água. Já, os valores mais elevados do índice (d) foram obtidos na comparação entre os sistemas PCNI e PCI, sendo respectivamente de 0,703346, 0,559248 e 0,773680 para $(\operatorname{Kr}(\Theta))$, $(\mathrm{K}(\theta))$ e $(\operatorname{Dr}(\Theta))$, indicando uma maior similaridade das propriedades hidráulicas.

Diante do exposto e observando novamente a Tabela 13 pode-se concluir que as diferenças entre as propriedades hidráulicas foram mais pronunciadas na comparação dos sistemas PDI e PCI do que entre os sistemas PCNI e PDI, e principalmente em relação à comparação PCNI e PCI. Isto decorre do fato de que no sistema convencional, de modo geral a estrutura da camada superficial $(0,00-0,07 \mathrm{~m} \mathrm{e}$ $0,07-0,14 \mathrm{~m}$ ) foi mais intensamente alterada, ocorrendo uma maior homogenização da 
massa do solo devido ao efeito dos implementos, o que não ocorre no sistema plantio direto irrigado. Deste modo, o maior número de poros com raio equivalente $r$ entre os valores $r_{1}=29,376 \mu \mathrm{m}$ e $r_{2}=1,469 \mu \mathrm{m}$ dos sistemas convencional não irrigado e convencional irrigado, ainda que muitos sejam descontínuos, favorece o fluxo não saturado, o que implica em valores mais elevados de $(\operatorname{Kr}(\Theta)),(\operatorname{K}(\theta))$ e $(\operatorname{Dr}(\Theta))$, para os mesmos, quando comparados com o sistema plantio direto irrigado.

A Figura 14, seguinte, apresenta os valores do $\ln \operatorname{Kr}(\Theta)(\ln =$ logaritmo neperiano) em função da umidade relativa $(\Theta)$, para a seqüência dos sistemas plantio convencional não irrigado, direto irrigado e convencional irrigado, na profundidade de 0,07 - 0,14 m. Através da mesma pode-se notar os valores mais elevados de $(\operatorname{Kr}(\Theta))$ no plantio convencional irrigado em relação ao plantio direto irrigado.

As curvas $\ln \operatorname{Kr}(\Theta) \times(\Theta)$ confirmam os valores mais elevados de $(\mathrm{Kr} \Theta))$ para o sistema convencional irrigado, vindo a seguir o sistema convencional não irrigado e por último o plantio direto irrigado. Diferenças básicas ocorrem então entre os sistemas de cultivo. No plantio direto irrigado o máquinario utilizado, pela própria característica do não revolvimento do solo, com apenas o sulcamento leve na linha de plantio e também devido ao seu peso transmitido diretamente à superficie do solo, conduz à uma maior compactação nesta posição, quando comparado com o plantio convencional, onde a compactação ocorre geralmente no segmento de profundidade de $20-30 \mathrm{~cm}$, a qual é normalmente afetada pela profundidade de corte do arado ou mesmo de uma grade pesada. Não obstante é possível que uma amostragem do solo logo após o preparo convencional não mostre momentâneamente os efeitos da compactação, sendo que os mesmos podem se manifestar após um determinado tempo, como já comentado anteriormente.

Para a camada de solo de 0,27 - 0,34 m que será discutida a seguir, já ocorrem algumas mudanças nas propriedades hidráulicas em relação às camadas suprajacentes $(0,00-0,07$ e $0,07-0,14)$ 


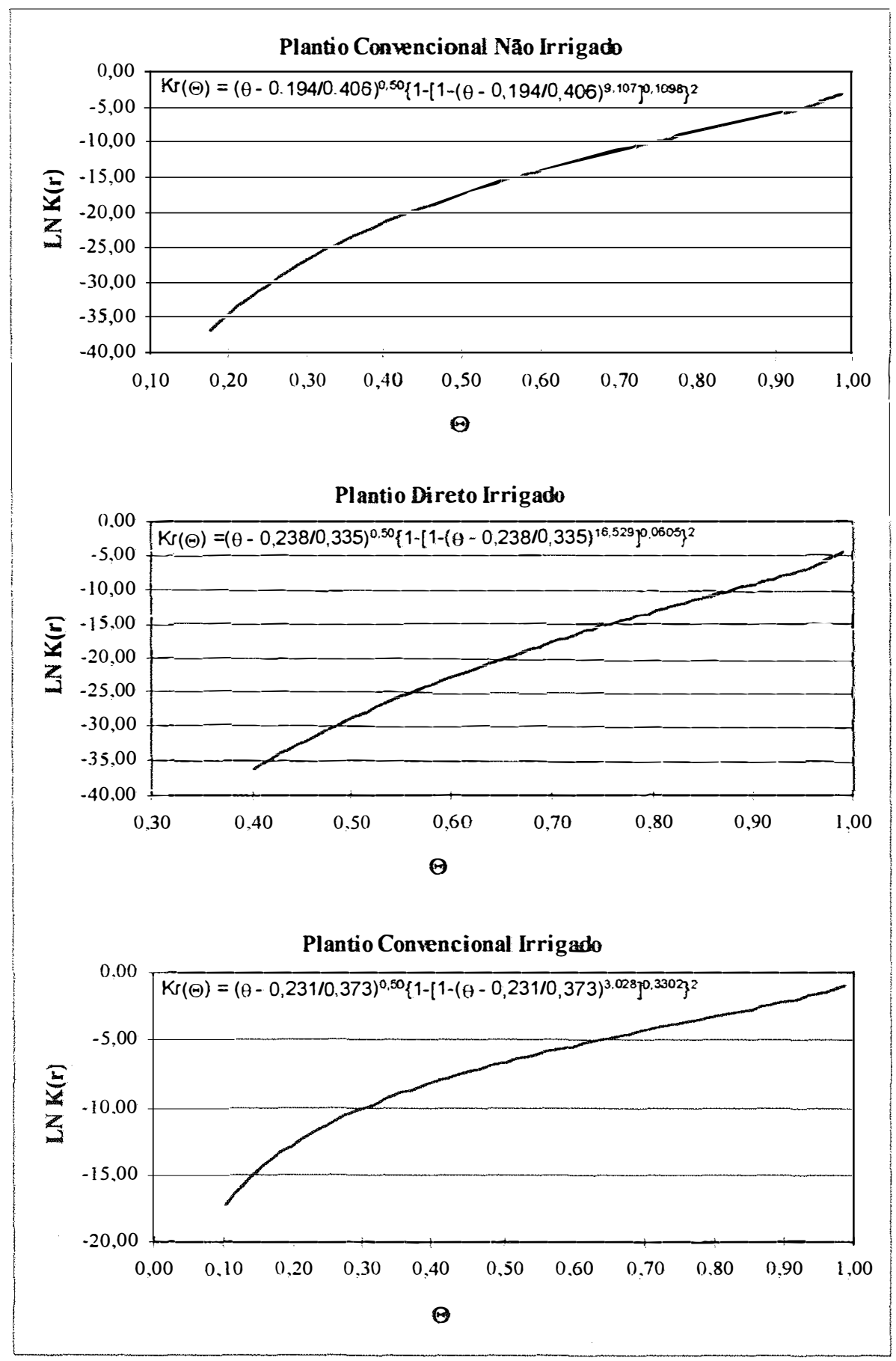

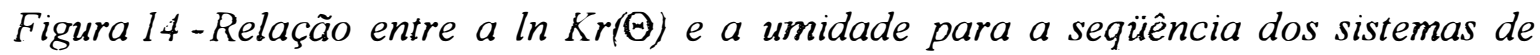
cultivo plantio convencional não irrigado, plantio direto irrigado $e$ convencional irrigado na profundidade 0,07-0,14 $\mathrm{m}$. 


\subsection{Profundidade de $0,27-0,34 \mathrm{~m}$}

Esta camada tem o limite inferior de $0,34 \mathrm{~m}$ coincidente com a profundidade de operação do arado e também com limite de 0,30m estabelecido na separação dos horizontes superficiais do solo, para cada um dos sistemas de cultivo, por ocasião da descrição do perfil a campo (Anexo A).

\subsubsection{Sistemas de cultivo plantio convencional não irrigado, plantio direto irrigado e plantio convencional irrigado.}

Para análise dos parâmetros fisicos entre os diferentes sistemas de cultivo, a ordem estabelecida é a mesma observada para a camada de 0,00 - 0,14 m, iniciando-se portanto pela curva de retenção da água no solo $(\mathrm{h}(\theta))$.

\subsubsection{Curvas de retenção da água no solo}

Os valores da umidade volumétrica $(\theta)$ correspondentes aos níveis de tensão de 0,$5 ; 1,0 ; 2,0 ; 5,0 ; 8,0 ; 30,0 ; 60,0 ; 300,0$ e 1500,0 kPa são apresentados na Tabela 14, acompanhados também dos valores da densidade do solo (média de 3 repetições), para os sistemas de cultivo plantio convencional não irrigado, direto irrigado e convencional irrigado. No Anexo B são mostrados os dados das curvas de retenção, juntamente com os parâmetros do ajuste através do método de Genuchten (1980), com as três repetições.

Tabela 14 - Valores numéricos das curvas de retenção da água no solo e da densidade para a seqüência dos sistemas plantio convencional não irrigado, direto irrigado e convencional irrigado na profundidade de 0,27 - 0,34 $\mathrm{m}$ com as médias (3 repetições), desvios padrões e coeficientes de variação.

\begin{tabular}{|c|c|c|c|c|c|c|}
\hline \multicolumn{7}{|c|}{ Plantio Convencional Não Irrigado } \\
\hline \multirow{2}{*}{$\begin{array}{c}\text { Potencial } \\
\text { mátrico }\left(\phi_{m}\right) \\
k P a\end{array}$} & \multicolumn{6}{|c|}{$0,27-0,34 m$} \\
\hline & $\begin{array}{c}\theta \\
m^{3} m^{-3}\end{array}$ & $\begin{array}{l}\text { Desvio } \\
\text { Padrão }\end{array}$ & $\begin{array}{l}\text { Coeficiente } \\
\text { de variação }\end{array}$ & $\begin{array}{c}\text { densidade } \\
\mathrm{kg} \mathrm{m}^{-3}\end{array}$ & $\begin{array}{l}\text { Desvio } \\
\text { Padrão }\end{array}$ & $\begin{array}{l}\text { Coeficiente } \\
\text { de variação }\end{array}$ \\
\hline 0,50 & 0,5924 & 0,0076 & 1,29 & 1063 & 7,572 & 0,71 \\
\hline 1,00 & 0,5626 & 0,0034 & 0,61 & 1039 & 53,861 & 5,18 \\
\hline 2,00 & 0,5315 & 0,0104 & 1,96 & 1068 & 25,514 & 2,40 \\
\hline 5,00 & 0,4420 & 0,0174 & 3,94 & 1066 & 14.047 & 1,32 \\
\hline 8,00 & 0,3804 & 0,0154 & 4,06 & 1066 & 14.047 & 1,32 \\
\hline 30,00 & 0,3315 & 0,0275 & 8,30 & 1063 & 7,572 & 0,71 \\
\hline 60,00 & 0,2955 & 0,0176 & 5,98 & 1039 & 53,861 & 5,18 \\
\hline 300,00 & 0,2632 & 0,0244 & 9,30 & 1068 & 25,514 & 2,40 \\
\hline 1500,00 & 0,2386 & 0,0250 & 10.5 & 1066 & 14,047 & 1,32 \\
\hline
\end{tabular}

continua. 
continuação

\begin{tabular}{|c|c|c|c|c|c|c|}
\hline \multicolumn{7}{|c|}{ Plantio Direto Irrigado } \\
\hline \multirow{2}{*}{$\begin{array}{c}\text { Potencial } \\
\text { mátrico }\left(\phi_{m}\right) \\
k P a\end{array}$} & \multicolumn{6}{|c|}{$0,27-0,34 m$} \\
\hline & $\begin{array}{c}\theta \\
m^{3} m^{-3} \\
\end{array}$ & $\begin{array}{l}\text { Desvio } \\
\text { Padrão } \\
\end{array}$ & $\begin{array}{l}\text { Coeficiente } \\
\text { de variação }\end{array}$ & $\begin{array}{c}\text { densidade } \\
\mathrm{kg} \mathrm{m}^{-3}\end{array}$ & $\begin{array}{l}\text { Desvio } \\
\text { Padrão }\end{array}$ & $\begin{array}{l}\text { Coeficiente } \\
\text { de variação }\end{array}$ \\
\hline 0,50 & 0,6056 & 0,0484 & 7,99 & 1054 & 11,37 & 1,08 \\
\hline 1.00 & 0,5551 & 0,0322 & 5.80 & 1050 & 30.83 & 2.94 \\
\hline 2.00 & 0,4934 & 0,0132 & 2,68 & 1004 & 5,51 & 0,55 \\
\hline 5.00 & 0,4218 & 0,0130 & 3,08 & 1063 & 51,39 & 4,83 \\
\hline 8,00 & 0,3919 & 0,0151 & 3,85 & 1063 & 51,39 & 4,83 \\
\hline 30.00 & 0,3457 & 0,0190 & 5,50 & 1059 & 11,31 & 1,07 \\
\hline 60.00 & 0,3199 & 0,0152 & 4,75 & 1050 & 30,83 & 2,94 \\
\hline 300.00 & 0.2858 & 0,0083 & 2,92 & 1004 & 5.51 & 0,55 \\
\hline 1500.00 & 0,2655 & 0.0180 & 6,70 & 1063 & 51.39 & 4,83 \\
\hline \multicolumn{7}{|c|}{ Plantio Convencional Irrigado } \\
\hline Potencial & \multicolumn{6}{|c|}{$0,27-0,34 \mathrm{~m}$} \\
\hline $\begin{array}{c}\text { mátrico }\left(\phi_{m}\right) \\
k P a\end{array}$ & $\begin{array}{c}\theta \\
m^{3} m^{-3}\end{array}$ & $\begin{array}{l}\text { Desvio } \\
\text { Padrão }\end{array}$ & $\begin{array}{l}\text { Coeficiente } \\
\text { de variação }\end{array}$ & $\begin{array}{c}\text { densidade } \\
k_{\mathrm{g}} \mathrm{m}^{-3}\end{array}$ & $\begin{array}{l}\text { Desvio } \\
\text { Padrão }\end{array}$ & $\begin{array}{l}\text { Coeficiente } \\
\text { de variação }\end{array}$ \\
\hline 0.50 & 0,5846 & 0,0273 & 4.66 & 1041 & 39,31 & 3,78 \\
\hline 1.00 & 0,5141 & 0,0182 & 3,53 & 1007 & 44,44 & 4,41 \\
\hline 2.00 & 0,4556 & 0,0160 & 3,51 & 1000 & 41,60 & 4,16 \\
\hline 5,00 & 0,3898 & 0,0094 & 2,42 & 1011 & 31,50 & 3,12 \\
\hline 8,00 & 0,3598 & 0,0082 & 2,29 & 1011 & 31.50 & 3,12 \\
\hline 30.00 & 0,3017 & 0,0078 & 2,60 & 1041 & 39.31 & 3,78 \\
\hline 60.00 & 0.2789 & 0.0096 & 3,44 & 1007 & 44,44 & 4.41 \\
\hline 300,00 & 0,2526 & 0,0049 & 1,95 & 1000 & 41,60 & 4,16 \\
\hline 1500.00 & 0,2284 & 0,0160 & 7.01 & 1011 & 31,50 & 3,16 \\
\hline
\end{tabular}

Estes valores também são apresentados na forma de gráfico através da Figura 15. A análise dos dados numéricos da Tabela 14 e também dos gráficos (Figura 15) não indicam diferenças significativas entre as curvas de retenção para os três sistemas de cultivo. Isto é confirmado através dos valores dos índices (d) de Willmott obtidos para cada situação e apresentados na Tabela 15.

Tabela 15 - Índices de Willmott para comparação da função $h(\theta)$ entre os sistemas plantio convencional não irrigado, plantio direto irrigado e plantio convencional irrigado, na profundidade de 0,27 - 0,34 m.

\begin{tabular}{lc|cc}
\hline \hline \multicolumn{1}{c}{ Indices de Willmott (d) para comparação dos valores da função $(\boldsymbol{h}(\theta))$} \\
\multicolumn{4}{c}{$\mathbf{0 , 2 7 - 0 , 3 4} \boldsymbol{m}$} \\
\hline PCNI & Comparações & indice (d) \\
PCNI & PDI & 0,914943 \\
PDI & PCI & 0,972120 \\
\hline \hline
\end{tabular}


Os valores dos índices de Willmott próximos da unidade são indicativos da forte similiraridade das curvas de retenção $(h(\theta))$ entre os sistemas de cultivo, quando comparados entre si, o que é devido ao solo ser bastante homogêneo, mesmo sob condições distintas de cultivo. Porém esta homogeneidade não se manifesta, quando se analisa os valores das função derivada $d \theta / d \tau$ das curvas de retenção, para cada sistema de cultivo e que são apresentadas no item seguinte.
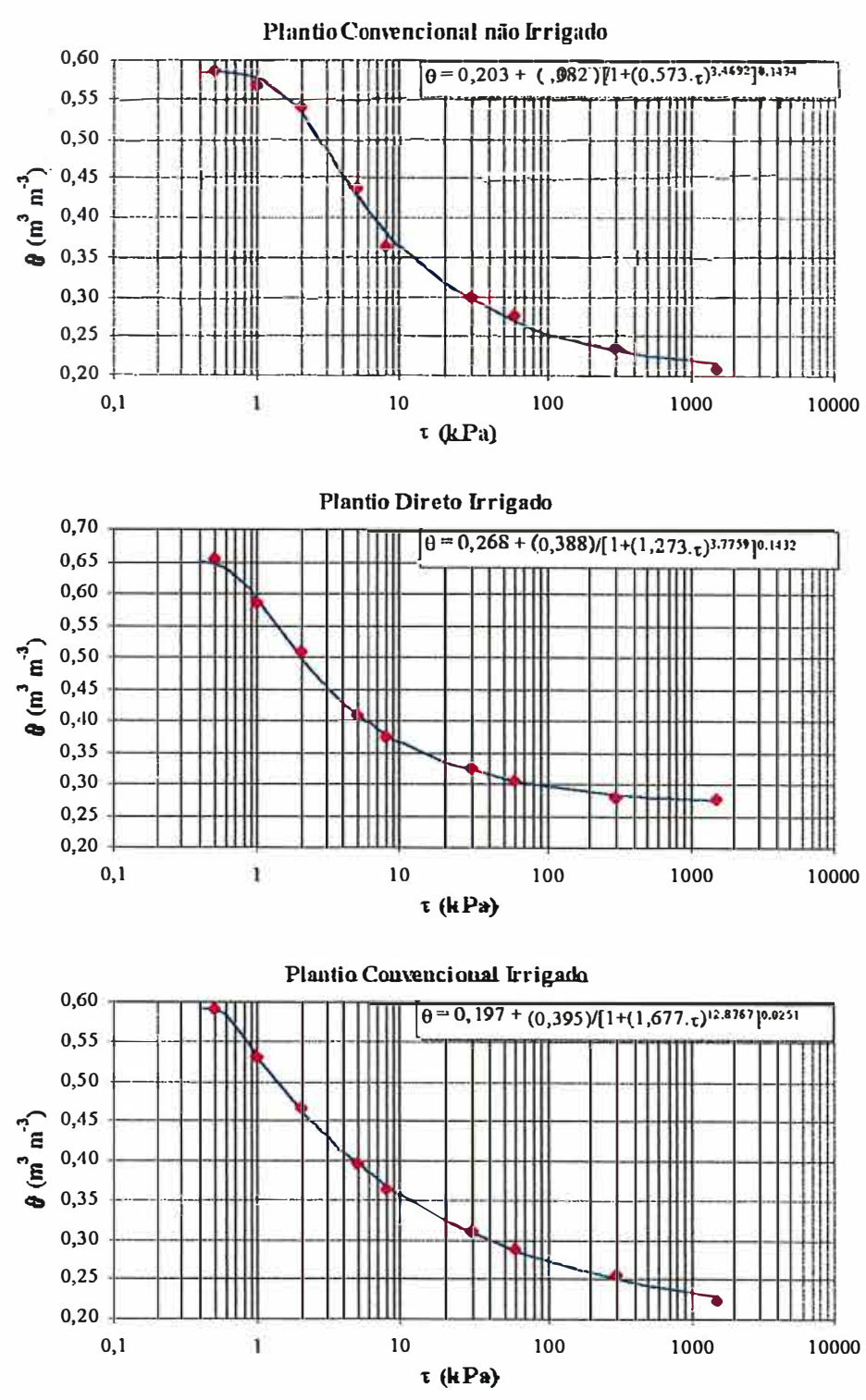

Figura 15 -Curvas de retenção da água de Latossolo Roxo, para os sistemas de cultivo plantio convencional não irrigado, plantio direto irrigado e convencional. irrigado, na profundidade de 0,27 - 0,34 m. 


\subsubsection{Análise da distribuição do tamanho de poros através da curva de retenção da água no solo.}

A Figura (16) abaixo, apresenta os valores da derivada $\mathrm{d} \theta / \mathrm{d} \tau$ em função da tensão $\tau$ para a seqüência de sistemas de cultivo plantio convencional não irrigado, direto irrigado e convencional irrigado.

Analisando os valores das funções $\mathrm{d} \theta / \mathrm{d} \tau$ através da equação de Kelvin, e considerando o mesmo intervalo de tensões dos casos anteriores, ou seja, $\tau_{1}$ e $\tau_{2}$, e aplicando-se a tensão $\tau_{1}=0,5 \mathrm{kPa}$, todos os poros de raio equivalente $\mathrm{r}_{1}=29,376 \mu \mathrm{m}$ serão esvaziados, e quando se aplica a tensão $\tau_{2}=10 \mathrm{kPa}$, todos os poros de raio equivalente $r_{2}=1,469 \mu \mathrm{m}$ serão esvaziados. Assim, o aumento da tensão de $\tau_{1}$ para $\tau_{2}$ faz com que sejam esvaziados todos os poros de raio menor que $r_{1}$ e maior que $r_{2}\left(r_{2}<r_{1}\right)$, com o volume de água liberado do solo estimado pela diferença de umidade verificada nestes dois níveis de tensão, o que por sua vez é igual ao volume de poros de raio equivalente menor que $r_{1}=29,376 \mu \mathrm{m}$ e maior que $r_{2}=1,469 \mu \mathrm{m}$. Nesta altura, já podem ser observadas diferenças entre os sistemas de cultivo quanto ao volume de água liberado do solo. Assim, para o plantio convencional não irrigado (PCNI), $\Delta \theta_{(\mathrm{PCNI})}=0,5843$ $0,3632=0,221 \mathrm{~m}^{3} \mathrm{~m}^{-3}$, sendo que no plantio direto irrigado (PDI), $\Delta \theta_{(\mathrm{PDI})}=0,6468$ $0,3660=0,281 \mathrm{~m}^{3} \mathrm{~m}^{-3}$, e para o plantio convencional irrigado $(\mathrm{PCI}), \Delta \theta_{(\mathrm{PCD})}=0,5910$ $0,3558=0,235 \mathrm{~m}^{3} \mathrm{~m}^{-3}$. Então, para a profundidade de $0,27-0,34 \mathrm{~m}$, o sistema plantio direto irrigado tem o maior número de poros com raio equivalente $r$ entre os valores $r_{1}=29,376 \mu \mathrm{m}$ e $r_{2}=1,469 \mu \mathrm{m}$, vindo a seguir o plantio convencional irrigado e após o convencional não irrigado. Esta ocorrência já é diferente daquela observada para a profundidade de $0,07-0,14 \mathrm{~m}$ que tem $\Delta \theta_{(\mathrm{PCI})}=0,244 \mathrm{~m}^{3} \mathrm{~m}^{-3}>\Delta \theta_{(\mathrm{PDI})}=0,181 \mathrm{~m}^{3} \mathrm{~m}^{-3}$ $>\Delta \theta_{(\mathrm{PCN})}=0,178 \mathrm{~m}^{3} \mathrm{~m}^{-3}$, e mostra que a medida que se aprofunda no perfil do solo (de 0,00 m - 0,07 m para 0,07 m- 0,14 m e 0,27 - 0,34 m) o efeito da mobilização pela prática do plantio direto tem menor influencia no sentido de alterar a dinâmica dos poros do solo, e consequentemente permitindo a ocorrência de um maior volume de poros e melhor continuidade dos mesmos, em relação aos sistemas convencionais, principalmente 
na camada sub-superficial (profundidade geralmente entre $0,20-0,30 \mathrm{~m}$ ) que normalmente promovem o adensamento e a compactação nesta posição.

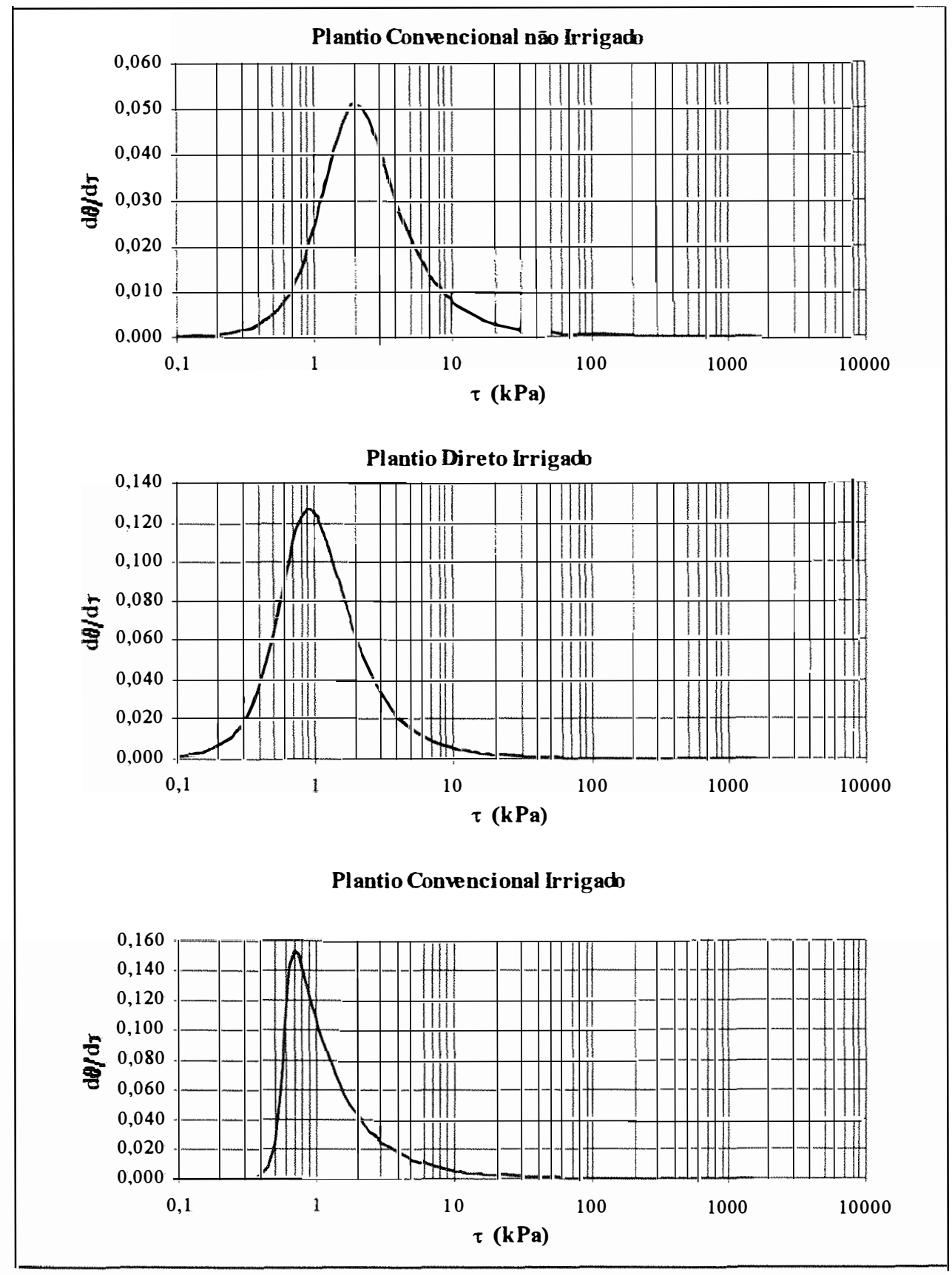

Figura I6 -Distribuição do tamanho de poros do Latossolo Roxo, nos sistemas plantio convencional não irrigado, plantio direto irrigado e plantio convencional irrigado, na profundidade de 0,27 - 0,34 m. 
A Tabela 16, mostra os valores máximos da derivada $\mathrm{d} \theta / \mathrm{d} \tau$ para os sistemas de cultivo plantio convencional não irrigado, plantio direto irrigado e plantio convencional irrigado, juntamente com os correspondentes valores de tensão $\tau^{*}$, do raio equivalente $r^{*}$, da umidade $\theta^{*}$, e os valores da condutividade hidráulica saturada $K_{0}$, na profundidade de $0,27-0,34 \mathrm{~m}$.

Tabela 16 - Valores máximos da derivada $\mathrm{d} \theta / \mathrm{d} \tau$, com os correspondentes valores da tensão $\tau^{*}$, do raio equivalente $\mathrm{r}^{*}$, da umidade $\theta^{*}$ e os valores da condutividade hidráulica do solo saturado $\left(\mathrm{K}_{\mathrm{o}}\right)$, na profundidade de $0,27-0,34 \mathrm{~m}$.

\begin{tabular}{lccccc}
\hline \hline \multicolumn{1}{c}{ Sistema de cultivo } & $\tau^{*}$ & $\mathrm{r}^{*}$ & $\theta^{*}$ & $\mathrm{~d} \theta / \mathrm{d} \tau$ & $\mathrm{K}_{\mathrm{O}}$ \\
\hline Plantio Convencional Não Irrigado & 2,0 & 7,344 & 0,5360 & $5,10 \times 10^{-2}$ & $4,03 \times 10^{-5}$ \\
Plantio Direto Irrigado & 0,9 & 16,320 & 0,6051 & $1,27 \times 10^{-1}$ & $3.39 \times 10^{-5}$ \\
Plantio Convencional Irrigado & 0,7 & 20,893 & 0,5709 & $1,53 \times 10^{-1}$ & $4,59 \times 10^{-5}$ \\
\hline
\end{tabular}

Obs.: Os valores de tensão $\tau^{*}$, do raio equivalente $\mathrm{r}^{*}$ e da umidade volumétrica $\theta$ são acompanhados do asterisco para indicar neste caso, que são valores específicos relativos à função derivada $\mathrm{d} \theta / \mathrm{d} \tau$.

Observando o Quadro 1 (pág. 32) verifica-se que os valores dos raios equivalentes $r^{*}$ para os três sistemas de cultivo estão no intervalo considerado dos mesoporos (plantio convencional não irrigado) e macroporos ( plantio direto irrigado e plantio convencional irrigado). O pico da curva diferencial, ou seja, o máximo valor da função $d \theta / d \tau$ indica nesta situação a maior frequência da ocorrência de poros com raio equivalente $\mathrm{r}^{*}=7,344 \mu \mathrm{m}$ para o plantio convencional não irrigado, sendo que no plantio direto, os poros que ocorrem em maior número têm raio equivalente $r^{*}=16,320 \mu \mathrm{m}$, e no plantio convencional irrigado ocorre uma maior número de poros com raio equivalente $r^{*}=20,983 \mu \mathrm{m}$.

Comparando os valores dos raios equivalentes $r^{*}$ relacionados ao máximo valor da derivada $\mathrm{d} \theta / \mathrm{d} \tau$, para os três sistemas de cultivo na profundidade de 0,27 - 0,34 m (Tabela 16) com os mesmos valores dos sistemas plantio direto irrigado e convencional irrigado na profundidade 0,00 - 0,07 m (Tabela 2 pág. 40) e ainda, com os valores respectivos dos sistemas plantio convencional não irrigado, plantio direto irrigado e plantio convencional irrigado, na profundidade de 0,07 - 0,14 m (Tabela 10, pág 53) pode-se notar que para o sistema plantio direto irrigado, o raio equivalente de poro $\mathrm{r}^{*}$ 
aumentou de $6,528 \mu \mathrm{m}(0,00-0,07 \mathrm{~m})$ para $\mathrm{r}^{*}=16,320 \mu \mathrm{m}$ nas profundidades de 0,07 $0,14 \mathrm{~m} \mathrm{e} 0,27-0,34 \mathrm{~m}$, sendo que no plantio convencional irrigado o aumento do número de poros com raio equivalente $\mathrm{r}^{*}$ foi de $5,875 \mu \mathrm{m}(0,00-0,07 \mathrm{~m})$ para $9,180 \mu \mathrm{m}$ em 0,07 - 0,14 m, e de 20,983 $\mu \mathrm{m}$ em 0,27 - 0,34 m. Para o plantio convencional não irrigado, praticamente não ocorreram mudanças nos valores do raio equivalente $r^{*}$ entre as profundidades de $0,07-0,14 \mathrm{~m}\left(\mathrm{r}^{*}=8,640 \mu \mathrm{m}\right)$ e $0,27-0,34 \mathrm{~m}\left(\mathrm{r}^{*}=7,344 \mu \mathrm{m}\right)$.

Analisando inicialmente os resultados para o plantio direto irrigado observa-se que a camada de 0,00 - 0,07 $\mathrm{m}$ foi a mais afetada por este sistema de cultivo, em comparação com as camadas de 0,07 - 0,14 m e 0,27 - 0,34m. Isto é devido à uma maior mobilização superficial do solo pelo implemento mecânico, alterando a porosidade e a estrutura do solo, quando comparado com a menor intensidade desta ação nas camadas subjacentes $(0,07-0,14$ e 0,27 - 0,37 m), onde a continuidade de poros no plantio direto devido à atividade da fauna também é maior.

Por outro lado, no plantio convencional não irrigado, a semelhança nos valores de raio equivalente $\mathrm{r}^{*}$ verificada para as camadas nas distintas profundidades, sugere uma homogenização do solo através de implementos, com alteração da estrutura original das camadas de 0,00 - 0,07 m, de 0,07-0,14 m e de 0,27-0,34 m até um limite em torno de 0,4 m. Porém o mesmo não se verifica para o plantio convencional irrigado onde os valores de $\mathrm{r}^{*}$ foram sempre crescentes com a profundidade do solo. Esta discrepância entre os dois sistemas acima em termos da maior ocorrência do número de poros considerando as diferentes profundidades é conseqüência da umidade mais elevada devido ao processo de irrigação, dando origem a um potencial de pressão, que provavelmente age no sentido de uma maior mobilização de poros para o fluxo, nas camadas subjacentes.

As observações de Gjettermann et al. (1997) corroboram a afirmação acima, onde para baixas intensidades de irrigação, o fluxo de água na camada superficial do solo tem lugar através uma proporção relativamente grande da matriz do solo devido a grande influência das forças capilares, limitando o fluxo preferencial nas camadas 
subjacentes. À medida em que a intensidade de irrigação aumenta, como é o caso do sistema convencional irrigado, origina-se na superficie do solo um potencial de pressão, responsável pelo inicio do fluxo preferencial através de um maior número de macroporos nas camadas subjacentes.

$\mathrm{Na}$ Tabela 17 estão relacionados os valores da porosidade total, da macroporosidade e da microporosidade calculados para os diferentes sistemas de cultivo, na profundidade de $0,27-0,34 \mathrm{~m}$.

Tabela 17 - Valores da porosidade total, da macroporosidade e da microporosidade calculadas, para a seqüência dos sistemas de cultivo plantio convencional não irrigado, plantio direto irrigado e plantio convencional irrigado, na profundidade de $0,27-0,34 \mathrm{~m}$.

\begin{tabular}{|c|c|c|}
\hline Plantio Convencional Näo Irrigado. & Plantio Direto Irrigado. & Plantio Convencional Irrigado \\
\hline \multicolumn{3}{|c|}{$0,27-0,34 \mathrm{~m}$} \\
\hline \multicolumn{3}{|c|}{ Porosidade total calculada (\% volume) } \\
\hline 58.5 & 65.6 & 59,2 \\
\hline \multicolumn{3}{|c|}{ Macroporosidade (\% volume) } \\
\hline 22.2 & 29,0 & 23,6 \\
\hline \multicolumn{3}{|c|}{ Microporosidade (\% volume) } \\
\hline 36,3 & 36,6 & 35,6 \\
\hline
\end{tabular}

Através dos dados apresentados acima pode-se notar uma maior similaridade entre os sistemas de cultivo convencional não irrigado e convencional irrigado em termos de porosidade total, macroporosidade e microporosidade, do que a combinação de qualquer um dos dois acima, com o plantio direto irrigado. Tal fato no entanto não pode ser utilizado de forma isolada para interpretar o comportamento das funções $(\operatorname{Kr}(\Theta)),(\operatorname{K}(\theta))$ e $(\operatorname{Dr}(\Theta))$, que serão discutidos em seqüência.

\subsubsection{Condutividade hidráulica relativa $(\operatorname{Kr}(\Theta))$, condutividade hidráulica do solo não saturado $(K(\theta))$ e difusividade relativa $(\operatorname{Dr}(\Theta))$.}

Os valores destas funções estão listados na Tabela 18, juntamente com os correspondentes valores da tensão $\tau$, da umidade volumetrica $(\theta)$ e relativa $(\Theta)$. 
Tabela 18 - Valores da tensão $\tau(\tau=-\phi \mathrm{m}$, onde $-\phi \mathrm{m}=$ potencial mátrico), da umidade volumetrica $(\theta)$ e relativa $(\Theta)$, da condutividade hidráulica relativa $(\operatorname{Kr}(\Theta))$, da condutividade hidráulica do solo não saturado $(\mathrm{K}(\theta))$ e da difusividade relativa $(\operatorname{Dr}(\Theta))$, para a seqüência dos sistemas plantio convencional não irrigado, plantio direto irrigado e convencional irrigado, na profundidade de $0,27-0,34 \mathrm{~m}$.

Plantio Convencional Não Irrigado

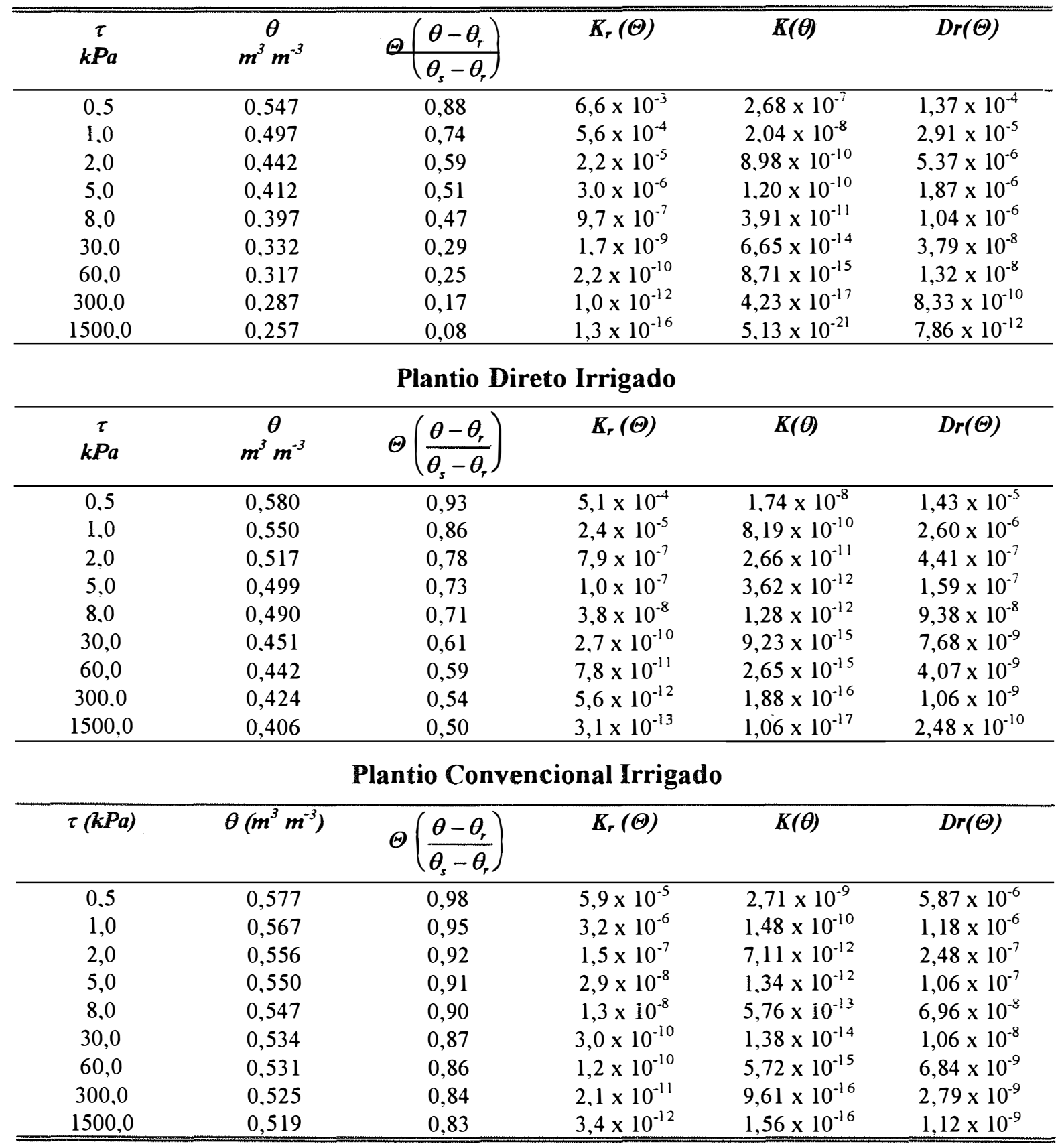


Os dados da Tabela acima mostram os valores mais elevados de $(\operatorname{Kr}(\Theta)),(\operatorname{K}(\theta))$ e $(\operatorname{Dr}(\Theta))$ para o plantio convencional não irrigado, vindo na seqüência o plantio direto irrigado e após o plantio convencional irrigado.

No plantio convencional não irrigado, a ação do implemento mecânico na profundidade em torno de $0,30 \mathrm{~m}$ proporciona as condições para o estabelecimento do fluxo não saturado, de certo modo confinado dentro deste limite de profundidade, ao mesmo tempo que retarda este fluxo nas camadas inferiores, devido à redução no padrão de continuidade dos poros do solo na direção das mesmas. Isto já não ocorre com o plantio direto irrigado, onde a maior continuidade dos poros permite o estabelecimento do fluxo preferencial nas camadas imediatamente seguintes à camada 0,27 - 0,34 m em questão.

No plantio convencional irrigado, embora também ocorra uma certa descontinuidade dos poros provocada pelo implemento mecânico, à semelhança do convencional não irrigado, o processo de irrigação relativamente intenso também induz o aparecimento de um potencial de pressão que por sua vez age no sentido do aumento do fluxo preferencial nas camadas abaixo (como já discutido anteriormente) o que não ocorre com o sistema convencional não irrigado que tem o fluxo mais restrito na profundidade de $0,27-0,34 \mathrm{~m}$, e explica os valores mais elevados nesta posição das funções $(\operatorname{Kr}(\Theta)$, $(K(\theta))$ e $(\operatorname{Dr}(\Theta))$ do sistema plantio convencional não irrigado em relação ao plantio direto irrigado e convencional irrigado.

A seguir, na Tabela 19, estão relacionados os índices (d) de Willmott para a comparação dos valores destas funções entre os diferentes sistemas de cultivo, na profundidade $0,27-0,34 \mathrm{~m}$ 
Tabela 19 - Indices de concordância (d) de Willmott obtidos na comparação dos valores das funções $(\operatorname{Kr}(\Theta),(\operatorname{K}(\theta))$ e $(\operatorname{Dr}(\Theta))$ entre os sistemas plantio convencional não irrigado (PCNI), plantio direto irrigado (PDI) e plantio convencional irrigado (PCI), na profundidade 0,27 - 0,34 m.

\begin{tabular}{cccc}
\hline \multicolumn{4}{c}{$\begin{array}{c}\text { Índices (d) } \text { de Willmott } \\
\mathbf{0 , 2 7}-\mathbf{0 , 3 4} \boldsymbol{m}\end{array}$} \\
\hline Funções & PCNI x PDI & PCNI x PCI & PDI x PCI \\
\hline $\operatorname{Kr}(\Theta)$ & 0,452225 & 0,154400 & 0,219415 \\
$\mathrm{~K}(\theta)$ & 0,398927 & 0,154748 & 0,285518 \\
$\operatorname{Dr}(\Theta)$ & 0,362294 & 0,162912 & 0,622046 \\
\hline \hline
\end{tabular}

Observando os dados acima, pode-se notar para as funções $(\operatorname{Kr}(\Theta))$, $(\mathrm{K}(\theta))$ e $(\operatorname{Dr}(\Theta))$, os mais baixos valores para os índices (d), respectivamente de $0,154400,0,154748$ e 0,162912 para a combinação plantio convencional não irrigado (PCNI) e plantio convencional irrigado (PCI), refletindo a discrepância dos valores das funções acima entre os dois sistemas, e confirmando a observação anterior sobre a atuação do potencial de pressão no sistema convencional irrigado

Para a comparação plantio direto irrigado (PDI) e plantio convencional irrigado (PCI), os índices de Willmott ainda são baixos e indicam que os valores de $(\operatorname{Kr}(\Theta)),(\operatorname{K}(\theta))$ e $(\operatorname{Dr}(\Theta))$ são discrepantes e diferem entre si, porém já são mais elevados em relação ao caso anterior. Nesta situação, o sistema plantio direto irrigado com uma maior número de poros com raio equivalente entre os valores $r_{1}=29,376 \mu \mathrm{m}$ e $r_{2}=1,469$ $\mu \mathrm{m}$, e também com o valor intermediário $\mathrm{r}^{*}=16,320 \mu \mathrm{m}$ correspondente ao máximo valor da função derivada $d \theta / d \tau$, e que significa uma maior freqüência de ocorrência de poros com esse raio equivalente, no intervalo $r_{1}-r_{2}$, tem os valores de $(\operatorname{Kr}(\Theta)),(K(\theta))$ e $(\operatorname{Dr}(\Theta))$ mais elevados com relação aos valores correspondentes destas funções, no sistema convencional irrigado (Tabela 19). Além disso, a continuidade dos poros para o sistema plantio direto irrigado também é maior e concorre para os valores mais elevados das funções hidráulicas nesta situação.

Por outro lado, o par constituido pelo plantio convencional não irrigado (PCNI) e plantio direto irrigado (PDI), apresentou para a comparação dos valores das 
funções $(\operatorname{Kr}(\Theta))$, $(\mathrm{K}(\theta))$ e $(\operatorname{Dr}(\Theta))$, índices (d) de Willmott, respectivamente de 0,452226, 0,398927 e 0,362294, sugerindo também neste caso, a discrepância ou não similaridade dos valores das referidas funções. No entanto estes valores são mais elevados se comparados com os valores obtidos nas combinações anteriores, na mesma profundidade, indicando que embora se tratando de sistemas de cultivo distintos e também de manejo (irrigado e não irrigado), cada qual apresenta individualmente algumas características que concorrem para o aumento relativo do grau de similaridade entre os valores das funções nos dois sistemas de cultivo. Assim, no plantio convencional não irrigado, a aração imprime uma certa descontinuidade de poros interrompendo a conexão na base de ação do implemento que corta e inverte a camada de solo, que é posteriormente homogenizada através da gradagem, com o fluxo de água ocorrendo em grande parte da matriz do solo e principalmente confinado na camada correspondente de $0,27-0,34 \mathrm{~m}$.

Para o plantio direto irrigado, a profundidade de 0,27 - 0,34 m já não é tão influenciada pela ação mecânica, visto que neste caso faz-se o basicamente o sulcamento do solo na linha de plantio. Nesta camada a continuidade dos poros facilita o estabelecimento do fluxo para as camadas inferiores, e como será visto a seguir, os valores da condutividade hidráulica aumentam com a profundidade do solo. No entanto, os valores mais elevados da densidade do solo na camada de 0,00 - 0,07 m do plantio direto dificulta a redistribuição da água para as camadas subjacentes $(0,00$ - 0,14 e 0,27 $0,34 \mathrm{~m}$ ), influenciando a ocorrência de valores mais baixos da condutividade hidráulica nesta posição do perfil de solo.

A Figura 17, a seguir, mostra os valores do $(\ln \operatorname{Kr}(\Theta))$ em função da umidade relativa $(\Theta)$.

Pode-se observar através da mesma, que os valores mais elevados da condutividade hidráulica relativa representados pela relação entre $(\ln \operatorname{Kr}(\Theta))$ versus $(\Theta)$ ocorrem para o plantio convencional não irrigado vindo em seqüência o plantio direto irrigado e após, o plantio convencional irrigado.Este comportamento dos valores das 
funções hidráulicas $(\operatorname{Kr}(\Theta),(\operatorname{K}(\theta))$ e $(\operatorname{Dr}(\Theta))$ já não se manifesta da mesma forma na profundidade de 0,97 - 1,04 m que será discutida em seqüência.

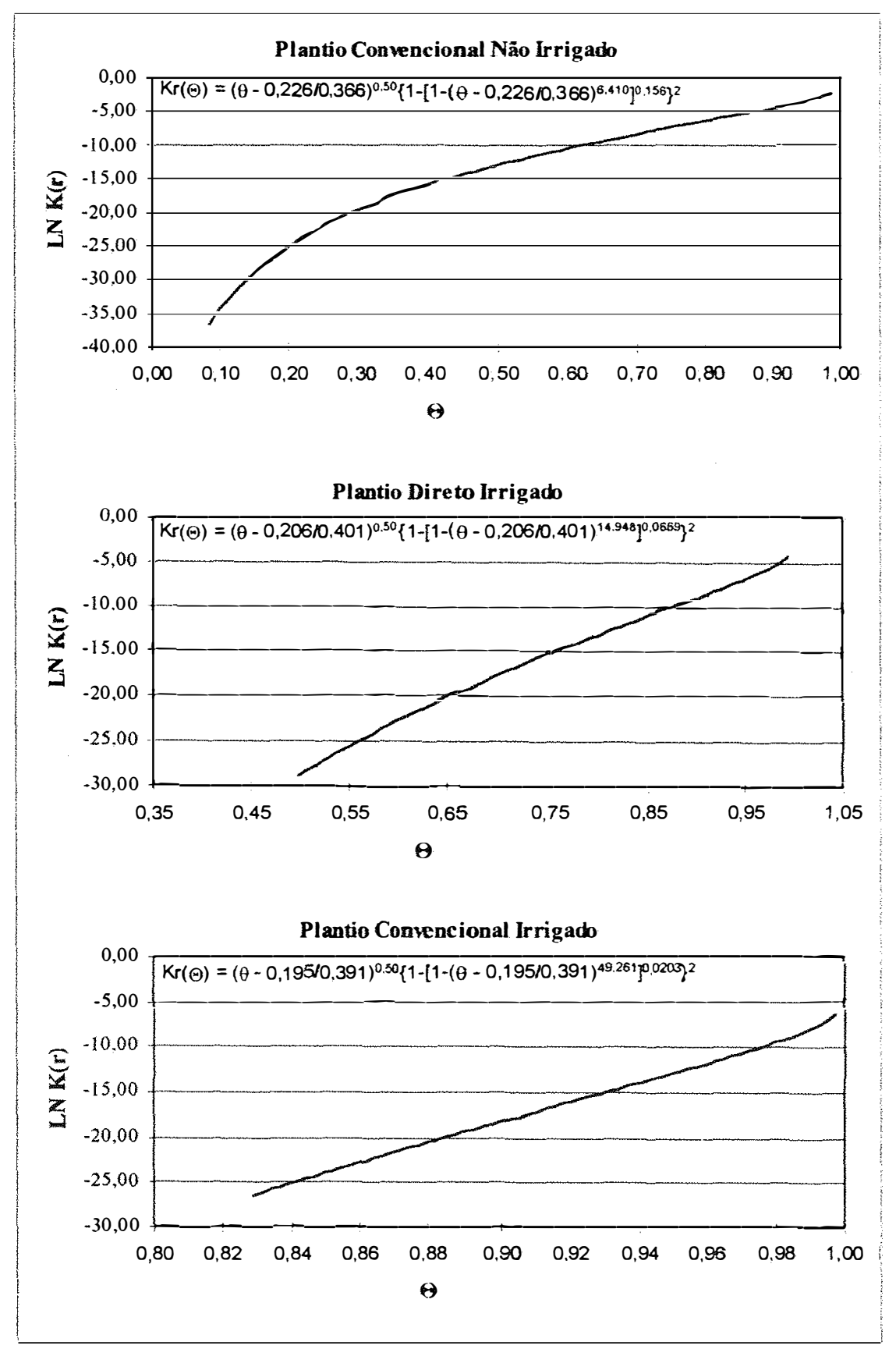

Figura 17 -Relação entre In Krr(@) e a umidade $\theta$ para a seqüencia dos sistemas plantio convencional não irrigado, plantio direto irrigado e convencional irrigado na profundidade 0,27-0,34 $\mathrm{m}$. 


\subsection{Profundidade de 0,97 - 1,04 m}

Devido à sua posição no perfil de solo, esta camada praticamente não sofre a influência da ação dos implementos mecânicos utilizados em qualquer dos três sistemas de cultivo descritos a seguir.

\subsubsection{Sistemas de cultivo plantio convencional não irrigado, plantio direto irrigado e plantio convencional irrigado.}

O estudo comparativo das propriedades fisico-hídricas do solo, entre os sistemas acima, tal como observados para as camadas suprajacentes iniciou-se pela curva de retenção da água no solo $h(\theta)$.

\subsubsection{Curvas de retenção da água no solo}

Na Tabela 20 são apresentados os valores da umidade volumétrica $(\theta)$, correspondentes aos níveis de tensão de 0,$5 ; 1,0 ; 2,0 ; 5,0 ; 8,0 ; 30,0 ; 60,0 ; 300,0$ e $1500,0 \mathrm{kPa}$, e ainda os valores da densidade do solo para os sistemas de cultivo plantio convencional não irrigado, direto irrigado e convencional irrigado (Média de 3 repetiçōes). No Anexo B estes valores são apresentados para cada repetição, juntamente com os paràmetros do ajuste através do método de Genuchten (1980).

Tabela 20 - Valores numéricos das curvas de retenção da água no solo e da densidade para a seqüência dos sistemas plantio convencional não irrigado, direto irrigado $\mathrm{e}$ convencional irrigado na profundidade de 0,97 - $1,04 \mathrm{~m}$ com as médias (3 repetições), desvios padrões e coeficientes de variação.

\begin{tabular}{|c|c|c|c|c|c|c|}
\hline \multicolumn{7}{|c|}{ Plantio Convencional Não Irrigado } \\
\hline \multirow{2}{*}{$\begin{array}{c}\text { Potencial } \\
\text { mátrico }\left(\phi_{m}\right) \\
k P a\end{array}$} & \multicolumn{6}{|c|}{$0,97-1,04 m$} \\
\hline & $\begin{array}{c}\theta \\
m^{3} m^{-3}\end{array}$ & $\begin{array}{l}\text { Desvio } \\
\text { Padrão }\end{array}$ & $\begin{array}{l}\text { Coeficiente } \\
\text { de variação }\end{array}$ & $\begin{array}{c}\text { densidade } \\
\mathrm{kg} \mathrm{m}^{-3}\end{array}$ & $\begin{array}{l}\text { Desvio } \\
\text { Padrão }\end{array}$ & $\begin{array}{l}\text { Coeficiente } \\
\text { de variaf̧ão }\end{array}$ \\
\hline 0.50 & 0.6450 & 0,0283 & 4,38 & 902 & 36,346 & 4,03 \\
\hline 1.00 & 0.6048 & 0,0184 & 3,04 & 889 & 11,015 & 1,24 \\
\hline 2.00 & 0.5646 & 0,0125 & 2,21 & 943 & 9,018 & 0,96 \\
\hline 5.00 & 0.4471 & 0,0161 & 3,60 & 873 & 43,189 & 4,95 \\
\hline 8.00 & 0.3580 & 0,0045 & 1,19 & 873 & 43,189 & 4,95 \\
\hline 30.00 & 0.2895 & 0,0174 & 6,02 & 902 & 36,346 & 4,03 \\
\hline 60.00 & 0,2670 & 0,0111 & 4,16 & 889 & 11,015 & 1,24 \\
\hline 300.00 & 0,2509 & 0,0084 & 3,34 & 943 & 9,018 & 0,96 \\
\hline 1500.00 & 0.2441 & 0.0060 & 2,46 & 873 & 43,189 & 4,95 \\
\hline
\end{tabular}

continua. 
continuaçào.

\begin{tabular}{|c|c|c|c|c|c|c|}
\hline \multicolumn{7}{|c|}{ Plantio Direto Irrigado } \\
\hline \multirow{2}{*}{$\begin{array}{c}\text { Potencial } \\
\left.\text { matrico ( } \phi_{a}\right) \\
k P a\end{array}$} & \multicolumn{6}{|c|}{$0,97-1,04 m$} \\
\hline & $\begin{array}{c}\theta \\
m^{3} m^{-3}\end{array}$ & $\begin{array}{l}\text { Desvio } \\
\text { Padrão }\end{array}$ & $\begin{array}{l}\text { Coeficiente } \\
\text { de variação }\end{array}$ & $\begin{array}{c}\text { densidade } \\
\mathrm{kg} \mathrm{m}^{-3}\end{array}$ & $\begin{array}{l}\text { Desvio } \\
\text { Padrão }\end{array}$ & $\begin{array}{l}\text { Coeficiente } \\
\text { de variação }\end{array}$ \\
\hline 0.50 & 0.6331 & 0,0033 & 0,52 & 898 & 17,58 & 1,96 \\
\hline 1.00 & 0.5983 & 0.0183 & 3.06 & 915 & 16,20 & 1,77 \\
\hline 2.00 & $0.53+5$ & 0.0182 & 3,42 & 910 & 9,074 & 1,00 \\
\hline 5.00 & 0.4295 & 0.0220 & 5.05 & 920 & 42,78 & 4,65 \\
\hline 8.00 & 0.3697 & 0.0130 & 3.51 & 920 & 42,78 & 4,65 \\
\hline 30.00 & 0.3258 & 0,0064 & 1,98 & 898 & 17,58 & 1,96 \\
\hline 60.00 & 0.2964 & 0.0124 & 4,19 & 915 & 16,20 & 1,77 \\
\hline 300.00 & 0.2657 & 0.0082 & 3,10 & 910 & 9,074 & 1,00 \\
\hline 1500.00 & $0.2+50$ & 0.0100 & 4.08 & 920 & 42.78 & 4,65 \\
\hline \multicolumn{7}{|c|}{ Plantio Convencional Irrigado } \\
\hline Potencial & \multicolumn{6}{|c|}{$0,97-1,04 \mathrm{~m}$} \\
\hline$\underset{k P a}{\operatorname{matrico}\left(\phi_{m}\right)}$ & $\begin{array}{c}\theta \\
m^{2} m^{-3}\end{array}$ & $\begin{array}{l}\text { Desvio } \\
\text { Padrão }\end{array}$ & $\begin{array}{l}\text { Coeficiente } \\
\text { de variação }\end{array}$ & $\begin{array}{c}\text { densidade } \\
\mathrm{kg} \mathrm{m}^{-3}\end{array}$ & $\begin{array}{l}\text { Desvio } \\
\text { Padrão }\end{array}$ & $\begin{array}{l}\text { Coeficiente } \\
\text { de variação }\end{array}$ \\
\hline 0.50 & 0.6192 & 0.0117 & 1,89 & 877 & 29,82 & 3,40 \\
\hline 1.00 & 0.5677 & 0.0154 & 2,71 & 918 & 53,80 & 5,86 \\
\hline 2.00 & 0.5152 & 0.0270 & 5,24 & 903 & 53,26 & 5,90 \\
\hline 5.00 & 0.4272 & 0.0222 & 5,20 & 942 & 13,61 & 1,44 \\
\hline 8.00 & 0.3555 & 0.0240 & 6,66 & 942 & 13,61 & 1,44 \\
\hline 30.00 & 0.3076 & 0.0178 & 5,80 & 877 & 29,82 & 3,40 \\
\hline 60.00 & 0.2770 & 0.0176 & 6.34 & 918 & 53,80 & 5.86 \\
\hline$\$ 00.00$ & $0.2+78$ & 0.0105 & 4,25 & 903 & 53.26 & 5.90 \\
\hline 1500.00 & 0.2376 & 0.0155 & 6.54 & 942 & 13.61 & 1.44 \\
\hline
\end{tabular}

Os valores das funções $(h(\theta))$ para os três sistemas de cultivo são muito semelhantes, o que também pode ser notado através da Figura 18, onde os mesmos são apresentados na forma de gráficos. $O$ índice (d) de Willmott que mede o grau de similaridade, quando da comparação destes valores entre os diferentes sistemas de cultivo è apresentado na Tabela 21.

Tabela 21 - Índice de concordância (d) de Willmott obtidos na comparação da função $h(\theta)$ entre os sistemas convencional não irrigado (PCNI), direto irrigado (PDI) e convencional irrigado (PCI), na profundidade de 0,97 - 1,04m.

\begin{tabular}{ll|l}
\hline \multicolumn{3}{c}{ Indices de Willmott (d) para comparação dos valores da função $(\boldsymbol{h}(\theta))$} \\
$\mathbf{0 , 9 7 - 1 , 0 4 m}$ \\
\hline \\
PCNI & Comparações & \\
PCNI & PDI & 0,964098 \\
PDI & PCI & 0,917340 \\
\hline \hline
\end{tabular}


Os índices de Willmott (d) indicam uma forte semelhança para os valores da função $(h(\theta))$ entre as diferentes combinações dos sistemas de cultivo. Tal similaridade também é observada através da relação entre a função $d \theta / d \tau \times \tau$ que representa a distribuição do tamanho de poros do solo nos diferentes sistemas, a ser discutida a seguir.
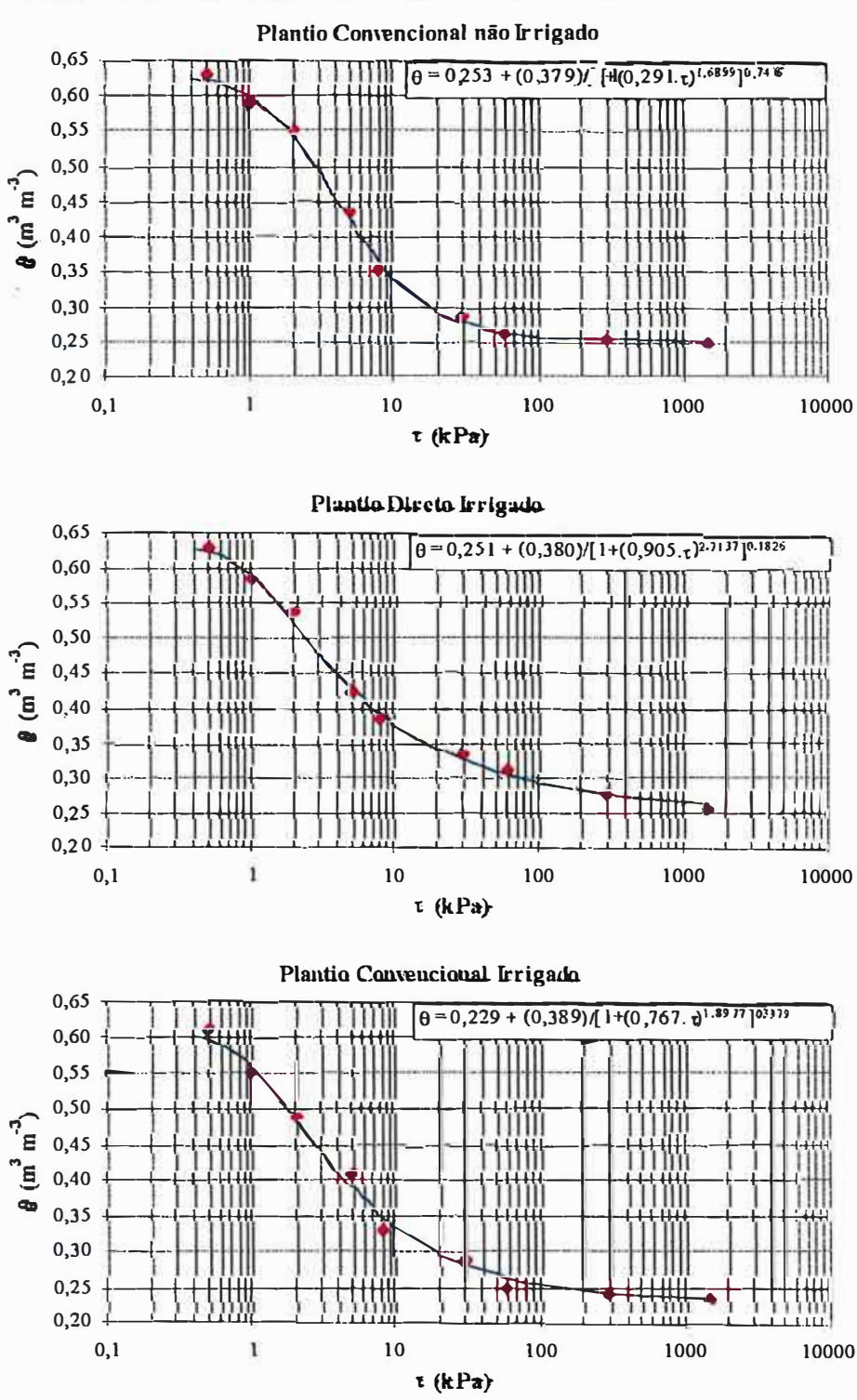

Figura 18 -Curvas de retenção da água de Latossolo Roxo, para os sistemas de cultivo plantio convencional não irrigado, plantio direto irrigado e convencional irrigado, na profundidade de 0,97-1,04 m. 


\subsubsection{Análise da distribuição do tamanho de poros através da curva de retenção da água no solo}

A Figura 19 representa os valores da relação $d \theta / d \tau \times \tau$, para a ordem estabelecida dos sistemas de cultivo plantio convencional não irrigado, plantio direto irrigado e plantio convencional irrigado.
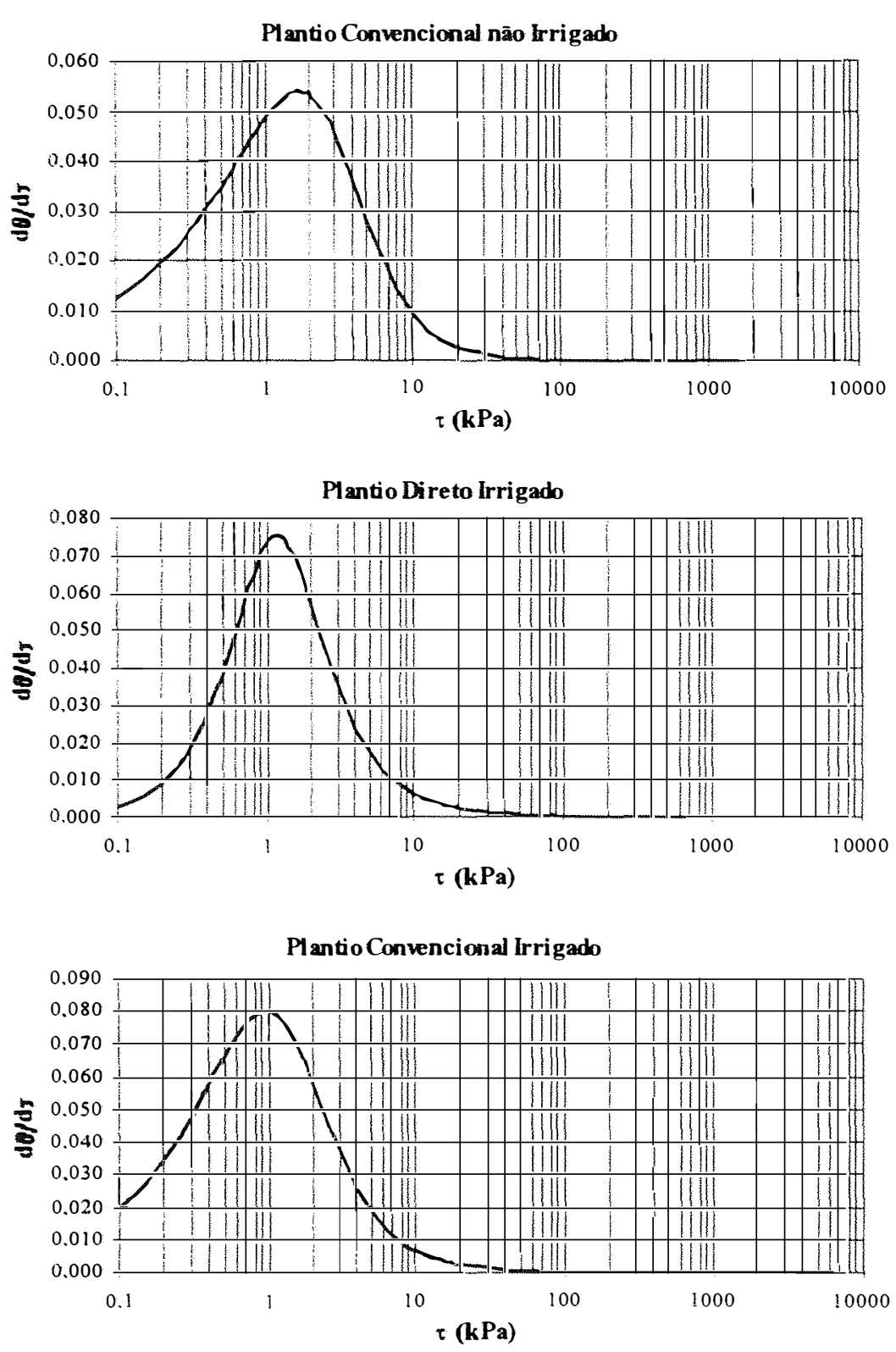

Figura 19 -Distribuição do tamanho de poros do Latossolo Roxo, nos sistemas plantio convencional não irrigado, plantio direto irrigado e plantio convencional irrigado, na profundidade de 0,97 - 1,04 m. 
Tendo em vista a equação de Kelvin (pág. 30) e assumindo $\tau_{1}=0,5 \mathrm{kPa}$, todos os poros de raio equivalente $r_{1}>29,376 \mu \mathrm{m}$ serão esvaziados, e quando se aplica a tensão $\tau_{2}=10 \mathrm{kPa}$, todos os poros de raio $r_{2}>1,469 \mu \mathrm{m}$ serão esvaziados. $O$ incremento de tensão de $\tau_{1}$ para $\tau_{2}$ faz com que sejam esvaziados todos os poros de raio menor que $r_{1}$ e maior que $r_{2}\left(r_{2}<r_{1}\right)$. Nestas condições, o volume de água liberado do solo é estimado pela diferença da umidade volumétrica $(\theta)$ nestas duas tensōes, sendo a mesma igual ao volume de poros do solo de raio menor que $r_{1}=$ $29.376 \mu \mathrm{m}$ e maior que $r_{2}=1,469 \mu \mathrm{m}$.

Para o plantio convencional não irrigado (PCNI), $\Delta \theta_{(\mathrm{PCN})}=0,6215$ $0.3409=0.281 \mathrm{~m}^{3} \mathrm{~m}^{-3}$, sendo que no plantio direto irrigado, $\Delta \theta_{(\mathrm{PDI})}=0,6234-0,3785=$ $0.245 \mathrm{~m}^{3} \mathrm{~m}^{-3}$, e para o plantio convencional irrigado, $\Delta \theta_{(\mathrm{PCI})}=0,5987-0,3336=$ $0,265 \mathrm{~m}^{3} \mathrm{~m}^{-3}=$ Deste modo tem-se que $\Delta \theta_{(\mathrm{PCN})}=0,281 \mathrm{~m}^{3} \mathrm{~m}^{-3}>\Delta \theta_{(\mathrm{PCl})}=0,265 \mathrm{~m}^{3} \mathrm{~m}^{-3}>$ $\Delta \theta_{(\mathrm{PDn}}=0,245 \mathrm{~m}^{3} \mathrm{~m}^{-3}$, porém a proximidade destes valores já se constitui num primeiro indicativo da maior uniformidade da camada 0,97 - 1,04 m, seja devido à menor mobilização pelos implementos mecânicos, como também pela predominância de uma estrutura do tipo granular, mais eficiente para o fluxo de água, em relação à de blocos subangulares, nesta situação.

$\mathrm{Na}$ Tabela 22 a seguir estão relacionados pela ordem descrita dos sistemas de cultivo, os valores máximos da função $\mathrm{d} \theta / \mathrm{d} \tau$, com os correspondentes valores da tensão $\tau^{*}$, do raio equivalente $r^{*}$, da umidade volumétrica $\theta^{*}$ e também dos valores da condutividade hidráulica do solo saturado $K_{0}$, na profundidade 0,97 - 1,04 m.

Tabela 22 - Valores máximos da derivada $\mathrm{d} \theta / \mathrm{d} \tau$, com os correspondentes valores da tensão $\tau^{*}$, do raio equivalente $r^{*}$, da umidade $\theta^{*}$ e os valores da condutividade hidráulica do solo saturado $\left(\mathrm{K}_{\mathrm{o}}\right)$, na profundidade de 0,97 - 1,04 m.

\begin{tabular}{lcrrrr}
\hline \hline \multicolumn{1}{c}{ Sistema de cultivo } & $\boldsymbol{\tau}$ & $\boldsymbol{r}$ & $\boldsymbol{\theta}^{*}$ & $\boldsymbol{d} \boldsymbol{\theta} \boldsymbol{d} \boldsymbol{d} \tau$ & $\boldsymbol{K}_{O}$ \\
\hline Plantio Convencionai Não Irrigado & 1,7 & 8,640 & 0,5638 & $5,38 \times 10^{-2}$ & $1,06 \times 10^{-4}$ \\
Plantio Direto Irrigado & 1,2 & 12,240 & 0,5787 & $7,52 \times 10^{-2}$ & $8,11 \times 10^{-5}$ \\
Plantio Convencional Irrigado & 1,0 & 14.688 & 0,5606 & $8,01 \times 10^{-2}$ & $8,06 \times 10^{-5}$ \\
\hline \hline
\end{tabular}


Através do Quadro 1 (pág. 32) constata-se que os valores dos raios equivalentes $r^{*}$ relativos aos três sistemas de cultivo estão no intervalo considerado dos mesoporos/ macroporos. Assim, quando se considera a tensão $\tau^{*}$ correspondente ao máximo valor da derivada $\mathrm{d} \theta / \mathrm{d} \tau$ para cada sistema, observa-se que os poros com raio equivalente $r^{*}=8.640 \mu \mathrm{m}, r^{*}=12,240 \mu \mathrm{m}$ e $r^{*}=14,688 \mu \mathrm{m}$ são os que ocorrem em maior número, respectivamente para os sistemas convencional não irrigado, plantio direto irrigado e plantio convencional irrigado. Devido à maior homogeneidade apresentada, esta camada pode ser tomada como índice na comparação dos valores de $\mathrm{r}^{*}$ nela expressos. com os correspondentes valores de $r^{*}$ das camadas suprajacentes, levando-se em consideração os diferentes sistemas de cultivo. Isto é possivel porque a "camada Indice" praticamente não sofre influencia do trabalho das máquinas e implementos, tanto como as camadas superiores.

Assim por exemplo,. a camada de 0,97 - 1,04 m (camada indice) tem para o plantio convencional irrigado um valor do raio equivalente $r^{*}=14,688 \mu \mathrm{m}$, que quando comparado ao valor de $\mathrm{r}^{*}=20,983 \mu \mathrm{m}$ do sistema convencional irrigado na camada de 0,27 - 0,34 m (Tabela 16) sugere que pelo menos uma parte dos poros que compõem a ocorrência mais frequente dos poros nesta ultima foram produzidos pela ação dos implementos mecânicos. O contrário também pode ocorrer, ou seja, atravès da ação do implemento, pode se iniciar um processo de adensamento do solo, influindo então na distribuição do tamanho de poros. Isto possivelmente explica os valores de $\mathrm{r}^{*}=9,180 \mu \mathrm{m}$ do plantio convencional irrigado (camada 0,07 - 0,14 m) (Tabela 10) mais baixos em relação ao valor de $r^{*}=20,983 \mu \mathrm{m}$ da camada 0,97 - 1,04 m. Para reforçar estas afirmaçōes, também pode-se observar no plantio direto irrigado, a semelhança dos valores de $r^{*}=16,320 \mu \mathrm{m}$ (camadas $0,07-0,14 \mathrm{~m}$ e 0,27-0,34 $\mathrm{m}$ ) com o valor de $\mathrm{r}^{*}=$ 14,688 da camada 0.97 - 1,04 m. Esta constância dos valores são o resultado da pouca influencia do trabalho das máquinas, que neste caso agem principalmente em superficie, o que é confirmado pelo valor de $\mathrm{r}^{*}=6,528 \mu \mathrm{m}$ mais baixo da camada $0,00-0,07 \mathrm{~m}$ 
indicando provavelmente o efeito da compactação detectado nesta posição, quando comparado com os outros valores de $r^{*}$ das camadas subjacentes descritos acima.

A homogeneidade da camada 0,97 - 1,04 m também é confirmada pela Tabela 23. onde são apresentados os valores da porosidade total, da macroporosidade e microporosidade. para a seqüência dos sistemas plantio convencional não irrigado, plantio direto irrigado e plantio convencional irrigado.

Tabela 23 - Valores da porosidade total, da macroporosidade e da microporosidade calculados para a seqüência dos sistemas de cultivo plantio convencional não irrigado, plantio direto irrigado e plantio convencional irrigado, na profundidade de $0.97-1,04 \mathrm{~m}$.

\begin{tabular}{|c|c|c|}
\hline Plantio Convenc. Não Irrigado. & Plantio Direto Irrigado & Plantio Convenc. Irrigado \\
\hline \multicolumn{3}{|c|}{$0,97-1,04 \mathrm{~m}$} \\
\hline \multicolumn{3}{|c|}{ Porosidade total calculada (\% volume) } \\
\hline 63.2 & 63.1 & 61.8 \\
\hline \multicolumn{3}{|c|}{ Macroporosidade (\% volume) } \\
\hline 29.1 & 25.3 & 28,4 \\
\hline \multicolumn{3}{|c|}{ Microporosidade (\% volume) } \\
\hline $3+1.1$ & 37.9 & 33.4 \\
\hline
\end{tabular}

Deste modo, para os diferentes sistemas de cultivos, a similaridade dos valores da porosidade total, da macroporosidade e microporosidade da camada 0,97 $1.04 \mathrm{~m}$ e um indicativo consistente de que nestas condições, outras propriedades do solo como por exemplo as funções hidráulicas temham um comportamento tal que não apresentam grandes variações dos valores entre os sistemas considerados. Assim, os valores da condutividade hidráulica do solo saturado $\left(\mathrm{K}_{\mathrm{o}}\right)$ (Tabela 22) não diferem significativamente entre si, quando comparados para os três sistemas de cultivo estudados. Além disso é necessário verificar também o comportamento das funções condutividade hidráulica relativa $(\operatorname{Kr}(\Theta))$, condutividade hidráulica do solo não saturado $(K(\theta))$ e da difusividade relativa $(\operatorname{Dr}(\Theta))$, o que é feito a seguir. 


\subsubsection{Condutividade hidráulica relativa $(\operatorname{Kr}(\Theta))$, condutividade hidráulica do solo não saturado $(K(\theta))$ e difusividade relativa $(\operatorname{Dr}(\Theta))$.}

A Tabela 24 mostra os valores destas funções para diferentes valores de tensão $\tau$

Tabela 24 - Valores da tensão $\tau(\tau=-\phi \mathrm{m}$, onde $-\phi \mathrm{m}=$ potencial mátrico), da umidade volumetrica $(\theta)$ e relativa $(\Theta)$, da condutividade hidráulica $(\operatorname{Kr}(\Theta))$, da condutividade hidráulica do solo não saturado $(K(\theta))$ e da difusividade relativa $(\operatorname{Dr}(\Theta))$, para a sequência dos sistemas plantio convencional não irrigado, plantio direto irrigado e convencional irrigado, na profundidade de $0,97-1,04 \mathrm{~m}$

Plantio Convencional Não Irrigado

\begin{tabular}{|c|c|c|c|c|c|c|}
\hline $\begin{array}{c}\tau \\
k P a\end{array}$ & $\begin{array}{c}\theta \\
m^{3} m^{-3}\end{array}$ & $\Theta$ & $\left.\frac{\theta-\theta_{r}}{\theta_{s}-\theta_{r}}\right)$ & $K_{r}(\Theta)$ & $K(\theta)$ & $\operatorname{Dr}(\Theta)$ \\
\hline 0.5 & 0.601 & & 0.89 & $3.6 \times 10^{-1}$ & $3,86 \times 10^{-5}$ & $2,11 \times 10^{-3}$ \\
\hline 1.0 & 0.551 & & 0,76 & $1,6 \times 10^{-1}$ & $1,73 \times 10^{-5}$ & $8,26 \times 10^{-4}$ \\
\hline 2.0 & 0.496 & & 0,62 & $6,4 \times 10^{-2}$ & $6,85 \times 10^{-6}$ & $3,68 \times 10^{-4}$ \\
\hline 5.0 & 0.466 & & 0,55 & $3.6 \times 10^{-2}$ & $3,90 \times 10^{-6}$ & $2,41 \times 10^{-4}$ \\
\hline 8.0 & 0.451 & & 0,51 & $2,7 \times 10^{-2}$ & $2,87 \times 10^{-6}$ & $1,94 \times 10^{-4}$ \\
\hline 30.0 & 0.386 & & 0,35 & $5,4 \times 10^{-3}$ & $5,79 \times 10^{-7}$ & $6,77 \times 10^{-5}$ \\
\hline 60.0 & 0.371 & & 0,31 & $3,4 \times 10^{-3}$ & $3,63 \times 10^{-7}$ & $5,07 \times 10^{-5}$ \\
\hline 300.0 & 0.341 & & 0.24 & $1,1 \times 10^{-3}$ & $1,18 \times 10^{-7}$ & $2.58 \times 10^{-5}$ \\
\hline 1500.0 & 0.311 & & 0.16 & $2.4 \times 10^{-4}$ & $2,51 \times 10^{-8}$ & $1,05 \times 10^{-5}$ \\
\hline \multicolumn{7}{|c|}{ Plantio Direto Irrigado } \\
\hline $\begin{array}{c}\tau \\
k P a\end{array}$ & $\begin{array}{c}\theta \\
m^{3} m^{-3}\end{array}$ & $\Theta$ & $\frac{\theta-\theta_{r}}{\theta_{s}-\theta_{r}}$ & $\overline{K_{r}(\Theta)}$ & $\bar{K}(\theta)$ & $\overline{D r}(\Theta)$ \\
\hline 0.5 & 0.598 & & 0,91 & $2.4 \times 10^{-2}$ & $2,00 \times 10^{-6}$ & $5,18 \times 10^{-4}$ \\
\hline 1.0 & 0.558 & & 0,81 & $4,6 \times 10^{-3}$ & $3,69 \times 10^{-7}$ & $1,60 \times 10^{-4}$ \\
\hline 2.0 & 0.514 & & 0,69 & $7,3 \times 10^{-4}$ & $5,92 \times 10^{-8}$ & $5,45 \times 10^{-5}$ \\
\hline 5.0 & 0.490 & & 0,63 & $2.5 \times 10^{-4}$ & $2,03 \times 10^{-8}$ & $3,01 \times 10^{-5}$ \\
\hline 8.0 & 0,478 & & 0,60 & $1,4 \times 10^{-4}$ & $1,15 \times 10^{-8}$ & $2,21 \times 10^{-5}$ \\
\hline 30.0 & 0.426 & & 0,47 & $8,7 \times 10^{-6}$ & $7,06 \times 10^{-10}$ & $4,97 \times 10^{-6}$ \\
\hline 60.0 & 0,414 & & 0,44 & $4,1 \times 10^{-6}$ & $3,33 \times 10^{-10}$ & $3,35 \times 10^{-6}$ \\
\hline 300.0 & 0.390 & & 0,38 & $7,7 \times 10^{-7}$ & $6,28 \times 10^{-11}$ & $1.39 \times 10^{-6}$ \\
\hline 1500.0 & 0.366 & & 0,31 & $1,1 \times 10^{-7}$ & $8,82 \times 10^{-12}$ & $4,98 \times 10^{-7}$ \\
\hline
\end{tabular}

continua. 
continuaçào.

\begin{tabular}{cccccc}
\hline \hline \multicolumn{5}{c}{ Plantio Convencional Irrigado } \\
\hline $\boldsymbol{r}+\boldsymbol{P a}$ & $\begin{array}{c}\boldsymbol{\theta} \\
\boldsymbol{m}^{3} \boldsymbol{m}^{-3}\end{array}$ & $\Theta\left(\frac{\theta-\theta_{r}}{\theta_{s}-\theta_{r}}\right)$ & $\boldsymbol{K}_{\boldsymbol{r}}(\Theta)$ & $\boldsymbol{K}(\boldsymbol{\theta})$ & $D_{\boldsymbol{r}(\Theta)}$ \\
\hline 0.5 & 0.577 & 0,89 & $5.40 \times 10^{-2}$ & $4,36 \times 10^{-6}$ & $8,08 \times 10^{-4}$ \\
1.0 & 0.527 & 0.76 & $1.12 \times 10^{-2}$ & $9.00 \times 10^{-7}$ & $2,54 \times 10^{-4}$ \\
2.0 & 0.472 & 0.62 & $1,8 \times 10^{-3}$ & $1,75 \times 10^{-7}$ & $9,32 \times 10^{-5}$ \\
5.0 & 0.442 & 0.54 & $6.0 \times 10^{-4}$ & $5.06 \times 10^{-8}$ & $4,51 \times 10^{-5}$ \\
8.0 & 0.427 & 0,51 & $3,0 \times 10^{-4}$ & $2,79 \times 10^{-8}$ & $3,23 \times 10^{-5}$ \\
30.0 & 0.362 & 0.34 & $1.4 \times 10^{-5}$ & $1,16 \times 10^{-9}$ & $5,74 \times 10^{-6}$ \\
60.0 & 0.347 & 0.30 & $5,6 \times 10^{-6}$ & $4,53 \times 10^{-10}$ & $3,46 \times 10^{-6}$ \\
300.0 & 0.317 & 0.23 & $5.6 \times 10^{-7}$ & $4,52 \times 10^{-11}$ & $1,01 \times 10^{-6}$ \\
1500.0 & 0.287 & 0.15 & $2.2 \times 10^{-8}$ & $1.74 \times 10^{-12}$ & $1,79 \times 10^{-7}$ \\
\hline
\end{tabular}

Para os très sistemas considerados, os valores destas funções são muito semelhantes, o que vem a diferenciar em termos de transmissão de água, a camada de 0.97 - $1.04 \mathrm{~m}$. daquelas suprajacentes onde estes valores foram discrepantes para os distintos sistemas de cultivo. Deste modo, a Tabela 25 abaixo mostra os valores do índice (d) de Willmott para a comparação dos valores das referidas funções nos diferentes sistemas de cultivo.

Tabela 25 - Indices de concordância (d) de Willmott (d) obtidos na comparação dos valores das funções $(\operatorname{Kr}(\Theta),(K(\theta))$ e $(\operatorname{Dr}(\Theta))$ entre os sistemas plantio convencional não irrigado (PCNI), plantio direto irrigado (PDI) e plantio convencional irrigado (PCI), na profundidade 0,97 - 1,04 m.

\begin{tabular}{cccc}
\hline \hline & $\begin{array}{c}\text { Índices (d) de Willmott } \\
\mathbf{0 , 9 7 - 1 , 0 4} \boldsymbol{~}\end{array}$ & \\
\hline Funções & PCNI x PDI & PCNI x PCI & PDI x PCI \\
\hline $\mathrm{K}(\Theta)$ & 0.729207 & 0,874494 & 0,954218 \\
$\mathrm{~K}(\theta)$ & 0,637815 & 0,791282 & 0,955477 \\
$\mathrm{D} r(\Theta)$ & 0.664723 & 0,809854 & 0,960296 \\
\hline \hline
\end{tabular}

Analisando os resultados acima, pode-se observar valores do índice (d) próximos da unidade, na comparação PDI e PCI, indicando neste caso grande similaridade nos valores das funções $(\operatorname{Kr}(\Theta))$, $(\mathrm{K}(\theta))$ e $(\operatorname{Dr}(\Theta))$. Na seqüência, com valores do índice (d) intermediários, mas ainda elevados, está a comparação dos sistemas PCNI e PCI, sendo os mais baixos índices (d) verificados na comparação PCNI e PDI, e denotando nestas condições uma certa discrepância nos valores das funções hidráulicas. Mesmo assim, estes indices são mais elevados em relação aos correspondentes para a 
mesma comparação nas camadas de 0,07 - 0,14 m e 0,27 - 0,34 m suprajacentes, e que por essa razão ainda imprimem um maior grau relativo de similaridade dos valores das funções $(\operatorname{Kr}(\Theta)),) \mathrm{K}(\theta))$ e $(\operatorname{Dr}(\Theta))$ da comparação PCNI e PDI, na profundidade 0,97 $1,04 \mathrm{~m}$, em relação às duas anteriores.

Outro fato a ser observado é de que os índices (d) de Willmott mais elevados foram obtidos quando da comparação entre dois sistemas de cultivo sob regime de irrigação ou seja, PDI e PCI, do que quando se comparou entre si sistemas irrigados e não irrigados (PCNI e PCI, PCNI e PDI). Isto é corroborado pelas observações de Gjettermann et al. (1997) conforme visto anteriormente, de que para intensidades mais elevadas de irrigação inicia-se o processo de estabelecimento de um potencial de pressão na camada superficial do solo, o que favorece o fluxo preferencial através de um número relativamente alto de macroporos no sub-solo, aumentando desta forma os valores das funçōes condutividade hidráulica. A Figura 20 seguinte mostra a relação entre $(\ln \operatorname{Kr}(\Theta)$ versus $(\Theta))$ para cada sistema em particular.

Através da mesma nota-se que as maiores diferenças ocorrem quando se comparam as curvas $\ln \operatorname{Kr}(\Theta) \times(\Theta)$, do plantio convencional não irrigado, com aquelas do plantio direto irrigado. Para esta camada observou-se também uma tendência do aumento dos valores das funções $(\operatorname{Kr}(\Theta))$, $(\operatorname{K}(\theta))$ e $(\operatorname{Dr}(\Theta))$, quando comparadas com os respectivos valores dessas funções na camada de 0,27 - 0,34 m.

Resultados semelhantes foram obtidos por Reichardt \& Libardi (1974) em um solo Terra Roxa Estruturada Latossólica no qual, os valores da condutividade hidráulica do solo não saturado aumentaram com a profundidade do solo, sendo os valores de $(\mathrm{K}(\theta))$ mais baixos observados na camada $0,00-0,45 \mathrm{~m}$; valores de $(\mathrm{K}(\theta))$ intermediários na camada de 0,45 - 0,75 m, e os valores mais elevados a uma profundidade superior ao limite de $0,75 \mathrm{~m}$

Este aumento de $(K(\theta))$ em profundidade no perfil de solo reflete de certa maneira a influência das operações de preparo do solo, que reduz em superficie os 
os valores da condutividade hidráulica, através de modificações na estrutura e na porosidade do solo

Roth et al. (1988) estudando o efeito de diferentes sistemas de cultivo em algumas propriedades físicas de um latossolo, entre elas a condutividade hidráulica do solo não saturado obtiveram valores mais elevados desta função na profundidade em torno de $0,80 \mathrm{~m}$, quando comparado com as camadas superficiais mais suscetíveis à alterações pelo cultivo.

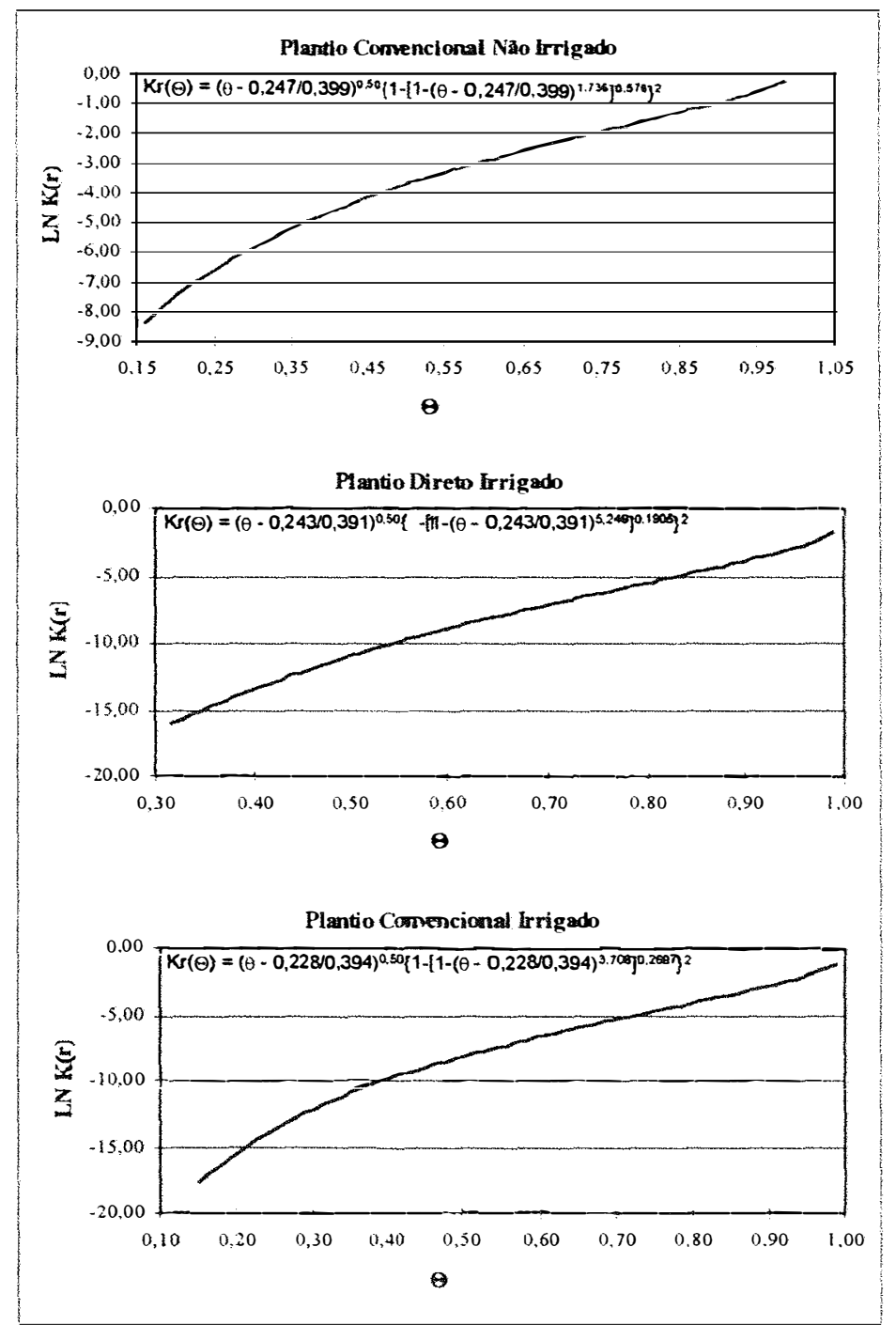

Figura 20 -Relação entre ln $\mathrm{Kr}(\Theta)$ e a umidade $\theta$ para a seqüência dos sistemas plantio convencional não irrigado, plantio direto irrigado e convencional irrigado na profundidade 0,97 - 1,04 $\mathrm{m}$. 


\section{CONCLUSÕES}

Os resultados obtidos para as propriedades de retenção e de transmissão da agua de um Latossolo Roxo Distrófico sob os sistmas de cultivo plantio convencional não irrigado (PCNI), plantio direto irrigado (PDI) e plantio convencional irrigado (PCI) conduziram às seguintes conclusões:

- Em termos de retenção da água no solo,os valores da função $h=h(\theta)$ não diferiram significativamente entre si para os três sistemas de cultivo, quando se comparou entre os mesmos. as camadas de $0.00-0,07 \mathrm{~m}$, o mesmo ocorrendo com as camadas de 0,07 $-0.14 \mathrm{~m}$, de $0.27-0.34 \mathrm{~m}$ e de $0,97-1,04 \mathrm{~m}$

- Na camada de 0,00 - 0,07 m, o plantio direto irrigado (PDI) devido à maior densidade do solo apresentou em relação ao plantio convencional irrigado (PCI), valores mais baixos da porosidade total e macroporosidade, e mais elevados da microporosidade, o que resultou para o plantio direto irrigado valores também mais baixos da condutividade hidráulica do solo saturado $\left(\mathrm{K}_{\mathrm{o}}\right)$, e também das funções condutividade hidráulica relativa $(\operatorname{Kr}(\Theta))$, condutividade hidráulica do solo não saturado $(K(\theta))$ e da difusividade relativa $(\operatorname{Dr}(\Theta))$.

- Para a camada de 0,07 - 0,14 m, os valores da condutividade hidráulica saturada $\left(\mathrm{K}_{\mathrm{o}}\right)$ não diferiram entre si para os sistemas plantio convencional não irrigado ( $\mathrm{PCNI}$ ), plantio direto irrigado (PDI) e plantio convencional irrigado (PCI). No entanto, as maiores discrepâncias dos valores das funções $(\operatorname{Kr}(\Theta)),(K(\theta))$ e $(\operatorname{Dr}(\Theta))$ foram observadas na comparação entre os sistemas plantio direto irrigado (PDI) (valores mais baixos) e plantio convencional irrigado (PCI) (valores mais altos). Neste caso, o valor mais elevado da densidade do solo do plantio direto irrigado, na camada de 0,00 - 
$0,07 \mathrm{~m}$ dificultou o processo de redistribuição da água para a camada de 0,07 - 0,14 m deste sistema o que ocasionou para a mesma um decréscimo dos valores daquelas funçōes hidráulicas.

- Na camada de 0,27 - 0,34 m ocorreram discrepâncias nos valores das funções $(\operatorname{Kr}(\Theta))$, $(\mathrm{K}(\theta))$ e $(\operatorname{Dr}(\theta))$ para todas as comparações dos sistemas de cultivo ou seja: plantio convencional não irrigado (PCNI) (valores mais altos) e plantio direto irrigado (PDI) (valores mais baixos)); plantio convencional não irrigado (PCNI) (valores mais elevados) e plantio convencional irrigado (PCI) (valores mais baixos); plantio direto irrigado (PDI)) (valores mais altos) e plantio convencional irrigado (PCI) (valores mais baixos), indicando ser esta a camada do solo mais suscetível às alteraçōes impostas pelos implementos mecànicos.

- Para a camada de 0,97 - 1,04 m as discrepâncias observadas nos valores das funções $(\operatorname{Kr}(\Theta)),(\operatorname{K} \theta))$ e $(\operatorname{Dr}(\Theta))$ quando da comparação entre os diferentes sistemas de cultivo diminuiram acentuadamente sugerindo uma maior uniformidade desta camada com relação à distribuição e arranjo dos poros, e por conseguinte no comportamento das funçōes hidráulicas, $(\operatorname{Kr}(\Theta))$, $(\operatorname{K}(\theta))$ e $(\operatorname{Dr}(\Theta))$ que apresentaram valores crescentes com a profundidade do solo, onde $(\operatorname{Kr}(\Theta)),(\operatorname{K}(\theta))$ e $(\operatorname{Dr}(\Theta))_{(0.97-1.04 m)}>(\operatorname{Kr}(\Theta))$, $(\mathrm{K}(\theta))$ e $(\operatorname{Dr}(\Theta))(0.27-0.34 \mathrm{~m}))>(\operatorname{Kr}(\Theta)),(\mathrm{K}(\theta))$ e $(\operatorname{Dr}(\Theta))_{(0,07-0.14 \mathrm{~m})}$, confirmando a maior homogeneidade da camada $0,97-1,04 \mathrm{~m}$.

Finalizando, a hipótese do trabalho foi comprovada, uma vez que, as funçōes de retenção e transmissão da água de um perfil de Latossolo Roxo, não sofreram influências no sistema de cultivo adotado, quando a profundidade da camada de estudo foi superior a $0,97 \mathrm{~m}$. 
Anexo A 
Descrição morfológica e características fisicas e químicas dos perfis de Latossolo Roxo Distrofico sob os sistemas de cultivo plantio convencional não irrigado (PCNI), plantio direto irrigado (PDI) e plantio convencional irrigado (PCI) - Região de Guaira, Fazenda Cachoeirinha - SP.

\section{Perfil 2 - plantio convencional não irrigado}

Ap $\quad 0,00-0,30 \mathrm{~m}$ bruno avermelhado escuro (2,5 YR 2/4 úmido); argila; moderada pequena blocos subangulares que se desfaz a granular; ligeiramente duro friável, ligeiramente plástico e pegajoso transição gradual e plana; raizes muitas; muitos poros pequenos.

BA $\quad 0.30-0.70 \mathrm{~m}$ bruno avermelhado escuro (2,5 YR 3/4 úmido); argila moderada pequena a média blocos subangulares que se desfaz a granular; ligeiramente duro, friável, ligeiramente plástico e pegajoso transição gradual e plana; raízes muitas, muitos poros.

BW1 0.70 - 1,20 m bruno avermelhado escuro a bruno escuro (2,5 YR 3/5 úmido); argila: moderada a média blocos subangulares que se desfaz a granular; ligeiramente duro, friável, ligeiramente plástico e pegajoso, transição difusa e plana. raizes muitas. muitos poros pequenos.

BW2 $1.20-1.70 \mathrm{~m}+$ bruno avermelhado escuro a bruno escuro (2,5 YR úmido); argila; moderada a média blocos subangulares que se desfaz a granular, ligeiramente duro, friável ligeiramente plástico e pegajoso, transição difusa e plana, raízes comuns, muitos poros pequenos.

Tabela 1 - Características fisicas e químicas do perfil de Latossolo Roxo Distrófico no sistema de cultivo plantio convencional não irrigado.

\begin{tabular}{|c|c|c|c|c|c|c|c|c|c|}
\hline \multirow{3}{*}{ Horiz } & \multirow{3}{*}{ Pror, } & \multirow{3}{*}{ Cor de munsell } & \multicolumn{4}{|c|}{ Granulometria } & \multirow{3}{*}{$\begin{array}{c}\text { Argila } \\
\text { dispersa } \\
\text { em água } \\
\mathrm{g} \mathrm{kg}^{-1}\end{array}$} & \multirow{3}{*}{$\begin{array}{c}\text { Grau de } \\
\text { noculacão } \\
\% \\
\end{array}$} & \multirow{3}{*}{$\begin{array}{c}\text { Relaç̧̃o } \\
\text { Silte/argila }\end{array}$} \\
\hline & & & \multicolumn{2}{|c|}{ Areia } & Sitte & Argila & & & \\
\hline & & & \multicolumn{4}{|c|}{$\mathrm{g} \mathrm{kg}^{-1}$} & & & \\
\hline$A p$ & $0.0-0.3$ & 2.5 Y R 2/4 & 80 & 80 & 240 & 600 & 31 & 48 & 0,40 \\
\hline BA & $0.3-0.7$ & 25 YR 3:4 & 60 & 60 & 130 & 750 & . & 100 & 0,17 \\
\hline$B_{m+1}$ & $0.7-1.2$ & $25 \mathrm{YR} 3 / 5$ & 50 & 60 & 140 & 750 & - & 100 & 0,19 \\
\hline$B_{73}$ & $1.2-1.7$ & 2.5 YR $3 / 5$ & 60 & 60 & 140 & 740 & 2 & 97 & 0,19 \\
\hline
\end{tabular}

continua. 


\begin{tabular}{|c|c|c|c|c|c|c|c|c|c|c|c|c|c|c|c|c|}
\hline \multirow[b]{2}{*}{ Heriz. } & \multirow[b]{2}{*}{$\mathrm{H}_{2} \mathrm{O}$} & \multirow[b]{2}{*}{$\mathrm{KCl}$} & \multirow[b]{2}{*}{$\begin{array}{c}C \\
g \mathrm{~kg}^{-1}\end{array}$} & \multirow[b]{2}{*}{$\begin{array}{c}\mathrm{N} \\
\mathrm{g} \mathrm{kg} \cdot\end{array}$} & \multirow[b]{2}{*}{$\mathrm{C} / \mathrm{N}$} & \multirow[b]{2}{*}{$\begin{array}{c}\mathrm{P} \\
\mathrm{mg} \mathrm{kg}^{-1}\end{array}$} & \multicolumn{8}{|c|}{ Complexo Sortivo $\left(\mathrm{mmol}_{\mathrm{c}} \mathrm{kg}^{-1}\right)$} & \multicolumn{2}{|c|}{$\begin{array}{c}\% \\
\text { Saturação }\end{array}$} \\
\hline & & & & & & & $\mathrm{Ca}^{++}$ & $\mathrm{Mg}^{++}$ & $\mathrm{K}^{*}$ & $\mathrm{Na}^{+}$ & $\mathbf{S}$ & $\mathrm{H}^{+}$ & $\mathbf{A l}_{+}^{++}$ & CTC & Bases & Al \\
\hline$A p$ & 5.9 & 5.3 & 17.7 & 1.5 & 12 & 5.0 & 27,0 & 10.0 & 0.5 & 0,1 & 38 & 39 & . & 77 & 49 & - \\
\hline BA & 5.7 & 5.2 & 9.8 & 0.8 & 12 & 1,0 & 7,0 & 7,0 & 0.2 & 0,1 & 14 & 29 & - & 43 & 32 & - \\
\hline$B_{* 3}$ & 52 & 5.3 & 6.7 & 0.6 & 11 & 1.0 & 8.0 & 8,0 & 0.1 & 0,1 & 8 & 24 & - & 32 & 25 & - \\
\hline$B_{x<}$ & +.8 & 53. & 6.0 & 0.6 & 10 & 1,0 & 5.0 & 5.0 & 0.1 & 0.1 & 5 & 24 & - & 29 & 17 & - \\
\hline
\end{tabular}

\section{Perfil 3 - plantio direto irrigado}

Ap $\quad 0,00-0,28 \mathrm{~m}$ bruno avermelhado escuro (2,5 YR 3/4 úmido); argila; moderada pequena blocos subangulares que se desfaz a granular, ligeiramente duro, friável ligeiramente plástico e pegajoso, transição gradual e plana, raízes muitas, muitos poros pequenos.

BA $\quad 0.28-0,59 \mathrm{~m}$ vermelho escuro (2,5 YR 2,5/6 úmido); argila; moderada média blocos subangulares que se desfaz a granular; ligeiramente duro, friável, ligeiramente plástico e pegajoso, transição gradual e plana, raizes muitas, muitos poros pequenos.

BWl 0,59 - 1,00 m vermelho escuro (2,5 YR 2,5/6 úmido); argila, moderada média blocos subangulares que se desfaz a granular; ligeiramente duro, friável, ligeiramente plástico e pegajoso, transição difusa e plana, raízes comuns, muitos poros pequenos.

BW2 1,00 - 1,50 m vermelho escuro (2,5 YR 2,5/6 úmido); argila, moderada média blocos subangulares que se desfaz a granular, ligeiramente duro, friável, 
ligeiramente plástico e pegajoso, transição gradual e plana, raizes poucas, muitos poros pequenos.

Obs: Presença de cupins ao longo do perfil.

Tabela 2 - Características físicas e químicas do perfil de Latossolo Roxo Distrófico no sistema de cultivo plantio direto irrigado.

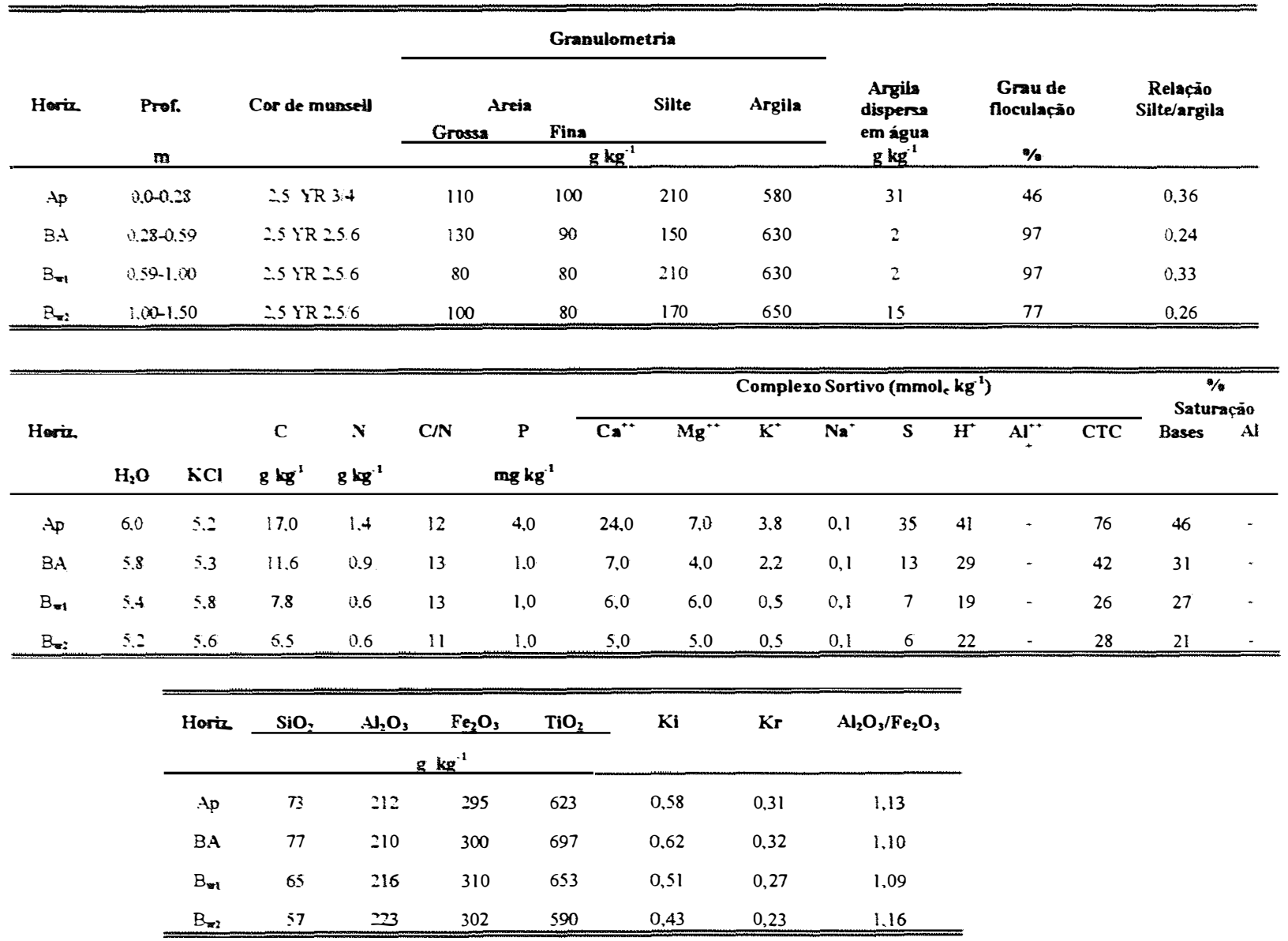

\section{Perfil 1 - plantio convencional irrigado}

Ap $\quad 0,00-0,30 \mathrm{~m}$ bruno avermelhado escuro (2,5 YR 2/4 úmido); argila; moderada pequena blocos subangulares que se desfaz em granular; ligeiramente duro, friável, ligeiramente plástico e pegajoso, transição gradual e plana, raizes comuns, muitos poros pequenos.

BA $0,30-0,60 \mathrm{~m}$ bruno avermelhado escuro (2,5 YR 2,5/4 úmido); argila, moderada pequena a média blocos subangulares que se desfaz a granular; ligeiramente duro, 
friável, ligeiramente plástico e pegajoso; transição gradual e plana; raizes comuns, muitos poros pequenos.

BWl 0,60-1,00 m vermelho escuro (2,5 YR 2,5/6 úmido); argila, moderada, média blocos subangulares que se desfaz a granular; ligeiramente plástico e pegajoso; transição gradual e plana; raizes comuns, muitos poros pequenos.

BW2 1,00 - 1,60 m+ vermelho escuro (2,5 YR 2,5/6 úmido); argila; moderada média blocos subangulares que se desfaz a granular; ligeiramente duro, friável, ligeiramente plástico e pegajoso, transição difusa e plana, raizes ausentes, muitos poros pequenos.

Tabela 3 - Características físicas e químicas do perfil de Latossolo Roxo Distrófico no sistema de cultivo plantio convencional irrigado.

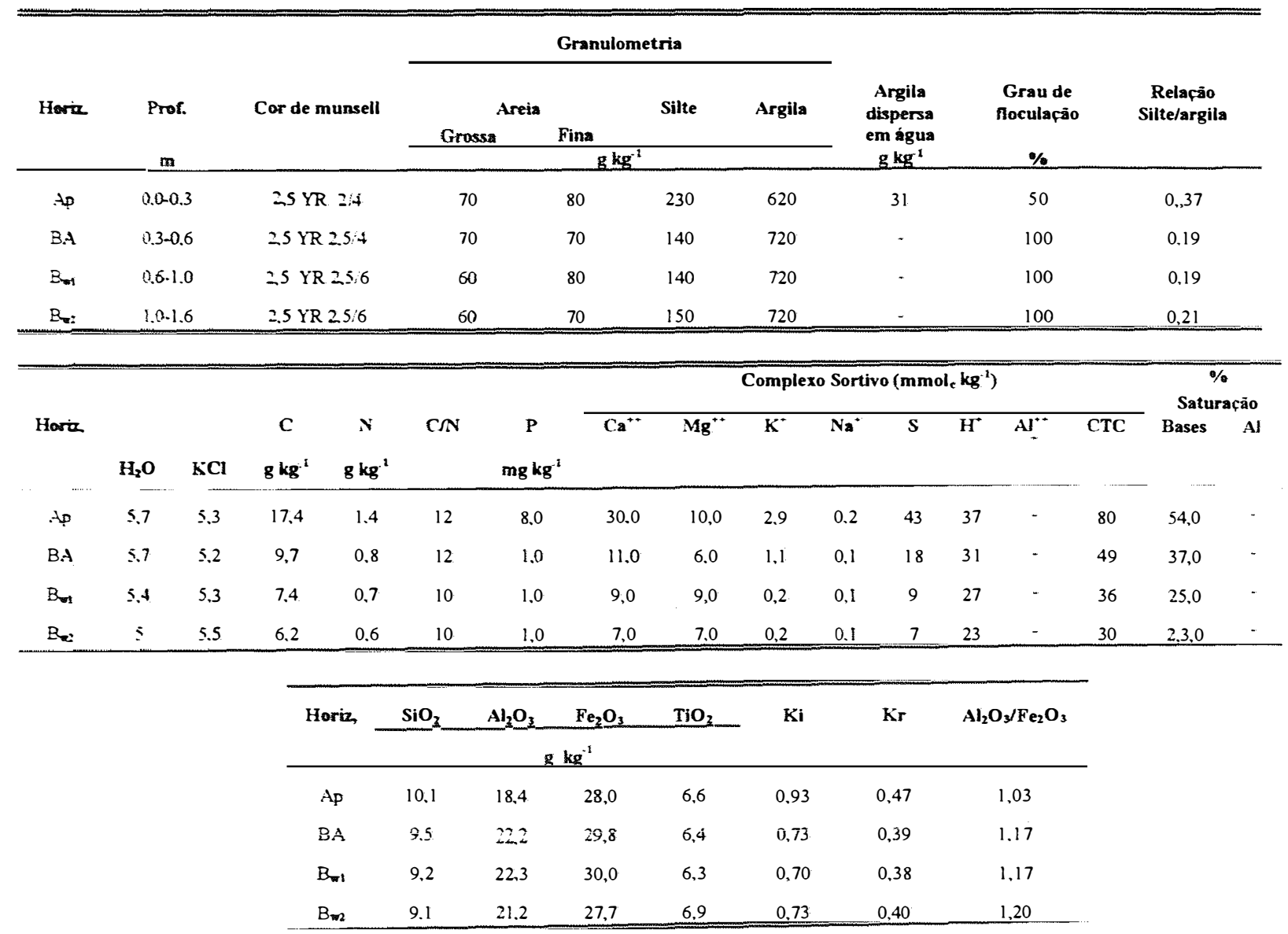


Anexo B 
Valores numéricos das curvas de retenção da água no solo, da densidade do solo e os paràmetros do ajuste das curvas de retenção através do método de Genuchten (1980) para os diferentes sistemas de cultivo, nas profundidades de 0,00 $0,07 \mathrm{~m}, 0,07-0,14 \mathrm{~m}, 0,27-0,34 \mathrm{~m}$ e $0,97-1,04 \mathrm{~m}$.

\begin{tabular}{|c|c|c|c|c|c|c|}
\hline \multicolumn{7}{|c|}{ Plantio Direto Irrigado } \\
\hline \multirow{2}{*}{$\begin{array}{c}\text { Potencial } \\
\text { matrico (h) } \\
\mathrm{KPa}\end{array}$} & \multicolumn{2}{|c|}{$0.00-0.07 \mathrm{~m}\left(1^{\underline{a}}\right.$ repetiçdo $)$} & \multicolumn{2}{|c|}{$0,00-0,07 \mathrm{~m}\left(2^{\underline{a}}\right.$ repetiça) } & \multicolumn{2}{|c|}{$0,00-0,07 m\left(3^{g}\right.$ repeticas $)$} \\
\hline & $\begin{array}{c}\theta \\
m^{3} m^{3}\end{array}$ & $\begin{array}{c}\text { densidade } \\
\qquad \mathrm{kg} \mathrm{m}^{-3}\end{array}$ & $\begin{array}{c}\theta \\
m^{3} m^{-3}\end{array}$ & $\begin{array}{c}\text { densidade } \\
\mathrm{kg} \mathrm{m}^{-3}\end{array}$ & $\begin{array}{c}\theta \\
m^{3} \boldsymbol{m}^{-3}\end{array}$ & $\begin{array}{c}\text { densidade } \\
\mathrm{kg} \mathrm{m}^{-3}\end{array}$ \\
\hline 0.50 & 0,5860 & 1096 & 0,5500 & 1129 & 0,5785 & 1114 \\
\hline 1.00 & 0,5406 & 1143 & 0,5397 & 1145 & 0,5756 & 1131 \\
\hline 2.00 & 0.4935 & 1145 & 0,5090 & 1108 & 0,5171 & 1188 \\
\hline 5.00 & 0.4446 & 1154 & 0,4237 & 1094 & 0,4399 & 1096 \\
\hline 8.00 & 0.4108 & 1192 & 0,3918 & 1110 & 0,4280 & 1175 \\
\hline \multicolumn{7}{|c|}{ Plantio Convencional Irrigado } \\
\hline Potencial & \multicolumn{2}{|c|}{$0.00-0.07 \mathrm{~m}\left(1^{a}\right.$ repetiçao) } & \multicolumn{2}{|c|}{$0,00-0.07 \mathrm{~m}\left(2^{a}\right.$ repetiçao) } & \multicolumn{2}{|c|}{$0,00-0,07 \mathrm{~m}\left(3^{g}\right.$ repetiça) } \\
\hline $\begin{array}{c}\text { matrico (h) } \\
\qquad P a\end{array}$ & $\begin{array}{c}\theta \\
\boldsymbol{m}^{3} \boldsymbol{m}^{-3} \\
\end{array}$ & $\begin{array}{c}\text { densidade } \\
\mathrm{kg} \mathrm{m}^{-3}\end{array}$ & $\begin{array}{c}\theta \\
m^{3} m^{-3} \\
\end{array}$ & $\begin{array}{c}\text { densidade } \\
\qquad \mathrm{kg} \mathrm{\textrm {m } ^ { - 3 }}\end{array}$ & $\begin{array}{c}\theta \\
m^{3} m^{-3} \\
\end{array}$ & $\begin{array}{c}\text { densidade } \\
\mathrm{kg} \mathrm{m}^{-3}\end{array}$ \\
\hline 0.50 & 0,6187 & 0983 & 0,6275 & 0989 & 0,6066 & 1006 \\
\hline 1,00 & 0,5700 & 1005 & 0,6049 & 0974 & 0,5876 & 1003 \\
\hline 2.00 & 0,5184 & 1034 & 0,5571 & 1003 & 0,5459 & 0974 \\
\hline 5.00 & 0,4004 & 1028 & 0,3875 & 0960 & 0,3920 & 0994 \\
\hline 8.00 & 0.3628 & 1026 & 0,3693 & 1016 & 0,3621 & 1021 \\
\hline
\end{tabular}

Obs: não foram coletadas amostras indeformadas no sistema de plantio convencional não irrigado $(0.00-0.07 \mathrm{~m})$ devido o solo estar muito seco na ocasião da amostragem.

\begin{tabular}{|c|c|c|c|c|c|c|}
\hline \multicolumn{7}{|c|}{ Plantio Convencional Não Irriga do } \\
\hline \multirow{2}{*}{$\begin{array}{l}\text { Potencial } \\
\text { mátrico }(\phi) \\
k P a\end{array}$} & \multicolumn{2}{|c|}{$0,07-0,14 m$} & \multicolumn{2}{|c|}{$0,27-0,34 \mathrm{~m}$} & \multicolumn{2}{|c|}{$0,97-1,04 \mathrm{~m}$} \\
\hline & $\begin{array}{c}\theta \\
m^{3} m^{-3} \\
\end{array}$ & $\begin{array}{c}\text { densidade } \\
\mathrm{kg} \mathrm{m}^{-3}\end{array}$ & $\begin{array}{c}\theta \\
m^{3} m^{-3}\end{array}$ & $\begin{array}{c}\text { densidade } \\
\mathrm{kg} \mathrm{m}^{-3}\end{array}$ & $\begin{array}{c}\theta \\
m^{3} m^{-3} \\
\end{array}$ & $\begin{array}{c}\text { densidade } \\
\mathrm{kg} \mathrm{m}^{-3}\end{array}$ \\
\hline 0.50 & 0,6027 & 1097 & 0,6011 & 1054 & 0,6776 & 911 \\
\hline 1.00 & 0.5761 & 1134 & 0.5650 & 1059 & 0.6254 & 882 \\
\hline 2.00 & 0.5493 & 1067 & 0,5199 & 1049 & 0,5733 & 934 \\
\hline 5.00 & 0.4640 & 1173 & 0,4276 & 1067 & 0,4437 & 832 \\
\hline 8.00 & 0.4372 & 1173 & 0,3907 & 1067 & 0,3592 & 832 \\
\hline 30.00 & 0,3738 & 1097 & 0,3461 & 1054 & 0,2747 & 911 \\
\hline 60.00 & 0.3104 & 1134 & 0,3015 & 1059 & 0,2623 & 882 \\
\hline 300.00 & 0.2654 & 1067 & 0,2778 & 1049 & 0,2413 & 934 \\
\hline 1500.00 & 0.2350 & 1173 & 0,2500 & 1067 & 0,2380 & 832 \\
\hline
\end{tabular}

continua. 
coninuação

Plantio Direto Irrigado

\begin{tabular}{|c|c|c|c|c|c|c|}
\hline \multirow{2}{*}{$\begin{array}{c}\text { Potencial } \\
\text { mático (\$) } \\
k P a\end{array}$} & \multicolumn{2}{|c|}{$0,07-0,14 m$} & \multicolumn{2}{|c|}{$0,27-0,34 \mathrm{~m}$} & \multicolumn{2}{|c|}{$0,97-1,04 m$} \\
\hline & $\begin{array}{c}\theta \\
m^{3} m^{-3}\end{array}$ & $\begin{array}{c}\text { densidade } \\
\mathrm{kg} \mathrm{m}^{-3}\end{array}$ & $\begin{array}{c}\theta \\
m^{3} m^{-3}\end{array}$ & $\begin{array}{c}\text { densidade } \\
\mathrm{kg} \mathrm{m}^{-3}\end{array}$ & $\begin{array}{c}\theta \\
m^{3} m^{-3}\end{array}$ & $\begin{array}{c}\text { densidade } \\
\mathrm{kg} \mathrm{m}^{-3}\end{array}$ \\
\hline 0.50 & 0.5554 & 1120 & 0,6070 & 1051 & 0,6360 & 918 \\
\hline 1.00 & 0,5174 & 1148 & 0.5555 & 1060 & 0,6189 & 896 \\
\hline 2.00 & 0,4794 & 1032 & 0,4901 & 1009 & 0,5147 & 917 \\
\hline 5.00 & 0.4440 & 1150 & 0,4221 & 1052 & 0,4128 & 926 \\
\hline 8.00 & 0.4090 & 1150 & 0,3854 & 1052 & 0,3685 & 926 \\
\hline 30.00 & 0.3681 & 1120 & 0,3490 & 1051 & 0,3227 & 918 \\
\hline 60.00 & 0.3300 & 1148 & 0,3126 & 1060 & 0,2769 & 896 \\
\hline 300.00 & 0.3040 & 1032 & 0,2954 & 1009 & 0,2640 & 917 \\
\hline 1500.00 & 0.2710 & 1150 & 0.2750 & 1052 & 0.2350 & 926 \\
\hline
\end{tabular}

Plantio Convencional Irrigado

\begin{tabular}{|c|c|c|c|c|c|c|}
\hline \multirow{2}{*}{$\begin{array}{c}\text { Potencial } \\
\text { mátrico }\left(\phi_{m}\right) \\
k P a\end{array}$} & \multicolumn{2}{|c|}{$0,07-0,14 \mathrm{~m}$} & \multicolumn{2}{|c|}{$0,27-0,34 \mathrm{~m}$} & \multicolumn{2}{|c|}{$0,97-1,04 \mathrm{~m}$} \\
\hline & $\begin{array}{c}\theta \\
m^{3} m^{-3}\end{array}$ & $\begin{array}{c}\text { densidade } \\
\mathrm{kg} \mathrm{m}^{-3}\end{array}$ & $\begin{array}{c}\theta \\
m^{3} m^{-3}\end{array}$ & $\begin{array}{c}\text { densidade } \\
\mathrm{kg} \mathrm{m}^{-3}\end{array}$ & $\begin{array}{c}\theta \\
m^{3} m^{-3}\end{array}$ & $\begin{array}{c}\text { densidade } \\
\mathrm{kg} \mathrm{m}^{-3}\end{array}$ \\
\hline 0.50 & 0.5544 & 1038 & 0,6076 & 1086 & 0,6327 & 869 \\
\hline 1.00 & 0,5463 & 1088 & 0,5170 & 1022 & 0,6114 & 907 \\
\hline 2.00 & 0.5170 & 1077 & 0,4620 & 1035 & 0.5150 & 856 \\
\hline 5.00 & 0.4700 & 1156 & 0,3790 & 980 & 0,4208 & 957 \\
\hline 8.00 & 0.4273 & 1156 & 0,3506 & 980 & 0,3753 & 957 \\
\hline 30.00 & 0.3400 & 1038 & 0,2950 & 1086 & 0,3228 & 869 \\
\hline 60.00 & 0.3000 & 1088 & 0,2800 & 1022 & 0.2703 & 907 \\
\hline 300.00 & 0.2751 & 1077 & 0,2550 & 1035 & 0,2415 & 856 \\
\hline 1500,00 & 0.2550 & 1156 & 0,2461 & 980 & 0,2250 & 957 \\
\hline
\end{tabular}

Plantio Convencional Não Irrigado

\begin{tabular}{|c|c|c|c|c|c|c|}
\hline \multirow{2}{*}{$\begin{array}{c}\text { Patencial } \\
\text { mátrico (申no) } \\
k P a\end{array}$} & \multicolumn{2}{|c|}{$0,07-0,14 \mathrm{~m}$} & \multicolumn{2}{|c|}{$0,27-0,34 \mathrm{~m}$} & \multicolumn{2}{|c|}{$0,97-1,04 \mathrm{~m}$} \\
\hline & $\begin{array}{c}\theta \\
m^{3} m^{-3}\end{array}$ & $\begin{array}{c}\text { densidade } \\
\mathrm{kg} \mathrm{m}^{-3}\end{array}$ & $\begin{array}{c}\theta \\
m^{3} m^{-3}\end{array}$ & $\begin{array}{c}\text { densidade } \\
\mathrm{kg} \mathrm{m}^{-3}\end{array}$ & $\begin{array}{c}\theta \\
m^{3} m^{-3}\end{array}$ & $\begin{array}{c}\text { densidade } \\
\mathrm{kg} \mathrm{m}^{-3}\end{array}$ \\
\hline 0.50 & 0,6132 & 1133 & 0,5892 & 1054 & 0,6274 & 862 \\
\hline 1.00 & 0.5966 & 1147 & 0,5620 & 1059 & 0.5988 & 884 \\
\hline 2.00 & 0.5771 & 1131 & 0,5347 & 1049 & 0,5703 & 952 \\
\hline 5.00 & 0,4846 & 1037 & 0,4614 & 1067 & 0,4646 & 918 \\
\hline 8.00 & 0,4147 & 1037 & 0,3880 & 1067 & 0,3590 & 918 \\
\hline 30.00 & 0.3502 & 1133 & 0,3487 & 1054 & 0,3209 & 862 \\
\hline 60.00 & 0,3141 & 1147 & 0,3094 & 1059 & 0,2828 & 884 \\
\hline 300,00 & 0,2730 & 1131 & 0,2770 & 1049 & 0,2750 & 952 \\
\hline 1500.00 & 0.2550 & 1037 & 0,2560 & 1067 & 0,2600 & 918 \\
\hline
\end{tabular}

continua. 
continuação.

\section{Plantio Direto Irrigado}

\begin{tabular}{|c|c|c|c|c|c|c|}
\hline \multirow{2}{*}{$\begin{array}{c}\text { Potencial } \\
\text { mátrico (A) } \\
k P a\end{array}$} & \multicolumn{2}{|c|}{$0.07-0,14 m$} & \multicolumn{2}{|c|}{$0,27-0,34 \mathrm{~m}$} & \multicolumn{2}{|c|}{$0,97-1,04 \mathrm{~m}$} \\
\hline & $\begin{array}{c}\theta \\
m^{3} m^{-3} \\
\end{array}$ & $\begin{array}{c}\text { densidade } \\
\mathrm{kg} \mathrm{m}^{-3}\end{array}$ & $\begin{array}{c}\theta \\
m^{3} m^{-3}\end{array}$ & $\begin{array}{c}\text { densidade } \\
\mathrm{kg} \mathrm{m}^{-3}\end{array}$ & $\begin{array}{c}\theta \\
m^{3} m^{-3}\end{array}$ & $\begin{array}{c}\text { densidade } \\
\mathrm{kg} \mathrm{m}^{-3}\end{array}$ \\
\hline 0.50 & 0.5956 & 1118 & 0.5566 & 1067 & 0,6337 & 891 \\
\hline 1.00 & 0.5466 & 1130 & 0.5227 & 1074 & 0,5922 & 925 \\
\hline 2.00 & 0.5083 & 1114 & 0.4821 & 998 & 0.5507 & 914 \\
\hline 5.00 & 0.4316 & 1067 & 0.4346 & 1119 & 0.3854 & 875 \\
\hline 8.00 & 0.3930 & 1067 & 0.4052 & 1119 & 0,3573 & 875 \\
\hline 30.00 & 0.3602 & 1118 & 0,3628 & 1067 & 0,3000 & 891 \\
\hline 60.00 & 0.3275 & 1130 & 0.3350 & 1074 & 0.2857 & 925 \\
\hline 300.00 & 0.2980 & 1114 & 0.2806 & 998 & 0,2584 & 914 \\
\hline 1500.00 & 0.2850 & 1067 & 0.2450 & 1119 & 0.2450 & 875 \\
\hline
\end{tabular}

Plantio Convencional Irrigado

\begin{tabular}{|c|c|c|c|c|c|c|}
\hline \multirow{2}{*}{$\begin{array}{c}\text { Potencial } \\
\left.\text { mátrico ( } \phi_{m}\right) \\
k P_{a}\end{array}$} & \multicolumn{2}{|c|}{$0,07-0,14 m$} & \multicolumn{2}{|c|}{$0,27-0,34 \mathrm{~m}$} & \multicolumn{2}{|c|}{$0,97-1,04 \mathrm{~m}$} \\
\hline & $\begin{array}{c}\theta \\
m^{3} m^{-3}\end{array}$ & $\begin{array}{c}\text { densidade } \\
\mathrm{kg} \mathrm{m} \mathrm{m}^{-3}\end{array}$ & $\begin{array}{c}\theta \\
m^{3} m^{-3}\end{array}$ & $\begin{array}{c}\text { densidade } \\
\mathrm{kg} \mathrm{m}^{-3}\end{array}$ & $\begin{array}{c}\theta \\
m^{3} m^{-3}\end{array}$ & $\begin{array}{c}\text { densidade } \\
\mathrm{kg} \mathrm{m}^{-3}\end{array}$ \\
\hline 0.50 & $0.6+13$ & 1047 & 0.5545 & 1016 & 0.6133 & 852 \\
\hline 1.00 & 0.5483 & 1082 & 0.4947 & 957 & 0,5780 & 976 \\
\hline 2.00 & 0,5326 & 991 & 0,4375 & 954 & 0,5423 & 961 \\
\hline 5.00 & 0.4746 & 1133 & 0.3941 & 1043 & 0,4520 & 937 \\
\hline 8.00 & 0.4201 & 1133 & 0,3666 & 1043 & 0.3620 & 937 \\
\hline 30.00 & 0.3400 & 1047 & 0.2986 & 1016 & 0,3120 & 852 \\
\hline 60.00 & 0.3076 & 1082 & 0,2688 & 957 & 0,2840 & 976 \\
\hline 300.00 & 0.2651 & 991 & 0.2469 & 954 & 0.2600 & 961 \\
\hline 1500.00 & 0.2494 & 1133 & 0.2150 & 1043 & 0.2550 & 937 \\
\hline
\end{tabular}

Plantio Convencional Não Irriga do

\begin{tabular}{|c|c|c|c|c|c|c|}
\hline \multirow{2}{*}{$\begin{array}{c}\text { Potencial } \\
\text { mátrico }\left(\phi_{m}\right) \\
k P_{a}\end{array}$} & \multicolumn{2}{|c|}{$0,07-0,14 \mathrm{~m}$} & \multicolumn{2}{|c|}{$0,27-0,34 \mathrm{~m}$} & \multicolumn{2}{|c|}{$0,97-1,04 \mathrm{~m}$} \\
\hline & $\begin{array}{c}\theta \\
m^{3} m^{-3}\end{array}$ & $\begin{array}{c}\text { densidade } \\
\mathrm{kg} \mathrm{m}^{-3}\end{array}$ & $\begin{array}{c}\theta \\
m^{3} m^{-3}\end{array}$ & $\begin{array}{c}\text { densidade } \\
\mathrm{kg} \mathrm{m}^{-3}\end{array}$ & $\begin{array}{c}\theta \\
m^{3} m^{-3}\end{array}$ & $\begin{array}{c}\text { densidade } \\
\mathrm{kg} \mathrm{m}^{-3}\end{array}$ \\
\hline 0.50 & 0.5853 & 1053 & 0,5868 & 1068 & 0,6299 & 933 \\
\hline 1.00 & 0.5712 & 1112 & 0.5689 & 978 & 0,5901 & 902 \\
\hline 2.00 & 0.5470 & 1057 & 0,5400 & 1058 & 0.5503 & 944 \\
\hline 5.00 & 0,4446 & 1101 & 0,4370 & 1051 & 0,4329 & 868 \\
\hline 8.00 & 0.4144 & 1101 & 0.3627 & 1051 & 0,3530 & 868 \\
\hline 30.00 & 0,3595 & 1053 & 0,2998 & 1068 & 0,2850 & 933 \\
\hline 60.00 & 0,3046 & 1112 & 0,2756 & 978 & 0,2620 & 902 \\
\hline 300.00 & 0.2592 & 1057 & 0.2350 & 1058 & 0,2550 & 944 \\
\hline 1500.00 & 0.2300 & 1101 & 0,2100 & 1051 & 0,2500 & 868 \\
\hline
\end{tabular}

continua. 
continuaçào.

Plantio Direto Irrigado

\begin{tabular}{|c|c|c|c|c|c|c|}
\hline \multirow{2}{*}{$\begin{array}{c}\text { Potencial } \\
\text { matrico (\$) } \\
k P a\end{array}$} & \multicolumn{2}{|c|}{$0,07-0.14 m$} & \multicolumn{2}{|c|}{$0,27-0,34 m$} & \multicolumn{2}{|c|}{$0,97-1,04 m$} \\
\hline & $m^{3} m^{-3}$ & $\begin{array}{c}\text { dessidade } \\
\mathrm{kg} \mathrm{m}^{-3}\end{array}$ & $\begin{array}{c}\theta \\
m^{3} m^{-3}\end{array}$ & $\begin{array}{c}\text { densidade } \\
\mathrm{kg} \mathrm{m}^{-3}\end{array}$ & $\begin{array}{c}\theta \\
m^{3} m^{-3}\end{array}$ & $\begin{array}{c}\text { densidade } \\
\mathrm{kg} \mathrm{m}^{-3}\end{array}$ \\
\hline 0.50 & 0.5653 & 1074 & 0.6534 & 1045 & 0.6295 & 885 \\
\hline 1.00 & 0.5300 & 1104 & 0.5871 & 1015 & 0.5838 & 923 \\
\hline 2.00 & 0.4896 & 884 & 0.5079 & 1004 & 0.5381 & 900 \\
\hline 5.00 & 0.4250 & 1076 & 0.4086 & 1018 & 0.4216 & 960 \\
\hline 8.00 & 0.3990 & 1076 & 0.3755 & 1018 & 0.3832 & 960 \\
\hline 30.00 & 0.3623 & 1074 & 0.3252 & 1045 & 0.3332 & 885 \\
\hline 60.00 & 0.3256 & 1104 & 0,3046 & 1015 & 0.3100 & 923 \\
\hline 300.00 & 0.3000 & 884 & 0.2813 & 1004 & 0.2746 & 900 \\
\hline 1500.00 & 0.2850 & 1076 & 0.2766 & 1018 & 0.2550 & 960 \\
\hline
\end{tabular}

Plantio Convencional Irrigado

\begin{tabular}{|c|c|c|c|c|c|c|}
\hline \multirow{2}{*}{$\begin{array}{c}\text { Potencial } \\
\text { mátrico (4) } \\
\text { kPa }\end{array}$} & \multicolumn{2}{|c|}{$0.07-0.14 \mathrm{~m}$} & \multicolumn{2}{|c|}{$0,27-0,34 \mathrm{~m}$} & \multicolumn{2}{|c|}{$0,97-1,04 \mathrm{~m}$} \\
\hline & $\begin{array}{c}\theta \\
m^{3} m^{-3}\end{array}$ & $\begin{array}{c}\text { densidade } \\
\mathrm{kg} \mathrm{m}^{-3}\end{array}$ & $\begin{array}{c}\theta \\
m^{3} m^{-3}\end{array}$ & $\begin{array}{c}\text { densidade } \\
\mathrm{kg} \mathrm{m}^{-3}\end{array}$ & $\begin{array}{c}\theta \\
m^{3} m^{-3}\end{array}$ & $\begin{array}{c}\text { densidade } \\
\mathrm{kg} \mathrm{m}^{-3}\end{array}$ \\
\hline 0.50 & 0.6084 & 937 & 0.5919 & 1020 & 0,6116 & 910 \\
\hline 1.00 & 0.5813 & 958 & 0.5307 & 1042 & 0.5500 & 870 \\
\hline 2.00 & 0.5401 & 954 & 0.4675 & 1011 & 0.4883 & 893 \\
\hline 5.00 & 0.4070 & 990 & 0.3963 & 1011 & 0.4090 & 931 \\
\hline 8.00 & 0.3770 & 990 & 0.3621 & 1011 & 0.3293 & 931 \\
\hline 30.00 & 0.3100 & 937 & 0.3100 & 1020 & 0.2880 & 910 \\
\hline 60.00 & 0.2800 & 958 & 0.2879 & 1042 & 0.2570 & 870 \\
\hline 300.00 & 0.2402 & 954 & 0.2558 & 1011 & 0,2420 & 893 \\
\hline 1500.00 & 0.2283 & 990 & 0.2240 & 1011 & 0.2330 & 931 \\
\hline
\end{tabular}

Paràmetros do ajuste das curvas de retenção da água no solo através do método de Genuchten (1980) para os sistemas de cultivo plantio direto irrigado e convencional irrigado na profundidade de 0,00-0,07 m.

\begin{tabular}{cccccccc}
\hline \hline \multicolumn{7}{c}{ Plantio Direto Irrigado $\mathbf{( 0 , 0 0}-\mathbf{0 , 0 7} \mathbf{m})$} & \\
\hline Curvas & $\boldsymbol{\alpha}$ & $\boldsymbol{m}$ & $\boldsymbol{n}$ & $\theta_{\boldsymbol{r}}$ & $\theta_{\boldsymbol{s}}$ & $\boldsymbol{R}^{\mathbf{2}}$ \\
\hline $\mathbf{1}$ & 0,1040 & 0,0370 & 19,8636 & 0,3700 & 0,5900 & 0,9960 \\
$\mathbf{2}$ & 0,0060 & 11,1470 & 1,6937 & 0,3820 & 0,5520 & 0,9980 \\
$\mathbf{3}$ & 0,0643 & 0,2833 & 6,0496 & 0,4180 & 0,5790 & 1,0000 \\
Média & 0,0581 & 3,8224 & 9,2023 & 0,3900 & 0,5737 & \\
Desvio Padrão & 0,0493 & 6,3445 & 9,4864 & 0,0250 & 0,0196 & \\
Coef. Variação & $\mathbf{8 4 , 8}$ & 166,0 & 103,1 & 6,4 & 3,4 & \\
\hline
\end{tabular}

continua. 
continuação.

Plantio Convencional Irrigado $(0,00-0,07 \mathrm{~m})$

\begin{tabular}{ccccccc}
\hline Curvas & $\boldsymbol{\alpha}$ & $\boldsymbol{m}$ & $\boldsymbol{n}$ & $\boldsymbol{\theta}_{\boldsymbol{r}}$ & $\boldsymbol{\theta}_{\boldsymbol{s}}$ & $\boldsymbol{R}^{2}$ \\
\hline $\mathbf{1}$ & 0,0416 & 0,7920 & 1,7936 & 0,3100 & 0,6230 & 0,9960 \\
$\mathbf{2}$ & 0,0790 & 19,4070 & 2,2195 & 0,3630 & 0,6270 & 0,9990 \\
$\mathbf{3}$ & 0,0740 & 18,6140 & 2,1634 & 0,3600 & 0,6080 & 1,0000 \\
\hline Média & 0,0649 & 12,9377 & 2,0588 & 0,3443 & 0,6193 & \\
Desvio Padrão & 0,0203 & 10,5259 & 0,2314 & 0,0298 & 0,0100 & \\
Coef. Variação & 31,3 & 81,4 & 11,2 & 8,6 & 1,6 & \\
\hline \hline
\end{tabular}

Paràmetros de ajuste das curvas de retenção da água no solo através do método de Genuchten (1980) para os sistemas de cultivo convencional não irrigado, plantio direto irrigado e convencional irrigado na profundidade de 0,07-0,14 m.

\begin{tabular}{|c|c|c|c|c|c|c|}
\hline \multicolumn{7}{|c|}{ Plantio Convencional Não Irrigado $(0,07-0,14 \mathrm{~m})$} \\
\hline Curvas & $\alpha$ & $m$ & $n$ & $\theta_{r}$ & $\theta_{s}$ & $R^{2}$ \\
\hline 1 & 0,0752 & 0,1223 & 2,1781 & 0,1640 & 0,6050 & 0,9960 \\
\hline 2 & 0,0503 & 0,1468 & 3,2573 & 0,2410 & 0,6100 & 0,9980 \\
\hline 3 & 0,0719 & 0,0602 & 4,9147 & 0,1790 & 0,5830 & 0,9960 \\
\hline Média & 0,0658 & 0,1098 & 3,4500 & 0,1947 & 0,5993 & \\
\hline Desvio Padrão & 0,0135 & 0,0446 & 1,3784 & 0,0408 & 0,0144 & \\
\hline Coef. Variação & 20,6 & 40,7 & 40,0 & 21,0 & 2,4 & \\
\hline \multicolumn{7}{|c|}{ Plantio Direto Irrigado $(0,07-0,14 \mathrm{~m})$} \\
\hline Curvas & $\alpha$ & $m$ & $n$ & $\theta_{r}$ & $\theta_{s}$ & $R^{2}$ \\
\hline 1 & 0,1743 & 0,0169 & 10,6817 & 0,1790 & 0,5560 & 0,9970 \\
\hline 2 & 0,1249 & 0,1309 & 2,9089 & 0,2660 & 0,5990 & 0,9960 \\
\hline 3 & 0,1351 & 0,0337 & 10,8308 & 0,2700 & 0,5650 & 0,9800 \\
\hline Média & 0,1448 & 0,0605 & 8,1405 & 0,2383 & 0,5733 & \\
\hline Desvio Padrão & 0,0261 & 0,0615 & 4,5313 & 0,0514 & 0,0227 & \\
\hline Coef. Variação & 18,0 & 101,7 & 55,7 & 21,6 & 4,0 & \\
\hline
\end{tabular}


continuaçào.

Plantio Convencional Irrigado $(0,07-0,14 \mathrm{~m})$

\begin{tabular}{ccccccc}
\hline Curvas & $\boldsymbol{\alpha}$ & $\boldsymbol{m}$ & $\boldsymbol{n}$ & $\theta_{\boldsymbol{r}}$ & $\boldsymbol{\theta}_{\boldsymbol{s}}$ & $\boldsymbol{R}^{2}$ \\
\hline $\mathbf{1}$ & 0,0227 & 0,4399 & 1,4757 & 0,2500 & 0,5570 & 0,9990 \\
$\mathbf{2}$ & 0,0584 & 0,4014 & 1,1169 & 0,2260 & 0,6470 & 0,9890 \\
$\mathbf{3}$ & 0,0726 & 0,1493 & 3,3796 & 0,2180 & 0,6070 & 0,9970 \\
\hline Média & 0,0512 & 0,3302 & 1,9907 & 0,2313 & 0,6040 & \\
Desvio Padrão & 0,0257 & 0,1578 & 1,2161 & 0,0167 & 0,0451 & \\
Coef. Variação & 50,2 & 47,8 & 61,1 & 7,2 & 7,5 & \\
\hline \hline
\end{tabular}

Paràmetros de ajuste das curvas de retenção da água no solo através do método de Genuchten (1980) para os sistemas de cultivo plantio convencional não irrigado plantio direto irrigado e convencional irrigado na profundidade de $0,27-0,34 \mathrm{~m}$.

\begin{tabular}{|c|c|c|c|c|c|c|}
\hline \multicolumn{7}{|c|}{ Plantio Convencional Não Irrigado $(0,27-0,34 \mathbf{m})$} \\
\hline Curvas & $\alpha$ & $m$ & $n$ & $\theta_{r}$ & $\overline{\theta_{s}}$ & $R^{2}$ \\
\hline 1 & 0,1001 & 0,1304 & 2,9211 & 0,2310 & 0,6030 & 0,9970 \\
\hline 2 & 0,0616 & 0,1942 & 2,3130 & 0,2430 & 0,5890 & 0,9940 \\
\hline 3 & 0,0573 & 0,1434 & 3,4692 & 0,2030 & 0,5850 & 0,9970 \\
\hline Média & 0,0730 & 0,1560 & 2,9011 & 0,2257 & 0,5923 & \\
\hline Desvio Padrão & 0,0236 & 0,0337 & 0,5784 & 0,0205 & 0,0095 & \\
\hline Coef. Variação & 32,3 & 21,6 & 19,9 & 9,1 & 1,6 & \\
\hline
\end{tabular}

Plantio Direto Irrigado (0,27 - 0,34 m)

\begin{tabular}{ccccccc}
\hline Curvas & $\boldsymbol{\alpha}$ & $\boldsymbol{m}$ & $\boldsymbol{n}$ & $\boldsymbol{\theta}_{\boldsymbol{r}}$ & $\boldsymbol{\theta}_{\boldsymbol{s}}$ & $\boldsymbol{R}^{2}$ \\
\hline $\mathbf{1}$ & 0,1510 & 0,0457 & 8,3552 & 0,2580 & 0,6080 & 0,9980 \\
$\mathbf{2}$ & 0,1744 & 0,0118 & 12,0842 & 0,0930 & 0,5570 & 0,9990 \\
$\mathbf{3}$ & 0,1273 & 0,1432 & 3,7759 & 0,2680 & 0,6560 & 0,9990 \\
Média & 0,1509 & 0,0669 & 8,0718 & 0,2063 & 0,6070 & \\
Desvio Padrão & 0,0236 & 0,0682 & 4,1614 & 0,0983 & 0,0495 & \\
Coef. Variação & 15,6 & 102,0 & 51,6 & 47,6 & 8,2 & \\
\hline
\end{tabular}

continua. 
continuaçăo.

Plantio Convencional Irrigado $(0,27-0,34 \mathrm{~m})$

\begin{tabular}{ccccccc}
\hline Curvas & $\boldsymbol{\alpha}$ & $\boldsymbol{m}$ & $\boldsymbol{n}$ & $\theta_{\boldsymbol{r}}$ & $\theta_{\boldsymbol{s}}$ & $\boldsymbol{R}^{2}$ \\
\hline $\mathbf{1}$ & 0,1835 & 0,0222 & 18,6963 & 0,2280 & 0,6090 & 0,9990 \\
$\mathbf{2}$ & 0,1910 & 0,0137 & 18,3329 & 0,1610 & 0,5560 & 0,9980 \\
$\mathbf{3}$ & 0,1677 & 0,0251 & 12,8767 & 0,1970 & 0,5920 & 0,9990 \\
\hline Média & 0,1807 & 0,0203 & 16,6353 & 0,1953 & 0,5857 & \\
Desvio Padrão & 0,0119 & 0,0059 & 3,2601 & 0,0335 & 0,0271 & \\
Coef. Variaf̧ão & 6,6 & 29,1 & 19,6 & 17,2 & 4,6 & \\
\hline \hline
\end{tabular}

Paràmetros de ajuste das curvas de retenção da água no solo através do método de Genuchten (1980) para os sistemas de cultivo convencional não irrigado plantio direto irrigado e convencional irrigado na profundidade de $0,97-1,04 \mathrm{~m}$.

\begin{tabular}{|c|c|c|c|c|c|c|}
\hline \multicolumn{7}{|c|}{ Plantio Convencional Não Irrigado $(0,97-1,04$ m) } \\
\hline Curvas & $\alpha$ & $m$ & $n$ & $\theta_{r}$ & $\theta_{s}$ & $R^{2}$ \\
\hline 1 & 0,0325 & 0,7087 & 1,6033 & 0,2400 & 0,6820 & 0,9980 \\
\hline 2 & 0,0472 & 0,2734 & 2,6012 & 0,2490 & 0,6240 & 0,9910 \\
\hline 3 & 0,0291 & 0,7466 & 1,6899 & 0,2530 & 0,6320 & 0,9980 \\
\hline Média & 0,0363 & 0,5762 & 1,9648 & 0,2473 & 0,6460 & \\
\hline Desvio Padrão & 0,0096 & 0,2629 & 0,5528 & 0,0067 & 0,0314 & \\
\hline Coef. Variação & 26,5 & 45,6 & 28,1 & 2,7 & 4,9 & \\
\hline \multicolumn{7}{|c|}{ Plantio Direto Irrigado $(0,97-1,04 \mathrm{~m})$} \\
\hline Curvas & $\alpha$ & $m$ & $n$ & $\theta_{r}$ & $\theta_{s}$ & $R^{2}$ \\
\hline 1 & 0,1060 & 0,0438 & 10,8293 & 0,2290 & 0,6360 & 0,9980 \\
\hline 2 & 0,0534 & 0,3451 & 2,0225 & 0,2500 & 0,6350 & 0,9920 \\
\hline 3 & 0,0905 & 0,1826 & 2,7137 & 0,2510 & 0,6310 & 0,9970 \\
\hline Média & 0,0833 & 0,1905 & 5,1885 & 0,2433 & 0,6340 & \\
\hline Desvio Padrão & 0,0270 & 0,1508 & 4,8973 & 0,0124 & 0,0026 & \\
\hline Coef. Variação & 32,4 & 79,2 & 94,4 & 5,1 & 0,4 & \\
\hline
\end{tabular}
continua 
continuaçào.

\section{Plantio Convencional Irrigado $(0,97-1,04 \mathrm{~m})$}

\begin{tabular}{ccccccc}
\hline Curvas & $\boldsymbol{\alpha}$ & $\boldsymbol{m}$ & $\boldsymbol{n}$ & $\boldsymbol{\theta}_{\boldsymbol{r}}$ & $\boldsymbol{\theta}_{\boldsymbol{s}}$ & $\boldsymbol{R}^{\mathbf{2}}$ \\
\hline $\mathbf{1}$ & 0,1111 & 0,0381 & 10,4769 & 0,2010 & 0,6330 & 0,9980 \\
$\mathbf{2}$ & 0,0413 & 0,4330 & 1,8773 & 0,2550 & 0,6140 & 0,9950 \\
$\mathbf{3}$ & 0,0767 & 0,3379 & 1,8977 & 0,2290 & 0,6180 & 0,9940 \\
Média & 0,0764 & 0,2697 & 4,7506 & 0,2283 & 0,6217 & \\
Desvio Padrão & 0,0349 & 0,2061 & 4,9591 & 0,0270 & 0,0100 & \\
Coef. Variação & 45,7 & 76,4 & 104,4 & 11,8 & 1,6 & \\
\hline \hline
\end{tabular}




\section{REFERÊNCIAS BIBLIOGRÁFICAS}

ARCHER. J.R.; SMITH, P.D. The relation between bulk density, available water capacity, and air capacity of soils. Journal of Soil. Science, v.23, n.4, p.475 - 480, 1972.

BLEVINS. R.L.; SMITH, M.S.; THOMAS, G.W. et al. Influence of conservation tillage on soil properties. Journal of Soil and Water Conservation, v.38, n.3, p. 301 $-305,1983$.

BLEWINS, R.L.; COOK. D.; PHILIPS, S.H. et al.. Influence of no-tillage on soil moisture. Agronomy Journal, v.63, n.4, p. 593 - 596, 1971.

BULLOCK. P.; THOMASSON, A.J. Rothamsted studies of soil structure II. Measurement and characterization of macroporosity by image analysis na comparison with data from water retention measurements. Journal of Soil Science, v.30, n.3, p. $391-413,1979$.

BURDINE、 N.T. Relative permeability calculation from size distribution data. American Society of Agricultural Engineering, v. 10, n.3, p. 400 - 404, 1953.

CAMPBELL, G.S. A simple method for determining unsaturated conductivity from moisture retention data. Soil Science, v.117, n.6, p. $311-314,1974$.

CHAN, K.Y.; HEENAN, D.P. Surface hidraulic properties of a red earth under continuous cropping with different management practices. Australian Journal Soil Research, v.31, n. 1, p.13 - 24, 1993.

CHIILDS, E.C.; COLLINS-GEORGE, N. The permeability of porous materials. Proceedings of the Royal Society of London. A, v.201, p.392 - 405, 1950. 
DARCY. H. Les fontaines publique de la Ville de Dijon. Paris: Victor Dalmont, 1856.

DAY. P.R. Particle fractionation and particle size analysis. In: BLACK, C.A.; (Ed.) Methods of soil analysis. America Society of Agronomy, p. 545 - 567, 1975.

DOURADO NETO, D.; JONG VAN LIER, Q. de; BOTREL T.A.et al.. Programa para confecção da água no solo utilizando o modelo de Genuchten. Engenharia Rural, v. 1, p.92-102, 1990.

empresa brasileira de Pesquisa Agropecuaria Manual de métodos de análise de solo. EMBRAPA/SNLCS, v.1, 1979.

GANTZER. C.J.; BLAKE, G.R. Physical characteristis of Le Sueur Clay Loam Soil following no-till and conventional tillage. Agronomy Journal, v.70, n.5, p.853 - 857, 1978

GARDNER. W.R. Laboratory measurements of available soil water. Soil Science Society of America Proceedings. v.35, n.5, p. 852, 1971.

GERMAN. P.; BEVEN, K. Water flow in soil macroporos. II. A combined flow model Journal of Soil Science, v.32, n. 1, p. 15 - 29, 1981 b.

GERMAN. P.; BEVEN. K. Water flow in soil macroporos. III. A statistical approach Journal of Soil Science, v.32, n.1, p. 31 - 39, 1981 c.

GERMAN, P.; BEVEN, K. Water flow in soil macroporos. I. An experimental approach. Journal of Soil Science v.32, n. 1, p. 1 - 13, 1981 a.

GJETTERMANN, B.; NIELSEN, K.L., PETERSEN, C.T. et al.. Preferencial flow in sandy loam soils as affected by irrigation intensity. Soil Technology, v.11, n.l, p. $139-152,1997$.

HAMBLIN, A.P. - The effect of tillage on soil surface properties and the water balance of Xerolfic Alfisol. Soil \& Tillage Research, v.9, n. 4, p. 540 559, 1984. 
JONES, A.J.; WAGENET, R.J. In situ estimation of hydraulic conductivity using simplified methods. Water Resources Research, v.20, n.11, p. 1620 - 1626, 1984.

KLUTE. A. The determination of the hydraulic conductivity and diffusivity of unsaturated soils. Soil Science, v.113, n.4, p. 264 - 276, 1972.

KOSUGUI. K. Three-parameter lognormal distribution model for soil water retention. Water Resources Research, v.30, n.4, p. 891 - 901, 1994.

LALIBERTE. G.E.: COREY. A.T. Hydraulic properties of disturbed and undisturbed samples. In: Permeability and capillarity of soils. ASTM STP 417, America Society of Testing Materials, p. $56-71,1967$.

LEMOS, R.C.; SANTOS, R.D. Manual de descrição e coleta de solo no campo. $2^{\underline{a}}$ ed. Campinas. Sociedade Brasileira de Ciência do Solo e Serviço Nacional de Levantamento e Conservação do Solo, 1984, 45p.

LIBARDI. P.L. Dinâmica da Água no Solo. Piracicaba: ESALQ, Departamento de Física e Meteorologia., 1995, 495 p.

LOW. A.J. The effect of cultivation on the structure and other physical characteristics of grassland and arable soils (1945 - 1970), Journal of Soil Science, v.23, n.4, p. 363 379. 1992.

LUXMOORE, R.J.; GRIZZARD, T.; PATTERSON, M.R. Hydraulic properties of Furllerton Cherty Silt Loam. Soil Science Society of America Journal, v.45, n.4, p. $692-698,1981$.

MARSHALL, T.J. A relation between permeability and size distribution of pores. Journal of Soil Science, v.9, n.1, p. 1 - 8, 1958.

MLLINGTON, R.T.; QUIRK, J.P. Permeability of porous media. Nature, v.183, n.1, p. 387-388, 1959. 
MORAES, S.O.; LIBARDI, P.L.; DOURADO NETO, D. Problemas metodológicos na obtenção da curva de retenção da água pelo solo. Scientia Agricola, v.50, n.3, p. $383-392,1993$

MUALEM, Y. A new model for predicting the hydraulic conductivity of unsaturated porous media. Water Resources Research, v. 12, n.3, p. 513 - 522, 1976.

PAULETTO, E.A.; LIBARDI, P.L.; MANFRON, P.A.; et al.. Determinação da condutividade hidráulica de solos a partir da curva de retenção. Revista Brasileira Ciência do Solo, v.12, p. 189 - 195, 1988.

RASMUSSEN. P.E.; ROHDE, C.R. Long term tillage and nitrogen fertilizer effects on organic nitrogen and urban in a semi-arid soil. Soil Science Society of America Journal, v.52, n.4, $1114-1117,1988$.

REICHARDT, K. \& LIBARDI, P.L. An analysis of soil water movement in the field. I. Hydrological field site characterization. Piracicaba, CENA, 1974, 2 lp.

RICHARDS, L.A. Capillary conduction of liquids through porous medium. Physics, v.1, p. $318-333,1931$.

ROTH, C.H.; MEYEER, B.; FREDE, H.G.; et al.. Effectt of mulch rates and tillage systems on infiltrability nd other soil physical properties of na Oxisol in Paraná, Brazil. Soil and Tillage Research. v.11, n.1, p. 1 - 18, 1988.

SCHUH. W.M.; BAUDER, J.W.; GUPTA, S.C. Evaluation of simplified methods for determining unsaturated hydraulic conductivity of layered soils. Soil Science Society of America Journal, v.48, n.4, p. 730 - 736, 1984.

SMITH, C.W., JOHNSTON, M.A.; LORENTZ, S. The effect of soil compaction and soil properties on the mechanical resistence of south African forestry soils. Geoderma, v.78, n.2, p. $93-111,1997$. 
TOLLNER, E.W.; HARGROVE, W.L.; LANGDALE, G.W. Influence of conventional and no-tillage practices on soil physical properties in the southern Piedmont. Journal Soil Water Conservation, v.39, n. 1, p. $73-76,1984$.

Van GENUCHTEN, M. TH. A closed form equation for predicting the hidraulic conductivity for unsatureted soils. Soil Science Society of America Journal, v.44, n.5, p. $892-898,1980$.

Van GENUCHTEN, M.TH.: NIELSEN, D.R. On describing and predicting the hydraulic properties of unsaturated soils. Annales Geophysicae, v.3, n.5, p. $615-628,1985$.

Van WESENBEECK. I.: KACHANOSKI, R.G.; ROLSTON, D.E. Temporal persistence of spatial patterns of sopil water content in the tilled layer under a corn crop. Soil Science Society of America Journal, v.52, n.4, p. 934 - 941, 1988.

WILLMOTT, C.J. - On the validation of models. Physical Geography. v.2, p.184 - 194, 1981.

YOUNGS, E. G.; LEEDS-HARRISON, P.B. Aspects of transport process in aggregated soils. Journal Soil Science, v.41, n.4, p. 665 - 675, 1990.

ZHAI. R.; KACHANOSKI, R.G.; VORONEY, R.P. Tillage effects on the spatial and temporal variations of soil water. Soil Science Society of America Journal, v.54, n. 1, p. $186-192,1990$.

ZUZEL, J.F.; PIKUL Jr., J.L.; RASMUSSEN, P.E. Tillage and Fertilizer efffects on water infiltration. Soil Science Society of America Journal, v. 54, n. 1, p. $205-208$, 1990. 